\title{
Urinary incontinence in primary care : diagnosis and interventions
}

Citation for published version (APA):

du Moulin, M. F. M. T. (2008). Urinary incontinence in primary care : diagnosis and interventions. [Doctoral Thesis, Maastricht University]. Datawyse / Universitaire Pers Maastricht.

https://doi.org/10.26481/dis.20081217mm

Document status and date:

Published: 01/01/2008

DOI:

$10.26481 /$ dis. $20081217 \mathrm{~mm}$

Document Version:

Publisher's PDF, also known as Version of record

\section{Please check the document version of this publication:}

- A submitted manuscript is the version of the article upon submission and before peer-review. There can be important differences between the submitted version and the official published version of record.

People interested in the research are advised to contact the author for the final version of the publication, or visit the DOI to the publisher's website.

- The final author version and the galley proof are versions of the publication after peer review.

- The final published version features the final layout of the paper including the volume, issue and page numbers.

Link to publication

\footnotetext{
General rights rights.

- You may freely distribute the URL identifying the publication in the public portal. please follow below link for the End User Agreement:

www.umlib.nl/taverne-license

Take down policy

If you believe that this document breaches copyright please contact us at:

repository@maastrichtuniversity.nl

providing details and we will investigate your claim.
}

Copyright and moral rights for the publications made accessible in the public portal are retained by the authors and/or other copyright owners and it is a condition of accessing publications that users recognise and abide by the legal requirements associated with these

- Users may download and print one copy of any publication from the public portal for the purpose of private study or research.

- You may not further distribute the material or use it for any profit-making activity or commercial gain

If the publication is distributed under the terms of Article $25 \mathrm{fa}$ of the Dutch Copyright Act, indicated by the "Taverne" license above, 



\section{Colophon}

Title: Urinary incontinence in primary care; diagnosis and interventions Monique FMT Du Moulin. Thesis, Maastricht University.

ISBN 978-90-5278-765-7

Universitaire Pers Maastricht

Printed by: Datawyse

Omslag: Charles Gemmeke

(C) Monique FMT Du Moulin, 2008, Maastricht

All rights reserved. No part of this thesis may be reproduced, stored in a retrieval system, or transmitted, in any form or by any means, electronic, mechanical, photocopying, recording, or otherwise, without written permission from the author or from the publisher holding the copyright of the published article.

Financial support for printing this thesis has been kindly provided by HOLLISTER B.V., PAUL HARTMANN B.V., MEDECO B.V., ABENA B.V., LAPROLAN B.V., SCA PERSONAL CARE (TENA). 


\title{
Urinary incontinence in primary care
}

\author{
diagnosis and interventions
}

\author{
PROEFSCHRIFT \\ Ter verkrijging van de graad van doctor aan de Universiteit Maastricht, \\ op gezag van de Rector Magnificus, Prof. Mr. G.P.M.F. Mols, \\ volgens het besluit van het College van Decanen, \\ in het openbaar te verdedigen op \\ woensdag 17 december 2008 om 16.00 uur
}

door

Monique François Marie Thérèse Du Moulin

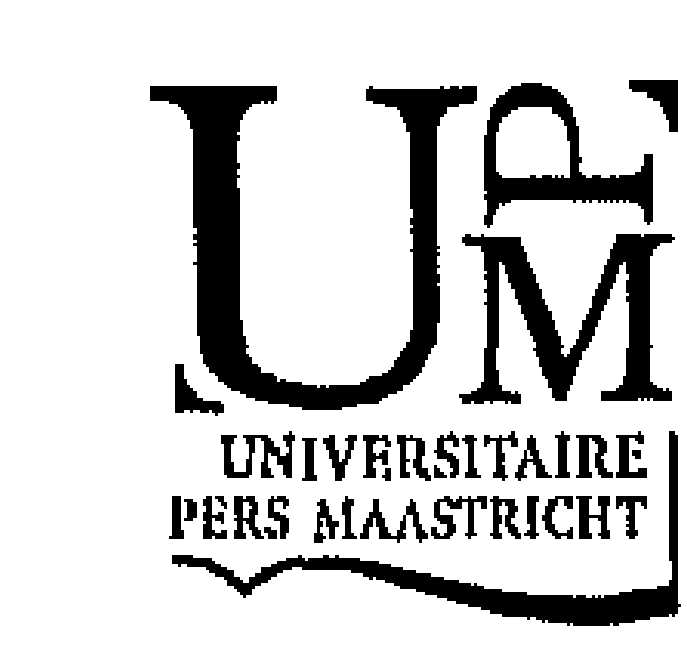


PROMOTOR

Prof. dr. J.P.H. Hamers

COPROMOTOREN

Dr. R.J.G. Halfens

Dr. A.T.G. Paulus

\section{BEOORDELINGSCOMMISSIE}

Prof. dr. J.M.G.A. Schols (voorzitter)

Prof. dr. T. van Achterberg (UMC St. Radboud, Nijmegen)

Dr. K.P.J. Delaere (Atrium Medisch Centrum Parkstad)

Prof. dr. G.I.J.M. Kempen

Prof. dr. A. de Wit 
Voor Cbarles, Cbristianne \&o Stefanie 


\section{CONTENTS}

Chapter 1 General introduction 9

Chapter 2 Prevalence of urinary incontinence in older adults 23 receiving homecare

Chapter 3 Urinary incontinence in older adults receiving homecare, 41 diagnosis and strategies

Chapter 4 Quality systems to improve care in elderly patients with urinary incontinence receiving homecare: do they work?

Chapter 5 The role of the nurse in community continence care: a systematic review

Chapter 6 Effects of introducing a specialized nurse in the care of community dwelling women suffering from urinary incontinence

- a randomized controlled trial -

Chapter $7 \quad$ General discussion

Chapter 8 Summary

Samenvatting

Dankwoord

Curriculum Vitae 


\section{Chapter}

General introduction

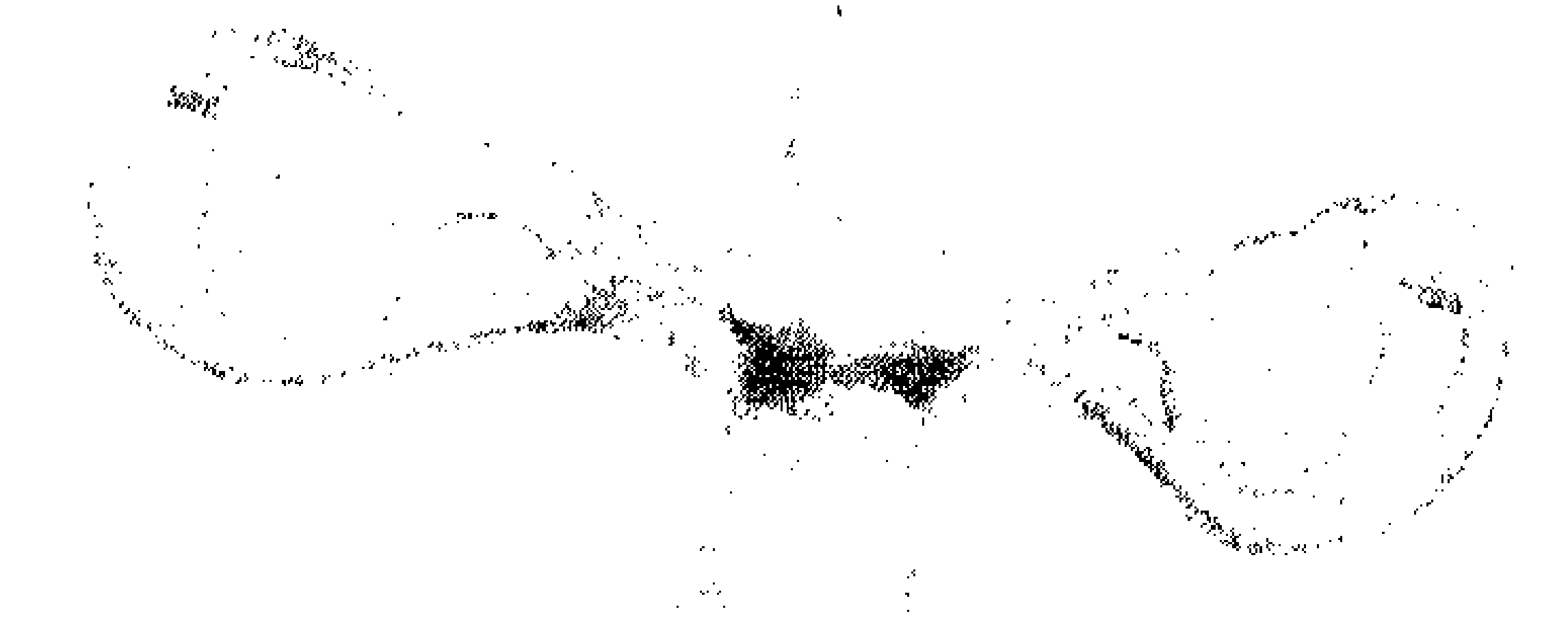

W 


\section{BACKGROUND}

7 his thesis focuses on community-dwelling adults who suffer from urinary

1 incontinence (UI). UI is defined by the International Continence Society as

"the complaint of any involuntary loss of urine"1. It is a common symptom, especially in older people, ${ }^{2}$ with prevalence values ranging between $10 \%$ and $41 \%{ }^{3-8}$. In the Netherlands, about 800,000 people suffer from UI ${ }^{9}$. Research shows that it can have negative physical, mental and social consequences ${ }^{10.13}$ and also is associated with high costs ${ }^{14,15}$. To treat UI adequately, the patient has to be assessed before a therapy or management plan can be recommended. However, studies have shown that, especially in the elderly, UI care can be substandard due to, for instance, a lack of motivation or knowledge about UI on the part of the healthcare worker ${ }^{16}$. Other studies show that patients with symptoms of UI are not always diagnosed and thus go untreated ${ }^{17-19}$ or receive inappropriate treatment ${ }^{20}$. According to the Health Council of the Netherlands, elderly patients with UI, whether at home or institutionalised, are too often prescribed absorbent materials ${ }^{21}$. Also, because of co morbidity, healthcare workers often focus their attention on diagnosing and treating symptoms other than UI, which is not considered life-threatening. In recent years, several quality systems for improving continence care have been described. Educating healthcare workers about UI and appointing continence nurses in afflicted patients are some examples ${ }^{22,23}$.

In this thesis, which consists of two parts, UI in community-dwelling adults is described in terms of how it is addressed as how UI care can be improved. The first part focused on older adults receiving homecare, and investigates the prevalence and treatment of UI as well as quality systems to improve care. The second part of the thesis dealt with community-dwelling women with UI who visited their GP for help, and aimed to investigate the effects of introducing a continence nurse in the care for women suffering from UI.

This chapter presents a description of the types, impact, assessment and treatment of UI. Background information about current care in the community is then provided, followed by the aims and research questions. Finally, after a description of the studies, the thesis outline is presented.

\section{Types of UI}

Several types of UI can be identified. The most common are stress, urge, mixed and functional incontinence. Stress incontinence is defined as 'the complaint of involuntary leakage on effort of exertion, or on sneezing or coughing'. Its possible causes include ageing, obesity and smoking ${ }^{24}$. Urge incontinence is defined as 'the complaint of involuntary leakage accompanied by or immediately preceded by urgency ". It may result from neurological diseases (such as multiple sclerosis), infection, bladder cancer or bladder stones. Mixed incontinence is the combination of the first two forms, while functional incontinence is the 
involuntary loss of urine caused by factors outside the lower urinary tract, such as impaired physical or cognitive functioning. Sufferers of functional incontinence may also experience other types of incontinence.

The aetiology of UI in older adults is almost always multi-factorial. Agerelated changes in the lower urinary tract often cause or contribute to UI. Urodynamic changes associated with higher age may include lower bladder capacity and voided volume, and increased residual volume and involuntary detrusor contractions. Age-associated conditions or factors outside the lower urinary tract can also cause or contribute to UI. The following conditions can be identified: comorbid medical illnesses (e.g., diabetes mellitus, degenerative joint disease, chronic pulmonary disease, severe constipation); neurological and psychiatric disorders (e.g., stroke, dementia, Parkinson's disease, depression); and medication, functional impairments and environmental factors (e.g., inaccessible toilets, visual impairment, inadequate lighting, lack of handrails, obstacles on the path to the bathroom) ${ }^{25}$.

\section{Impact of UI}

Though not life threatening, UI can have a tremendous effect on the sufferer's quality of life. It is frequently accompanied by depression, embarrassment, low self-esteem, stigmatisation, and avoidance of social or sexual activities. UI can also be a risk factor for institutionalisation ${ }^{26,27}$ and falls ${ }^{28}$ in elderly people. Sufferers may not seek help for a number of reasons: ${ }^{20,30}$ they may be too embarrassed to discuss the problem with a health professional; lack knowledge about the availability of treatment; fear surgery; or not perceive UI as bothersome ${ }^{31}$. One study examining such reasons shows that incontinence is often not viewed as a legitimate medical condition but rather as a normal part of ageing ${ }^{30,32}$. Also, commercials advertising incontinence pads in the media contribute to already persistent lay beliefs that UI is a normal complaint after childbirth or with increasing age ${ }^{33,34}$.

Many sufferers use strategies to conceal UI, which may include: using disposable pads, restricting fluid intake, making frequent toilet visits, and carrying a change of clothes or underwear ${ }^{35}$. Bothersome UI and severe symptoms have been found to be associated with help seeking ${ }^{20.36}$. The effects of UI can be devastating for patients as well as caregivers, ${ }^{37}$ and strategies to reduce its incidence or severity should be used where possible to lessen the burden for those involved.

\section{Assessment and treatment of UI}

Given the impact of UI on the lives of those who suffer from it, it is imperative that the symptom is addressed adequately in order to improve quality of life.

Initial assessment usually includes history taking (e.g., relevant medical, surgical and obstetric history, current medication, bowel habits, urinary 
symptoms and date of onset), a frequency/volume chart (e.g., how much urine is lost, day/night frequency, incontinent episodes, fluid intake), and physical examination and testing (e.g., mobility, dexterity, eyesight, abdominal, residual urine, urinalysis or pad test ${ }^{38}$. After a diagnosis as to type has been reached, the appropriate treatment can be determined.

The most common treatment strategies are pelvic floor exercises, medication and bladder training. Pelvic floor exercises are recommended as the first-choice treatment for stress UI when urinary tract infections and other physical impairments that may cause UI have been excluded ${ }^{39}$. The purpose of these exercises, which involve repetitive contractions and relaxations of the pelvic floor muscles, is to increase muscle volume. Evidence demonstrates that such exercises can reduce the frequency of incontinence ${ }^{40-42}$. At the same time, treating urge incontinence with anticholinergic drugs results in statistically significant symptom improvement ${ }^{43}$. These medications aim to relax the involuntary contraction of the bladder and improve bladder function. The side effects, however (dry mouth, blurred vision, tachycardia, constipation), need to be monitored carefully, especially in older people. Finally, bladder training is another strategy for treating urge incontinence ${ }^{44}$. By gradually increasing the interval between visits to the toilet, bladder capacity increases and urinary accidents can decrease. In mixed incontinence, the symptoms of one type may be more severe than others. Treatment will depend on which symptoms are more bothersome to the patient.

Assessment and treatment of UI in the elderly is more difficult than in younger people ${ }^{38}$. Because of its multi-factorial character in the elderly, the first assessment step is to identify all treatable, potentially reversible factors that cause or contribute to UI (e.g., optimal pharmacologic and non-pharmacologic pain management to improve mobility, cough suppression to reduce stress UI, appropriate use of stool softeners, adequate fluid intake and exercise, environmental alterations). Obtaining all the information necessary for an accurate history in an older patient - particularly one with cognitive disorders may take longer than assessing a healthier younger person ${ }^{38}$. At the same time, functional assessment is vital in these patients, and should include transfer ability (e.g., bed to chair), mobility, manual dexterity, eyesight and toileting ability ${ }^{38}$. Cognitive function (poor mental function is associated with incontinence) and social (e.g., whether the person lives with someone able to help) as well as environmental considerations (e.g., adequacy of the lighting, easy access to the toilet) also need to be taken into account.

Although older people often prefer diapers, ${ }^{45}$ healthcare workers as well as patients should realise that the symptom will not disappear; also, research shows that incontinence pads are not always used for the appropriate reasons ${ }^{46}$. Strategies to promote or maintain continence in the elderly are essentially the same as for younger people. Besides these, there are also interventions that can treat or manage UI in the elderly with cognitive and/or physical impairments. 
Behavioural interventions (e.g., prompted voiding, habit training, and timed voiding) have no side effects and are recommended as treatments of choice in the elderly $39,47,48,49,50,51$.

\section{UI care in the community}

With the proper assessment and therapy, continence can be achievable in many cases. However, in spite of the options available to treat or manage UI, there are indications that care is not optimal, especially for older people. There is a widespread and unfortunate belief amongst many health professionals and the general public that incontinence is an inevitable part of ageing and that nothing can be done about it ${ }^{52}$. In fact, healthcare professionals often do not ask even high-risk patients about UI. The first national audit of incontinence care for older people in the United Kingdom revealed that patients were often not examined thoroughly or given full assessments. Efforts to determine underlying causes were limited, and in most cases only the symptoms were managed ${ }^{16}$. In a study by Cheater et al. on patients receiving community nursing services nurses reported insufficient time to complete comprehensive continence assessment as a barrier to providing optimum care ${ }^{53}$. Moreover, data collected by Bignell and Getliffe revealed limited knowledge of continence care in community nurses ${ }^{54}$. In the Netherlands, too, UI care does not appear to be optimal. Based on research into the quality of care of 640 nursing homes, the Dutch Health Care Inspectorate (IGZ) concluded that protocols and instructions for employees on dealing with incontinence remain uncommon ${ }^{55}$. In addition, the management of UI in daily general practice seems insufficient ${ }^{56}$. Therapeutic nihilism, lack of time and the complexity of the problem are all cited by GPs as interfering with good management of UI in eldetly people. In 2003 the Health Care Insurance Board (CVZ) also concluded that care given to patients with UI was inefficient: ${ }^{57}$ healthcare workers often see UI as simply part of the ageing process and untreatable. Hence, to address the problem adequately, healthcare workers devoted to UI are needed who can advise patients about suitable therapy as well as other aspects, e.g., skin care, odour and shame ${ }^{21}$.

\section{Older adults receiving bomecare}

With increasing age, the risk of becoming incontinent also increases. Thus, as a result of the ageing population and the growing number of elderly who need homecare services due to mental or physical impairments, homecare agencies in the Netherlands will increasingly be confronted with UI. Especially in community-dwelling older people, its assessment and treatment needs full attention as UI increases the risk of institutionalisation ${ }^{27}$ and social isolation ${ }^{58-60}$. To assist healthcare workers address UI adequately, several quality systems have been proposed. For instance, the use of protocols in daily care has been shown to improve outcomes for UI patients in nursing homes ${ }^{61,62}$. Education on UI can also help nurses develop competency in its assessment and management ${ }^{22}$. 
In the Netherlands, there is a paucity of studies on the prevalence, diagnosis and treatment of $\mathrm{UI}$ in patients receiving homecare. Also, little is known about the extent to which homecare agencies use quality systems to improve the quality of UI care. More insight into UI's prevalence and the homecare given to older adults with UI will help healthcare workers be prepared to address the symptom and better understand their patients' needs.

\section{Community-dwelling women}

Another group suffering from UI is community-dwelling women who seek help for their problem. In most cases, women who complain of UI first visit their GP. Guidelines issued by the Dutch College of General Practitioners offer treatment guidelines for each UI type ${ }^{63}$. However, a retrospective cohort study of women newly identified with UI showed that in less than $50 \%$ of these women was the type of incontinence reported or assessable, and less than one-third were actively treated for it ${ }^{64}$. Instead, $66 \%$ of the women used absorbent products. It also seems that, due to time constraints, GPs cannot always spend enough time on the patient or lack sufficient UI knowledge ${ }^{65}$. To improve quality of care, a committee of UI experts recommended easily accessible care by specialised healthcare workers and better access for patients to independent information about treatment options ${ }^{65}$.

Thus, a new means of organising continence care to meet patients' needs is clearly necessary. For several years, a shift in care from physicians to nurses has been taking place ${ }^{6 !}$. Research has shown that transferring care for patients of Diabetes Mellitus " ${ }^{67}$ or COPD ${ }^{\text {af }}$ to nurses is justified; it seems that in UI care, too, a specialised nurse can be of benefit in terms of clinical outcomes after six months ${ }^{23,69}$. Nurses' interpersonal and technical skills are important factors in making treatment effective; Shaw et al. report that an informal, friendly approach by nurses with good communication skills relieves patient embarrassment and anxiety, which facilitates information exchange and care effectiveness ${ }^{70}$. However, whether these effects are still prevalent after a year remains to be seen, as positive results may decline over time ${ }^{71}$.

\section{Aims and research questions}

The aim of this thesis was twofold. The first aim was to gain insight into UI care for older adults living in the community receiving homecare services. Thus, UI's prevalence, diagnosis and treatment as well as quality systems to improve its care were investigated. The second aim was to gain insight into the effects of introducing a continence nurse into the care of community-dwelling women suffering from UI. 
The following research questions were addressed.

- What is the prevalence of UI in older adults receiving homecare?

- How many patients receiving homecare are diagnosed as to UI type, and what strategies are used to treat or manage UI?

- To what extent do homecare agencies use quality systems to improve UI care, and what is the association between these quality systems and UI's prevalence, diagnosis and severity?

- What are the effects of introducing a continence nurse into the care of community-dwelling women suffering from UI?

To answer these research questions several studies were initiated. These are described below.

\section{UI in older adults receiving homecare (Part 1)}

For this first investigation into older adults with UI receiving homecare, some cross-sectional studies were undertaken using data from homecare agencies participating in the Dutch National Prevalence Measurement of Health Care Problems ${ }^{72}$. This prevalence measurement takes place on a fixed day each year, and all homecare agencies in the Netherlands are asked to participate. Data collection takes place on three levels (the organisational, ward or team, and patient levels) regarding UI prevalence, the number of patients diagnosed as to type, the treatment or management method, and quality systems used by homecare agencies to improve care.

\section{UI in community-divelling women visiting their GP (Part 2)}

The second part focused on community-dwelling women with UI who visit their GP for help. An intervention was undertaken with a specialised continence nurse who guided women with UI for one year (intervention group). Before the start of the study, a multidisciplinary team (consisting of a GP, urologist, physiotherapist and continence nurse) wrote a protocol with evidence-based interventions to guide the nurse. Using this protocol and her own knowledge and experience, the nurse advised women as to the most suitable forms of treatment, as well as skin care, special garments, and how to deal with bad odour. The women visited the nurse four times throughout the year (at the start of the study, and after 3, 6 and 12 months). After each visit, the nurse would evaluate the treatment, teport her findings to the GP who remained responsible for their care and, if necessary, recommend another treatment or referral to a urologist. Women in the control group received usual care as delivered by their GP. Duting inclusion, and after 3,6 and 12 months, data on incontinence episodes, quality of life and satisfaction with UI care were collected in both study groups. 
Outline

Chapters 2, 3 and 4 focus on elderly UI patients receiving homecare.

In Chapter 2, UI prevalence in community-dwelling older adults receiving homecare is described.

Chapter 3 indicates the number of older adults with a diagnosis as to UI type, and the interventions used by homecare agencies to treat or manage UI.

In Chapter 4 , the use of quality systems to improve UI care for adults receiving homecare is described.

Chapters 5 and 6 focus on community-dwelling adults with UI who seek help. In Chapter 5 a systematic review of randomised controlled trials scored on methodological quality is described to gain insight into the effects of care by a continence nurse on UI patients. Chapter 6 presents the results of a randomised controlled trial assessing the effects of care by a continence nurse on community-dwelling women with UI.

This thesis ends with chapter 7 presenting a general discussion of the results and some methodological reflections of the studies. Also implications for practice and some recommendations for future research are outlined. 


\section{REFERENCES}

1. Abrams P, Cardozo LD, Fall M, et al. The standardisation of terminology in lower urinary tract function: report from the standardisation sub-committee of the International Continence Society. Urology. 2003;61(1):37-49.

2. Temml C, Haidinger G, Schmidbauer J, Schatzl G, Madersbacher S. Urinary incontinence in both sexes: prevalence rates and impact on quality of life and sexual life. Neurourology and Urodynamics. 2000;19:259-271.

3. Özerdogan N, Beji NK, Yalcin Ö. Urinary incontinence: its prevalence, risk factors and effects on the quality of life of women living in a region of Turkey. Gynecologic and Obstetric Investigation. 2004;58:145-150.

4. Diokno AC, Estanol M, Ibrahim I, Balasubramaniam M. Prevalence of urinary incontinence in community dwelling men: a cross sectional nationwide epidemiological survey. International Urology and Nephrology. 2007;39(1):129-136.

5. Anger JT, Saigal CS, Litwin MS. The Urologic Diseases of America Project. The prevalence of urinary incontinence among community dwelling adult women: results from the National Health and Nutrition Examination Survey. Journal of Urology. 2006;175:601-604.

6. Maggi S, Minicuci N, Langlois J, Pavan M, Enzi G, Crepaldi G. Prevalence rate of urinary incontinence in community-dwelling eldetly individuals. Journals of Gerontology Series A: Biological Sciences and Medical Sciences. 2001;56:M14-M18.

7. Song HJ, Bae JM. Prevalence of urinary incontinence and lower urinary tract symptoms for community-dwelling elderly 85 years of age and older. Journal of Wound, Ostomy, and Continence Nursing. 2007;34(5):535-541.

8. Choo MS, $\mathrm{Ku} \mathrm{JH}, \mathrm{Oh} \mathrm{SJ}$, et al. Prevalence of urinary incontinence in Korean women: an epidemiologic survey. International Urogynecology Journal. 2007;18:1309-1315.

9. De Wit J. Monitor hulpmiddelen 2003. Diemen: CVZ; 2003.

10. Dugan E, Cohen SJ, Bland DR, et al. The association of depressive symptoms and urinary incontinence among older adults. Journal of the American Geriatrics Society. 2000;48(4):413-416.

11. Kelleher CJ. Economic and social impact of OAB. European Urology Supplements. 2002/7 2002;1(4):11-16.

12. Ko Y, Lin S, Salmon J, Bron M. The impact of urinary incontinence on quality of life of the elderly. American Journal of Managed Care. 2005;11(4):S103-111.

13. Rassin M, Dubches L, Libshitz A, Adar E, Duvish T. Levels of comfort and ease among patients suffering from urinary incontinence. International Journal of Urological Nursing. 2007;1(2):64-70.

14. Wilson L, Brown JS, Shin GP, Luc K-O, Subak LL. Annual direct cost of urinary incontinence. Obstetrics \& Gynecology. 2001/9 2001;98(3):398-406. 
15. De Wit J. Monitor Hulpmiddelen 2006. Diemen: College voor Zorgverzekeringen; 22 June 2006. 26003070.

16. Mayor S. Incontinence management is inadequate, UK audit shows. British Medical Journal. 26 November 2005;331:1226.

17. Mardon RE, Halim S, Pawlson LG, Haffer SC. Management of urinary incontinence in Medicare Managed Care Beneficiaries. Archives of Internal Medicine. 2006;166:1128-1133.

18. Kinchen K, Lee J, Fireman B, Hunkeler E, Nehemiah J, Curtice 'T. The prevalence, burden, and treatment of urinary incontinence among women in a managed care plan. Journal of Women's Health. 2007;16(3):415-422.

19. Gibbs CF, Johnson MT, Ouslander JG. Office management of geriatric urinary incontinence. American Journal of Medicine. 2007;120:211-220.

20. Shaw C, Gupta R, Williams K, Assassa P, McGrother C. A survey of helpseeking and treatment provision in women with stress urinary incontinence. British Journal of Urology. 2006;97(4):752-757.

21. Health Council of the Netherlands. Urinary Incontinence. The Hague: Health Council of the Netherlands; 2001. 2001/12.

22. Collette C, Leclerc G, Tul M. Effectiveness of a geriatric urinary incontinence educational program for nursing staff. Canadian Journal of Nursing Leadership. 2003;16(4):99-109.

23. Williams K, Assassa P, Cooper N, et al. Clinical and cost-effectiveness of a new nurse-led continence service: a randomised controlled trial. British Journal of General Practice. 2005;55(518):696-703.

24. Luber KM. The definition, prevalence, and risk factors for stress urinary incontinence. Reviews in Urology. 2004;6(Suppl. 3):S3-S9.

25. Fonda D, Dubeau CE, Harari D, Ouslander JG, Palmer MH, Roe B. Incontinence in the frail elderly. In: Abrams P, Cardozo LD, Khoury S, Wein AJ, eds. Third International Consultation on Incontinence. Plymouth: Health Publication Ltd; 2004:1165-1239.

26. Matsumoto M, Inoue K. Predictors of institutionalization in elderly people living at home: the impact of incontinence and commode use in rural Japan. Journal of Cross-Cultural Gerontology. 2007;22(4):421-432.

27. Thom DH, Haan MN, van den Eeden SK. Medically recognized urinary incontinence and risks of hospitalization, nursing home admission and mortality. Age and Ageing. 1997;26(5):367-374.

28. Teo JSH, Briffa NK, Devine A, Dhaliwal SS, Prince RL. Do sleep problems or urinary incontinence predict falls in elderly women? Australian Journal of Physiotherapy. 2006;52:19-24.

29. Kinchen K, Burgio K, Diokno AC, Fultz NH, Bump RC, Obenchain R. Factors associated with women's decisions to seek treatment for urinary incontinence. Journal of Women's Health. 2003;12(7):687098.

30. Teunissen D, Weel C, Lagro Janssen TL. Urinary incontinence in older people living in the community: examining help-seeking behaviour. British Journal of General Practice. 2005;55(519):776-782. 
31. Perry S, Shaw C, Assassa P, et al. An epidemiological study to establish the prevalence of urinary symptoms and felt need in the community: the Leicestershire MRC Incontinence Study. Leicestershire MRC Incontinence Study Team. Journal of Public Health Medicine. 2000/9 2000;22(3):427-434.

32. Shaw C, Tansey R, Jackson C, Hyde C, Allan R. Bartiers to help seeking in people with urinary symptoms. Family Practice. 2001;18(1):48-52.

33. Hägglund $\mathrm{D}$, Wadensten $\mathrm{B}$. Fear of humiliation inhibits women's careseeking behaviour for long-term urinary incontinence. Scandinavian Journal of Caring Sciences. 2007;21:305-312.

34. Lose G. The burden of stress urinary incontinence. European Urology Supplements. 2005;4:5-10.

35. Johnson TM, Kincade JE, Bernard SL, Busby-Whitehead J, DeFriese GH. Self-care practices used by older men and women to manage urinary incontinence: results from the national follow-up survey on self-care and aging. Journal of the American Geriatrics Society. 2000;48(8):894-902.

36. Cetinel B, Demirkesen $O$, Tarcan $T$, et al. Hidden female urinary incontinence in urology and obstetrics and gynecology outpatient clinics in Turkey: what are the determinants of bothersome urinary incontinence and help-seeking behavior? International Urogynecology Journal. 2007;18:659664.

37. Cassells $C$, Watt $E$. The impact of incontinence on older spousal caregivers. Journal of Advanced Nursing. 2003;42(6):607-616.

38. Getliffe K, Dolman M, eds. Promoting Continence: A Clinical and Research Resource. Second ed: Baillière Tindall; 2003.

39. Teunissen TA, de Jonge A, Van Weel C, Lagro Janssen TL. Treating urinary incontinence in the elderly - conservative therapies that work: a systematic review. Journal of Family Practice. 2004;53(1):25-30.

40. Glazener CMA, Herbison GP, Wilson PD, et al. Conservative management of persistent postnatal urinary and faecal incontinence: randomised controlled. British Medical Journal. September 15, 2001 2001;323(7313)

41. Tibaek S, Gard G, Jensen R. Pelvic floor muscle training is effective in women with urinary incontinence after stroke: a randomised, controlled and blinded study. Neurourology and Urodynamics. 2005;24(348-357).

42. Dougherty MC, Dwyer JW, Pendergast JF, et al. A randomized trial of behavioral management for continence with older rural women. Research in Nursing \& Health. 2002;25(1):3-13.

43. Nabi G, Cody JD, Ellis G, Herbison P, Hay-Smith J. Anticholinergic drugs versus placebo for overactive bladder syndrome in adults. Cochrane Database of Systematic Reviews. 2006(4).

44. Fantl J, Wyman J, McClish D, et al. Efficacy of bladder training in older women with urinary incontinence. Journal of the American Medical Association. 1991;265(5):609-613.

45. Johnson TM, Ouslander JG, Uman GC, Schnell J. Urinary incontinence treatment preferences in long-term care. Journal of the American Geriatrics 
Society. 2001;49(6):710-718.

46. Palese A, Regattin L, Venuti F, et al. Incontinence pad use in patients admitted to medical wards: an Italian multicenter prospective cohort study. Journal of Wound, Ostomy and Continence Nursing. 2007;34(6):649-654.

47. Ouslander JG, Maloney C, Graswla TH, Rogers L, Walawander CA. Implementation of a nursing home urinary incontinence management progtam with and without tolterodine. Journal of the American Medical Directors Association. 2001;2(5):207-214.

48. Engberg S, Sereika SM, McDowell BJ, Weber E, Brodak I. Effectiveness of prompted voiding in treating urinary incontinence in cognitively impaired homebound older adults. Journal of Wound, Ostomy and Continence Nursing. 2002;29(5):252-265.

49. Ouslander JG, Blaustein J, Connor A, Pitt A. Habit training and oxybutynin for incontinence in nursing home patients: a placebo-controlled trial. Journal of the American Geriatrics Society. 1988;36(1):40-46.

50. Colling J, Owen TR, McCreedy M, Newman D. The effects of a continence program on frail community-dwelling elderly persons. Urologic Nursing. 2003;23(2):117-131.

51. Ostaszkiewicz J, Johnson L, Roe B. Timed voiding for the management of urinary incontinence in adults. Cochrane Database of Systematic Reviews. 2004;1.

52. Newman DK. Conservative management of urinary incontinence in women. Primary Care Update for OB/GYNS. 2001;8(4):153-162.

53. Cheater FM, Baker R, Gillies $C$, et al. The nature and impact of urinary incontinence experienced by patients receiving community nursing services: a cross-sectional cohort study. International Journal of Nursing Studies. doi:10.1016/j.jijnurstu.2006.09.006.

54. Bignell V, Getliffe K. Clinical guidelines for the promotion of continence in primary care: community nurses' knowledge, practice and perceptions of their role. Primary Health Care Research and Development. 2001;2(3):173186.

55. Inspectie voor de Gezondheidszorg . Verpleeghuiszorg: kwaliteitsslag is gaande. Resultaat van geïntensiveerd toezicht 2005-2006 . The Hague; December 2006.

56. Teunissen D, van den Bosch W, Weel C, Lagro Janssen TL. Urinary incontinence in the elderly: attitudes and experiences of general practitioners; a focus group study. Scandinavian Journal of Primary Health Care. 2006;24(56-61).

57. College voor Zorgverzekeringen. Urine incontinentie bij volwassenen. Amstelveen 2003. HM200023.

58. Grimby A, Milsom I, Molander U, Wiklund I, Ekelund P. The influence of urinary incontinence on the quality of life of elderly women. Age and Ageing. 1993;22(2):82-89. 
59. Fultz NH, Herzog AR. Self-reported social and emotional impact of urinary incontinence. Journal of the American Geriatrics Society. 2001;49(7):892899.

60. Espino DV, Palmer RF, Miles TP, Mouton CP, Lichtenstein MJ, Markides KP. Prevalence and severity of urinary incontinence in elderly MexicanAmerican women. Journal of the American Geriatrics Society. 2003;51:1580-1586.

61. Krichbaum K, Pearson BD, Hanscom J. Better care in nursing homes: advanced practice nurses' strategies for improving staff use of protocols.

Clinical Nurse Specialist. 2000;14(1):40-46.

62. Sampselle CM, Wyman J, Thomas C, et al. Continence for women: a test of AWHONN's evidence-based protocol in clinical practice. Journal of Wound, Ostomy and Continence Nursing. 2000;27:109-117.

63. Lagro Janssen 'TL, Breedveldt Boer HP, Dongen JJAM, Lemain TJJ, Teunissen D, Pinxteren B. NHG-Standaard Incontinentie voor urine. Huisarts \& Wetenschap. 2006;49(10):501-510.

64. Penning-van Beest FJA, Sturkenboom MCJM, Bemelmans BLH, Herings RMC. Undertreatment of utinary incontinence in general ptactice. Annals of Pharmacotherapy. 2005;39(1):17-21.

65. Deskundigencommissie Incontinentie. Attentie voor incontinentie. February 2006.

66. Laurant M, Reeves D, Hermens R, Braspenning J, Grol R, Sibbald B. Substitution of doctors by nurses in primary care. Cochrane Database of Systematic Reviews. 2005;18(2):CD001271.

67. Vrijhoef HJM, Diederiks JPM, Spreeuwenberg C, Wolffenbuttel BHR. Substitution model with central role for nurse specialist is justified in the care for stable type 2 diabetic outpatients. Journal of Advanced Nursing. 2001;36(4):546-555.

68. Vrijhoef HJM, van den Bergh JH, Diederiks JPM, Weemhoff I, Spreeuwenberg C. Transfer of care for outpatients with stable chronic obstructive pulmonary disease from respiratory care physician to respiratory nurse - a randomized controlled study. Chronic Illness. 2007;3(2):130-144.

69. Du Moulin MFMT, Hamers JPH, Paulus A, Berendsen C, Halfens R. The role of the nurse in community continence care: a systematic review. International Journal of Nursing Studies. 2005;42(4):479-492.

70. Shaw C, Williams KS, Assassa RP. Patients' views of a new nurse-led continence service. Journal of Clinical Nursing. 2000;9(4):574-582.

71. Mouritsen L. Pelvic floor exercises for female stress urinary incontinence. International Urogynecology Journal. 1994(5):44-51.

72. Halfens R, Janssen M, Meijers J, Mistiaen P. Rapportage resultaten Landelijke Prevalentiemeting Zorgproblemen 2005. Maastricht University; November 2005.

73. Tulder M, Furlan $A$, Bombardier $C$, et al. Updated method guidelines for systematic reviews in the Cochrane Collaboration Back Review Group. Spine. 2003;28(12):1290-1299. 


\section{Chapter}

\section{Prevalence of urinary incontinence in older adults receiving homecare}

M.F.M.T. Du Moulin, J.P.H. Hamers, A.W. Ambergen, M.A.P. Janssen, R.J.G. Halfens

Accepted for publication in Research in Nursing \& Health 
W e conducted a cross-sectional survey in 2005 to determine the prevalence W of and factors associated with urinary incontinence (UI) in adults receiving homecare. Of the 2,866 patients surveyed, $46 \%$ suffered from UI; $6.5 \%$ had stress, $16.6 \%$ had urge, $9 \%$ had mixed, and $17.6 \%$ had functional incontinence. No diagnosis regarding type of UI had been established in $50.2 \%$. Factors associated with UI were advanced age, higher body mass index, and impaired mobility. UI is prevalent in older persons receiving homecare, but the lack of diagnosis of type of UI in half of the participants surveyed impedes management of UI. 


\section{INTRODUCTION}

T tinary incontinence (UI) is a common condition affecting many community-dwelling older adults. Besides medical consequences, UI has detrimental effects on patients' social and psychological wellbeing ${ }^{1,2}$. Although not life-threatening, UI decreases quality of life. Urinary incontinence is a risk factor for urinary tract infections ${ }^{3}$, falls, and increased risk of institutionalization ${ }^{4,5}$.

Several types of incontinence can be distinguished ". The most common types are stress, urge, mixed, and functional incontinence. Stress incontinence is any involuntary loss of urine that occurs during an activity causing a sudden rise in abdominal pressure (e.g., coughing or jumping). Urge incontinence occurs when a person has a strong desire to void, followed almost immediately by an involuntary loss of urine. Mixed incontinence is a combination of stress and urge incontinence. Functional incontinence is caused by factors outside the urinary tract that interfere with the ability to respond in a socially appropriate way to the urge to void, and it is often associated with cognitive or physical impairment (e.g., when a person does not recognize the need to void, does not know where the toilet is, or reaches the toilet too late). Several risk factors associated with UI in older people are advancing age, reduced or restricted mobility, functional disability, and stroke '. As the risk of becoming incontinent increases with age, it is expected that the aging of the population will cause an increase in the numbers of persons suffering from UI. In addition, the numbers of persons suffering from one or more chronic diseases will also increase. These developments are expected to lead to a growing demand for health care, especially homecare services and long-term care. Landi et al. ${ }^{8}$ found that about $50 \%$ of people living at home who were receiving formal homecare services were incontinent.

In order to effectively address UI, homecare service providers must diagnose the type of UI. Because a substantial proportion of patients receiving homecare suffer from impaired cognitive function and impaired mobility, type of UI is more difficult to assess, manage, or cure than in younger patients. Another factor that hampers adequate assessment of UI is lack of knowledge. Some patients and healthcare professionals believe that UI is part of normal aging and some professionals claim that the limited potential for cure in the elderly does not justify offering treatment 9, ${ }^{10}$. Yet, Perrin, Dauphinee, Corcos, Hanley, and Kuchel ${ }^{11}$ found that patients older than 75 years suffering from UI were good candidates for conservative UI treatment (e. g., pelvic floor muscle and bladder training). Other researchers have found that behavioral therapy in homebound older persons resulted in significant reduction in UI, despite high levels of comorbidity and functional impairment ${ }^{12-14}$.

Addressing the problem of UI requires research into the extent of the problem in homecare agencies. As UI increases the risk for institutionalization ${ }^{5}$ homecare service providers should be concerned with the management of UI to 
keep patients in their own homes as long as possible. Using the proper strategies, homecare service providers can help to treat or to prevent worsening of UI. With the aging of the population and the increasing number of patients suffering from UI, acquiring knowledge of the risk factors for UI in older patients with mental and/or physical impairments is essential. Although much research has been conducted on the prevalence and the risk factors of UI in community-living adults and residents in long-term care facilities ${ }^{15}$, few studies have been focused on UI in older adults receiving care from a homecare agency.

This study was designed to measure the prevalence of incontinence in community-dwelling persons aged 65 years or older and receiving services from a homecare agency. The following research questions were asked: (a) What is the prevalence of UI in older community-dwelling adults receiving homecare services? (b) What are the differences between persons with and without UI? (c) What are the severity, frequency, and timing of UI in patients suffering from different types of UI?

\section{METHOD}

A cross-sectional survey was conducted in April 2005. Data were obtained from the Dutch National Prevalence Measurement of Health Care Problems ${ }^{16}$, a nationwide cross-sectional study. Each year, all Dutch healthcare organizations are invited to participate in this survey. Participating organizations are free to choose which care problems they want to have surveyed for their organization. Participation enables the organizations to assess the prevalence of healthcare problems within their organization, and compare the results with the data from other organizations. A coordinator, who is responsible for organizing and implementing the study, is appointed in each organization. Nurses responsible for collecting data are educated to apply a standardized data collection method and to use the forms. After being informed about the study, patients are asked to participate. Only patients who give informed consent are included. All patients have the right to refuse to participate or withdraw from the study at any moment without any consequences. Healthcare organizations participating in this study are hospitals, nursing homes, institutions for the physically and mentally handicapped, and homecare agencies.

Clients of the homecare agencies were examined by the nurses during their regular visits. Twenty patients randomly chosen by the coordinator of each homecare agency were examined a second time by a different nurse to check the reliability of the examinations. In the present study, we used the data on incontinence collected from the homecare agencies.

\section{Sample and setting}

The sample for our study consisted of adults aged 65 years or older who were living at home and receiving care from a homecare agency. In order to receive 
homecare from such an agency in the Netherlands, a person must first apply to an independent assessment agency (called CIZ) to apply for homecare approval. Persons' need for care is assessed, including mobility, self-care agency, living conditions, and social network. Based on this assessment, a determination is made concerning the kind of care (e.g., domestic, personal, psychosocial, or nursing) and how much care is needed (ranging from one visit each week to 8 hours of intensive care per day). After CIZ grants approval, the person can contact a homecare agency for help. In 2004, 413,000 persons in the Netherlands, $80 \%$ of whom were older than 65 years ${ }^{17}$, received care from homecare agencies.

A description of the sample is shown in Table 1. Respondents were mostly female $(65 \%)$, and their mean age was 80 years $(S D=7.2)$. The average number of reasons given for admission to homecare services was 2.5 ( $\mathrm{SD}=1.4)$. On average, respondents received care from the homecare agency for 2.5 years $(\mathrm{SD}=5.2)$.

Table 1 Patient characteristics $(\mathrm{n}=2,866)$

\begin{tabular}{|c|c|c|}
\hline & $\mathbf{N}$ & $(\%)$ \\
\hline \multicolumn{3}{|l|}{ Sex } \\
\hline male & 996 & 34.8 \\
\hline female & 1,870 & 65.2 \\
\hline Age, mean (SD) & $80.1(7.2)$ & \\
\hline $65-69$ years & 195 & 6.8 \\
\hline $70-74$ years & 349 & 12.2 \\
\hline $75-79$ years & 601 & 21 \\
\hline $80-84$ years & 795 & 27.7 \\
\hline $85-89$ years & 593 & 20.7 \\
\hline 90 years or older & 333 & 11.6 \\
\hline $\mathrm{BMI}\left(\mathrm{kg} / \mathrm{m}^{2}\right)$, mean $(\mathrm{SD})$ & $26(7.4)$ & \\
\hline men & $25.5(4.4)$ & \\
\hline women & $26.3(8.6)$ & \\
\hline \multicolumn{3}{|l|}{ Fecal incontinence ${ }^{\dagger}$} \\
\hline yes & 385 & 14 \\
\hline no & 2,359 & 86 \\
\hline Number of reasons for admission, mean (SD) & $2.5(1.4)$ & \\
\hline Years since admission to homecare services, mean (SD) & $2.5(5.2)$ & \\
\hline
\end{tabular}

* Body Mass Index

$\dagger 122$ missing

\section{Data collection}

Patients were examined by the homecare nurse of the agency involved, using a standardized questionnaire. To identify whether patients were suffering from UI, the nurse asked about the frequency of involuntary loss of urine (never, 3-4 times/month, a few times/week, every day), in accordance with other studies ${ }^{18-21}$. Patients rated as never were regarded as continent. Questions were asked about the amounts of urine lost (drops, small splashes, entire bladder content) and the 
time of urine losses (at night, during the day, day and night) were asked. In addition, the patients were asked when the UI had started (before the start of homecare, after the start of homecare).

To answer these questions the nurse collected information from the patient and his/her medical record. For patients who were not able to answer questions, the informal caregiver, which in most cases was a close relative, was approached. To identify the type of incontinence (stress, urge, mixed, or functional incontinence), the nurse retrieved data from the medical record.

The questionnaire also included questions regarding patient and clinical characteristics that have been associated with UI in the literature, including sex ${ }^{22}$, age ${ }^{22.24}$, body mass index ${ }^{24,25}$, presence of fecal incontinence ${ }^{26}$, mobility impairments ${ }^{27}$, activities of daily living (ADL) impairments ${ }^{22}$, and conditions such as diabetes mellitus ${ }^{25,28}$, stroke ${ }^{24,29}$, and lung disease ${ }^{24,25}$. To measure mobility problems, one item was used consisting of a 4-point response scale ( 1 =bed bound; $2=$ chair bound; $3=$ walking with walking aids; $4=$ ambulatory).

\section{Data analysis}

The prevalence of UI was calculated using the homecare nurse's UI rating and reported as a percentage. Bivariate associations between patient characteristics and UI were tested using the Chi-square test for categorical variables and the ttest for continuous variables. Differences between the types of incontinence and urinary symptoms were analyzed using $\chi^{2}$-test and the Kruskal-Wallis test.

The association between UI and patient characteristics was analyzed using multivariate logistic regression. Only those characteristics with a statistically significant bivariate association $(p<.20)$ with UI were included in the model. Besides sex, age, BMI, numbers of reasons for admission, and mobility status, the following dichotomous variables (yes/no) were included in the regression analysis: fecal incontinence, tumor, diabetes, psychological disorder/dementia, cerebral vascular accident (CVA), respiratory disease, skin disease, nervous disease, and ADL impairment. The odds ratios (OR) and corresponding 95\% confidence intervals (CI) derived from the model are effect estimates simultaneously adjusted for other factors in the model. Analyses were performed using SPSS, with $\mathrm{p}<.05$ considered to be statistically significant.

The kappa statistic was used to measure the strength of agreement between the ratings by the homecare nurses on presence, type, severity, frequency, and timing of UI, fecal incontinence, healthcare worker who established the diagnosis, and time of onset of UI. Kappa values between 0.41 and 0.60 indicate moderate agreement, those between 0.61 and 0.80 good agreement and those above 0.80 very good agreement ${ }^{30}$. For each healthcare agency, 20 patients were assessed by two different nurses. Across the questions about the presence of UI and urinary symptoms, kappa values ranged between .69 and .86 . Across 10 questions on treatment and management options, kappa was .50 for special skin 
care; kappa values for the other options ranged from .62 to .94. The remaining questions (i.e., healthcare worker who established the diagnosis, time of onset of UI, and does the patient suffer from fecal incontinence) had good kappa values $(.84, .66$, and .80 , respectively).

\section{RESULTS}

In 2005, a total of 257 organizations, including 27 (10.5\%) homecare agencies, participated in the Dutch National Prevalence Measurement of Health Care Problems. Nineteen of the homecare agencies $(70 \%)$ participated in surveys of UI.

\section{Prevalence}

Of the 2,866 patients surveyed, 1,319 were suffering from UI, a prevalence rate of $46 \%$. Of these, $6.5 \%$ had stress incontinence, $16.6 \%$ urge incontinence, $9 \%$ mixed incontinence, and $17.6 \%$ functional incontinence. No diagnosis had been established in $50.2 \%$ of the patients. Of the patients suffering from UI, $33 \%$ had become incontinent after the start of homecare agency services (5\% stress, 15\% urge, $7 \%$ mixed, $18 \%$ functional, and $55 \%$ no diagnosis).

\section{Patient characteristics by continence status}

Table 2 shows several differences between the incontinent and continent groups. Women were more likely to be incontinent than men $(p<.001)$, and incontinent patients were older $(p<.001)$ and had a higher BMI $(p=.004)$. Eleven percent of patients suffered from urinary and fecal incontinence. Patients suffering from fecal incontinence $(p<.001)$, with more reasons for admission to homecare services $(p<.001)$, and a higher level of impaired mobility $(p<.001)$, were also more likely to suffer from UI.

ADL impairment was the most common reason for admission to homecare services. Patients with diabetes mellitus $(p=.023)$, psychological disorders or dementia $(p=.014), C V A /$ hemiparesis $(p=.004)$, or ADL impairments $(p<.001)$ were more likely to have UI than patients not suffering from these disorders. Having a tumor or suffering from a respiratory disorder was more prevalent in patients who were continent. 
Table 2 Differences in patient characteristics between incontinent and continent groups

\begin{tabular}{|c|c|c|c|c|c|}
\hline & \multirow{2}{*}{$\begin{array}{l}\text { Incontinent } \\
(n=1,319) \\
n(\%)\end{array}$} & \multirow{2}{*}{$\begin{array}{l}\text { Continent } \\
(n=1,494) \\
n(\%)\end{array}$} & \multicolumn{3}{|c|}{ Statistic } \\
\hline & & & tutest & $x^{2}$ & p-value \\
\hline Age, mean (SD) & $81.8(7.2)$ & $80.3(7.1)$ & -5.5 & & $<.001$ \\
\hline \multicolumn{6}{|l|}{ Sex } \\
\hline male & $384(29.1)$ & $595(39.8)$ & & \multirow{2}{*}{35.4} & \multirow[t]{2}{*}{$<.001$} \\
\hline female & $935(70.9)$ & $899(60.2)$ & & & \\
\hline \multicolumn{6}{|l|}{$\mathrm{BM}{ }^{*}\left(\mathrm{~kg} / \mathrm{m}^{2}\right)$, mean $(\mathrm{SD})$} \\
\hline men & $26.1(4.9)$ & $25.1(4.1)$ & -2.8 & & .005 \\
\hline women & $26.7(6.1)$ & $25.9(10.7)$ & -1.7 & & .091 \\
\hline \multicolumn{6}{|l|}{ Fecal incontinence } \\
\hline yes & $303(23.3)$ & $77(5.4)$ & & \multirow{2}{*}{180.7} & \multirow{2}{*}{$<.001$} \\
\hline no & $996(76.7)$ & $1,342(94.6)$ & & & \\
\hline \multicolumn{6}{|c|}{$\begin{array}{l}\text { Number of reasons for admission, } \\
\text { mean (SD) }\end{array}$} \\
\hline & & & -0.0 & & $<.001$ \\
\hline \multicolumn{6}{|l|}{ Mobility status } \\
\hline bed bound & $66(5.5)$ & $32(2.2)$ & & \multirow[t]{4}{*}{$-9.5^{t}$} & \multirow[t]{4}{*}{$<.001$} \\
\hline chair bound & $151(12.6)$ & $98(6.8)$ & & & \\
\hline walking with walking aids & $423(35.3)$ & $390(27)$ & & & \\
\hline ambulatory & $560(46.7)$ & $926(64)$ & & & \\
\hline \multicolumn{6}{|l|}{ Main reason for admission } \\
\hline ADI: impairment & $256(19.6)$ & $216(14.7)$ & & 12.2 & $<.001$ \\
\hline \multicolumn{6}{|l|}{$\begin{array}{l}\text { Disease of the heart and } \\
\text { vascular system }\end{array}$} \\
\hline vascular system & $134(10.3)$ & $142(9.6)$ & & .319 & .572 \\
\hline Diabetes & $143(11.0)$ & $124(8.4)$ & & 5.2 & .023 \\
\hline \multicolumn{6}{|l|}{ Disease of the musculoskelctal } \\
\hline \multirow{2}{*}{\multicolumn{6}{|c|}{$\begin{array}{l}\text { system / connective tissue } \\
\text { Psychological disorder / }\end{array}$}} \\
\hline & $108(8.3)$ & $87(5.9)$ & & 6.0 & .014 \\
\hline Tumor & $74(5.7)^{\circ}$ & $119(8.1)$ & & 6.2 & .013 \\
\hline $\mathrm{CVA}^{\mathrm{s}}$ / hemi paresis & $88(6.7)$ & $63(4.3)$ & & 8.2 & .004 \\
\hline Disease of the respiratory system & $39(3.0)$ & $84(5.7)$ & & 12.0 & .001 \\
\hline Disease of the skin & $44(3.4)$ & $71(4.8)$ & & 3.62 & .057 \\
\hline Disease of kidney / genitalia & $47(3.6)$ & $62(4.2)$ & & .67 & .415 \\
\hline Disease of the nervous system & $60(4.6)$ & $47(3.2)$ & & 3.73 & .053 \\
\hline Other & $71(5.4)$ & $118(8.0)$ & & 7.2 & .007 \\
\hline
\end{tabular}

Body Mass Index

+ Based on the Mann-Whitney U test

₹ Only categories $>100$ patients are presented

- Activities of Daily Living

s Cercbrovascular Attack

ADL impairment was the most common reason for admission to homecare services. Patients with diabetes mellitus $(\mathrm{p}=.023)$, psychological disorders or dementia $(\mathrm{p}=.014), \mathrm{CVA} /$ hemiparesis $(\mathrm{p}=.004)$, or ADL impairments $(\mathrm{p}<.001)$ were more likely to have UI than patients not suffering from these disorders. Having a tumor or suffering from a respiratory disorder was more prevalent in patients who were continent. 
Severity by incontinence type

Table 3 presents the severity and nature of urinary symptoms for each type of incontinence. In comparison with the other types, patients suffering from functional incontinence were most severely affected. More than half of these patients lost large amounts of urine $(p<.001)$, and $81.6 \%$ of the patients suffering from functional incontinence lost urine every day $(\mathrm{p}<.001)$.

Table 3 Severity and urinary symptoms by type of incontinence

\begin{tabular}{|c|c|c|c|c|c|c|c|}
\hline & \multirow{2}{*}{$\begin{array}{l}\text { Stress } \\
(\mathrm{n}=81) \\
\mathrm{n}(\%)\end{array}$} & \multirow{2}{*}{$\begin{array}{l}\text { Urge } \\
(n=205) \\
n(\%)\end{array}$} & \multirow{2}{*}{$\begin{array}{l}\text { Mixed } \\
(\mathrm{n}=112) \\
\mathrm{n}(\%)\end{array}$} & \multirow{2}{*}{$\begin{array}{l}\text { Functional } \\
(\mathrm{n}=217) \\
\mathrm{n}(\%)\end{array}$} & \multirow{2}{*}{$\begin{array}{l}\text { No diagnosis } \\
(n=620) \\
n(\%)\end{array}$} & \multicolumn{2}{|c|}{ Statistic } \\
\hline & & & & & & $\begin{array}{l}\text { Kruskal } \\
\text { Wallis }\end{array}$ & $\mathrm{p}$-value \\
\hline \multicolumn{8}{|l|}{ Severity } \\
\hline $\begin{array}{l}\text { drops } \\
\text { small splashes }\end{array}$ & $\begin{array}{l}48(62.3) \\
28(36.4)\end{array}$ & $\begin{array}{l}82(40.4) \\
73(36)\end{array}$ & $25(23.6)$ & $30(14.4)$ & $255(41.7)$ & 126.7 & $<.001$ \\
\hline $\begin{array}{l}\text { manl splashes } \\
\text { entire bladdle }\end{array}$ & $28(36.4)$ & $73(30)$ & $56(52.8)$ & $59(28.2)$ & $204(33.3)$ & & \\
\hline content & $1(1.3)$ & $48(23.6)$ & $25(23.6)$ & $120(57.4)$ & $153(25)$ & & \\
\hline \multicolumn{8}{|l|}{ Frequency } \\
\hline 3-4 times a month & $17(21)$ & $29(14.1)$ & $8(7.1)$ & $17(7.8)$ & $89(14.4)$ & 42.3 & $<.001$ \\
\hline a few times a week & $23(28.4)$ & $48(23.4)$ & $20(17.9)$ & $2.3(10.6)$ & $153(24.7)$ & & \\
\hline \multirow[t]{2}{*}{ every day } & $41(50.6)$ & $128(62.4)$ & $84(75)$ & $177(81.6)$ & $378(61)$ & & \\
\hline & & & & & & \multicolumn{2}{|c|}{ Statistic } \\
\hline Time of loss & & & & & & $x^{2}$ & p-value \\
\hline at day & $44(56.4)$ & $78(38.4)$ & $32(29.1)$ & $31(14.6)$ & $203(33,3)$ & 77.3 & $<.001$ \\
\hline at night & $10(12.8)$ & $20(9.9)$ & $7(6.4)$ & $16(7.5)$ & $85(13.9)$ & & \\
\hline night and day & $24(30.8)$ & $105(51.7)$ & $71(64.5)$ & $166(77.9)$ & $322(52.8)$ & & \\
\hline
\end{tabular}

In contrast, patients with stress incontinence were more likely to lose small amounts of urine $(62.3 \%)$ and to lose urine 3-4 times a month, whereas patients suffering from other types lost urine more frequently $(p<.001)$. Patients suffering from stress incontinence were more likely to lose urine during the day $(56.4 \%)$, while most patients suffering from mixed or functional incontinence lost urine night and day $(\mathrm{p}<.001)$.

\section{Factors associated with UI}

Patients who were not suffering from fecal incontinence were significantly less likely to be urinary incontinent than those suffering from fecal incontinence (see Table 4). 
Table 4 Odds of urinary incontinence according to potential risk factors

\begin{tabular}{|c|c|c|c|c|}
\hline \multirow[b]{2}{*}{ Variables in the model } & \multirow[b]{2}{*}{$\mathrm{OR}^{*}$} & \multicolumn{2}{|c|}{$95 \%$ CIt for OR } & \multirow[b]{2}{*}{$\mathrm{p}$-value } \\
\hline & & Lower & Upper & \\
\hline \multicolumn{5}{|l|}{ Sex } \\
\hline $\begin{array}{l}\text { male } \\
\text { female (referent) }\end{array}$ & .54 & .43 & .68 & $<.001$ \\
\hline Age & 1.03 & 1.01 & 1.05 & $<.001$ \\
\hline Body Mass Index & 1.03 & 101 & 1.05 & .005 \\
\hline \multicolumn{5}{|l|}{ Fecal incontinence } \\
\hline $\begin{array}{l}\text { no } \\
\text { yes (referent) }\end{array}$ & .26 & .18 & .37 & $<.001$ \\
\hline $\begin{array}{l}\text { Number of reasons for admission } \\
\text { Diaberes mallins }\end{array}$ & 1.09 & 1.01 & 1.17 & .026 \\
\hline $\begin{array}{l}\text { Diabetes mellitus } \\
\text { yes } \\
\text { no (referent) }\end{array}$ & 1.71 & 1.17 & 2,50 & .006 \\
\hline \multicolumn{5}{|l|}{ Mobility } \\
\hline bed bound & 2.03 & .99 & 4.13 & .052 \\
\hline chair bound & 1.62 & 1.08 & 2.44 & .021 \\
\hline $\begin{array}{l}\text { walking with walking aids } \\
\text { ambulatory (teferent) }\end{array}$ & 1.81 & 1.42 & 2.30 & $<.001$ \\
\hline Constant & .09 & & & .002 \\
\hline
\end{tabular}

- $\mathrm{OR}=$ Odds Ratio

i $\mathrm{CI}=$ confidence interval

Higher age, higher BMI, a larger number of reasons for admission to homecare, and impaired mobility were associated with increased risk of UI. Of the disorders considered in the model, patients with diabetes mellitus were more likely to suffer from UI when compared to patients without diabetes.

\section{DISCUSSION}

We found that $46 \%$ of patients in a population receiving homecare services were suffering from urinary incontinence and that, in most cases, moderate to large amounts of urine were lost on a daily basis. Risk factors for UI included high BMI, high age, being female, and a larger number of reasons for admission to homecare services. Having diabetes mellitus, and suffering from fecal incontinence or impaired mobility were also associated with UI. No diagnosis of type of incontinence had been established for half of the persons suffering from UI.

In a study among frail elderly people living in the community and receiving homecare services, Landi et al. ${ }^{8}$ recorded UI in $51 \%$ of the elderly persons, which is somewhat higher than our results. Gnanadesigan et al. ${ }^{31}$ found a prevalence rate of $36 \%$ in vulnerable older community-based patients enrolled in two managed care organizations. Although patients in the Gnanadesigan et al. study were older (mean age 81 years), and many of them had at least one limitation in ADL activities, or suffered from dementia $(6 \%)$ or recurrent or injurious falls $(13 \%)$, their study population was less physically or mentally 
impaired than the population receiving homecare services included in our study. Our study population suffered from an average of 2.5 comorbidities.

Our finding that no diagnosis of type of incontinence had been established in half of the persons suffering from UI, was comparable to Specht, Salsbury, Lyons, and Maas ${ }^{32}$, who conducted a study on special care units with older adults with dementia. They found that only $55 \%$ of the cases suffering from UI had at least one continence-related nursing diagnosis. In our study, over $58 \%$ of the patients without a diagnosis suffered from moderate or large incontinent episodes. Appropriate treatment or management strategies can only be determined after a diagnosis has been established ".

Thirty-three percent of the patients suffering from UI had become urinary incontinent after being admitted to homecare. New-onset incontinence is frequently caused by reversible or transient factors. Due to age-related changes in the anatomy and physiology of the lower urinary tract, the geriatric population has a high risk for transient episodes of UI. Nurses should use management strategies aimed at correcting the reversible factors within patient limitations.

Most of the factors that we found to be associated with UI were consistent with those found in other studies. In accordance with other studies are our findings that the prevalence of UI increases with age ${ }^{8,23,25,26,33}$, and that high BMI and female gender were associated with UI $8,25,27,33,34$. Noblett, Jensen, and Ostergard ${ }^{35}$ found a strong association between BMI and intra-abdominal pressure as well as intravesical pressure and surmised that these associations may explain why obesity is a risk factor for the development of UI.

The results of our study show that women suffering from diabetes mellitus are at increased risk of UI. This is consistent with the findings of other studies of the middle-aged and elderly ${ }^{8,25,36}$. Lewis et al. ${ }^{36}$ described insulin-requiring diabetes mellitus to be a risk factor for UI as it places patients at greater risk for neurological or vascular pathology.

Whereas other researchers have reported associations between disorders of the respiratory systems and UI ${ }^{24,36}$, we found no such association, although lung diseases may increase abdominal pressure and, therefore, lead to stress incontinence.

Poor mobility seems to be a risk factor for UI in both sexes ${ }^{8,22}$. Reduced mobility and poor dexterity may prevent patients from reaching the toilet in time or from removing clothing in order to void, and conditions such as cardiac diseases may cause patients to walk slowly. Nuotio, Jylhä, Luukkaala, and Tammela ${ }^{37}$ found in a Finnish population aged 70 and over an association between UI and ADL disability. In their view, this association could explain the widespread use of diapers among women.

In our study, $11 \%$ of the patients suffered from both urinary and fecal incontinence. Others reporting double incontinence in the community found lower prevalence rates ranging from $1.7 \%$ to $8 \%{ }^{38-42}$. 


\section{Limitations}

A strength of our study was that data collection was completed by homecare nurses who knew the patients well. For most questions, kappa values revealed good agreement between nurses rating the same patients. Yet, several methodological limitations should be considered. Under-reporting of information in the medical record may have influenced our results. We used a cross-sectional design and, therefore, cannot infer anything about the direction of relationships in our study. The number of variables included in the multivariate logistic regression model was limited. We selected those factors that were most common for our study population, namely, older adults receiving homecare. However, data collection was restricted by the measurement instrument used in this prevalence study. So, future researchers should focus on the development of a theoretical framework to enhance current knowledge and theory development.

The Dutch homecare system differs from homecare systems in other countries. In countries such as the Netherlands, homecare nurses play an important role in the care for elderly at home. They function relatively independently of the curative activities performed in medical care, and often find themselves in a transmural setting where boundaries between different forms of care no longer exist, and co-operation with other professionals, such as specialist nurses or general practitioners is frequent ${ }^{43}$. However, in more medically-oriented countries often informal caregivers are responsible for the care of the elderly at home. Physicians or hospitals that are responsible for supporting these informal caregivers are not equipped to provide care in the home setting ${ }^{4}$. So when interpreting our results these perspectives should be taken into account.

\section{CONCLUSION}

Our study had three important findings. First, was the high prevalence of UI in older adults receiving homecare. Second, the type of UI was diagnosed in only half of the adults suffering from UI. Finally, one third of the adults suffering from UI became incontinent after being admitted to homecare services. Older adults receiving homecare suffer from physical and/or mental impairments that may make diagnosis and treatment difficult. In most cases, the causes of UI are multi-factorial requiring a multidisciplinary approach. In a hospital or a longterm care setting, a patient can receive care by different providers, whereas the coordination of care in the home is more complex. These findings challenge homecare agencies to find ways better to assess, manage, and prevent UI. 


\section{REFERENCES}

1. Lin S-Y, Dougherty MC. Incontinence impact, symptom distress and treatment-seeking behavior in women with involuntary urine loss in Southern Taiwan. International Journal of Nursing Studies. 2003;40(3):227-234.

2. Dugan E, Cohen SJ, Bland DR, et al. The association of depressive symptoms and urinary incontinence among older adults. Journal of the American Geriatrics Society. 2000;48(4):413-416.

3. Richards C. Urinary tract infections in the frail elderly: issues for diagnosis, treatment and prevention. International Urology and Nephrology.
2004;36:457-463.

4. 'Thom DH, Haan MN, Van den Eeden SK. Medically recognized urinary incontinence and risks of hospitalization, nursing home admission and mortality. Age and Ageing. 1997;26(5):367-374.

5. Nuotio M, Tammela TLJ, Luukkaala T, Jylhä M. Predictors of institutionalization in an older population during a 13-year period: the effect of urge incontinence. Journals of Gerontology, Series A, Biological sciences and Medical sciences. 2003;58(8):756-762.

6. Getliffe K, Dolman M, eds. Promoting continence; a clinical and research resource. second ed: Baillière Tindall; 2003.

7. Fonda D, Dubeau CE, Harari D, Ouslander JG, Palmer MH, Roe B. Incontinence in the frail elderly. In: Abrams P, Cardozo LD, Khoury S, Wein AJ, eds. Third International Consultation on Incontinence. Plymouth: Health Publication Ltd; 2004:1165-1239.

8. Landi F, Cesari M, Russo A, Onder G, Lattanzio F, Bernabei R. Potentially reversible risk factors and urinary incontinence in frail older people living in community. Age and Ageing. 2003;32:194-199.

9. Penning-van Beest FJA, Sturkenboom MCJM, Bemelmans BLH, Herings RMC. Undertreatment of urinary incontinence in general practice. Annals of Pharmacotherapy. 2005;39(1):17-21.

10. Teunissen D, Bosch van den W, Weel C, Lagro Janssen TL. Urinary incontinence in the elderly: attitudes and experiences of general practitioners; a focus group study. Scandinavian Journal of Primary Health Care. 2006;24(56-61).

11. Perrin L, Dauphinee.S., Corcos J, Hanley JA, Kuchel GA. Pelvic floor muscle training with biofeedback and bladder training in elderly women: a feasibility study. Journal of Wound, Ostomy and Continence Nursing. May/June 2005;32(3):186-199.

12. McDowell BJ, Engberg S, Sereika SM, et al. Effectiveness of behavioral therapy to treat incontinence in homebound older adults. Journal of the American Geriatrics Society. 1999;47:309-318.

13. Burgio KL, Locher JL, Goode PS, et al. Behavioral vs drug treatment for urge urinary incontinence in older women: a randomized controlled trial. Journal of the American Medical Association.1998;280(23):1995-2000. 
14. Engberg S, Sereika SM, McDowell BJ, Weber E, Brodak I. Effectiveness of prompted voiding in treating urinary incontinence in cognitively impaired homebound older adults. Journal of Wound, Ostomy and Continence Nursing. 2002;29(5):252-265.

15. Shamliyan T, Wyman J, Bliss D, Kane R, Wilt T. Incontinence in Adults. Evidence Report/Technology Assessment. Rockville: Agency for Healthcare Research and quality; December 2007. 08-E003.

16. Halfens R, Janssen M, Meijers J, Mistiaen P. Rapportage resultaten Landelijke Prevalentiemeting Zorgproblemen 2005. Maastricht: Universiteit Maastricht; November 2005.

17. Mathijssen SW. Beschikbare capaciteit in materiaal en kapitaal. Den Haag: Ministerie van Volksgezondheid, Welzijn en Sport; 2005.

18. Sandvik H, Seim A, Vanvik A, Hunskaar S. A severity index for epidemiological surveys of female urinary incontinence: comparison with 48-hour pad-weighing tests. Neurourology and Urodynamics. 2000;19(2):137-145.

19. O'Brien J, Austin M, Sethi P, O'Boyle P. Urinary incontinence: prevalence, need for treatment, and effectiveness of intervention by nurse. BMJ Clinical research ed. 1991;303(6813):1308-1312.

20. Lagro Janssen TL, Smits AJ, Van Weel C. Women with urinary incontinence: self-perceived worries and general practitioners' knowledge of problem. British Journal of General Practice. 1990;40(337):331-334.

21. Ju CC, Swan LK, Merriman A, Choon TE, Viegas O. Urinary incontinence among the elderly people of Singapore. Age and Ageing. 1991;20(5):387.

22. Brandeis G, Baumann M, Hossain M, Morris J, Resnick N. The prevalence of potentially remediable urinary incontinence in frail older people: a study using the Minimum Data Set. Journal of the American Geriatrics Society. 1997;45(2):179-184.

23. Hannestad YS, Rortveit G, Sandvik H, Hunskaar S, the Norwegian EPINCONT study. A community-based epidemiological survey of female urinary incontinence. Epidemiology of Incontinence in the County of Nord-Trondelag. Journal of Clinical Epidemiology. 2000/11 2000;53(11):1150-1157.

24. Rohr G, Stovring H, Christensen K, Gaist D, Nybo H, Kragstrup J. Characteristics of middle-aged and elderly women with urinary incontinence. Scandinavian Journal of Primary Health Care. 2005;23:203-208.

25. Jackson R, Vittinghoff E, Kanaya A, et al. Urinary incontinence in elderly women: findings from the health, aging, and body composition study. Obstetrics and Gynecology. 2004;104:301-307.

26. Kocak I, Okyay P, Dundar M, Erol H, Beser E. Female urinary incontinence in the west of Turkey: prevalence, risk factors and impact on quality of life. European Urology. 2005;48:634-641. 
27. Stenzelius K, Mattiasson A, Rahm Hallbetg I, Westergren A. Symptoms of urinary and faecal incontinence among men and women $75+$ in relations to health complaints and quality of life. Neurourology and Urodynamics. 2004(23):211-222.

28. Danforth K, Townsend M, Lifford K, Curhan G, Resnick N, Grodstein F. Risk factors for urinary incontinence among middle-aged women. American Journal of Obstetrics and Gynecology. 2006;194:339-345.

29. Minassian VA, Drutz HP, Al-Badr A. Urinary incontinence as a worldwide problem. International Journal of Gynecology \& Obstetrics. 2003;82:327-338.

30. Altman D. Practical statistics for medical research. London: Chapman \& Hall; 1993.

31. Gnanadesigan $N$, Saliba $D$, Roth $C P$, et al. The quality of care provided to vulnerable older community-based patients with urinary incontinence. Journal of the American Medical Directors Association. 2004;5:141-146.

32. Specht JK, Salsbury Lyons S, Maas ML. Patterns and treatments of urinary incontinence on special care units. Journal of Gerontological Nursing. 2002;25(5):13-21.

33. Espino DV, Palmer RF, Miles TP, Mouton CP, Lichtenstein MJ, Markides KP. Prevalence and severity of urinary incontinence in elderly MexicanAmerican women. Journal of the American Geriatrics Society. 2003;51:1580-1586.

34. Oskay UY, Beji NK, Yalcin O. A study on urogenital complaints of postmenopausal women aged 50 and over. Acta Obstetricia et Gynecologica Scandinavica. 2005;84:72-78.

35. Noblett KL, Jensen JK, Ostergard DR. The relationship of body mass index to intra-abdominal pressure as measured by multichannel cystometry. International Urogynecology Journal and Pelvic Floor Dysfunction. 1997;8(6):323-326.

36. Lewis CM, Schrader R, Many A, Mackay M, Rogers RG. Diabetes and urinary incontinence in 50- to 90-year-old women: a cross-sectional population-based study. American Journal of Obstetrics and Gynecology. 2005;193:2154-2158.

37. Nuotio M, Jylhä M, Luukkaala T, Tammela TLJ. Urinary incontinence in a Finnish population aged 70 and over. Scandinavian Journal of Primary Health Care. 2003;21:182-187.

38. Teunissen TA, Bosch van den WJ, Hoogen van den HJ, Lagro-Janssen A. Prevalence of urinary, fecal and double incontinence in the elderly living at home. International Urogynecology Journal and Pelvic Floor Dysfunction. 2004;15:10-13.

39. Nakanishi N, Tatara $\mathrm{K}$, Shinsho F, et al. Mortality in relation to urinary and faecal incontinence in elderly people living at home. Age and Ageing. 1999;28:301-306. 
40. Roberts RO, Jacobsen SJ, Reilly WT, Pemberton JH, Lieber MM, Talley NJ. Prevalence of combined fecal and urinary incontinence: a community-based study. Journal of the American Geriatrics Society. 1999;47(7):837-841.

41. Ostbye T, Seim A, Krause KM, et al. A10-year follow-up of urinary and fecal incontinence among the oldest old in the community: the Canadian Study of Health and Aging. Canadian Journal of Aging. 2004;23(4):319-331.

42. Bliss D, Fischer LR, Savik k, Avery M, Mark P. Severity of fecal incontinence in community-living elderly in a health maintenance organization. Research in Nursing \& Health. 2004;27(3):162-173.

43. Boom vd H, Philipsen H, Stevens F. Home nursing in the Netherlands since 1950. Gewina. 2004:27(2):100-119.

44. Lamura G, Mnich E, Wojszel B, et al. Erfahrungen von pflegenden Angehörigen älterer Menschen in Europa bei der Inanspruchnahme von Unterstützungsleistungen. Zeitschrift Gerontologie und Geriatrie. 2006;39:429-442. 


\section{Chapter}

\section{Urinary incontinence in older adults receiving homecare; diagnosis and strategies}

M.F.M.T. Du Moulin, J.P.H. Hamers, A.W. Ambergen, R.J.G. Halfens Accepted for publication in Scandinavian Journal of Caring Sciences 


\section{ABSTRACT}

T rinary incontinence (UI) is a major health problem mostly affecting older people. With the shift toward healthcare delivery in the home setting, it is necessary for home healthcare workers to know how to manage UI in the elderly. Little is known about the care for patients receiving homecare suffering from UI. The aim of this study was to assess the prevalence of UI in older adults receiving homecare and to gain insight into caring for patients with UI. A cross-sectional survey using data from the Dutch National Prevalence Measurement of Health Care Problems was conducted.

Of the 2866 patients, $46 \%$ were suffering from UI. In $49 \%$ of these patients the type of UI was diagnosed. Patients with a diagnosis suffered more from their UI and were offered more strategies when compared with patients without a diagnosis. Most patients used pads. Relatively few patients were offered bladder training or pelvic floor muscle exercises (PFME).

Urinary incontinence is a highly prevalent condition in older patients receiving homecare. In half of the patients with UI no diagnosis regarding the type of incontinence was made. However, to treat or manage UI it is essential to assess the type of UI, as UI is treatable even in older people. As this study had a cross-sectional design, only strategies being offered at a fixed point in time are documented.

Despite studies reporting the success of behavioural interventions for adults suffeting from UI, most patients use pads. With the aging of the population and the increasing number of older adults suffering from UI, homecare agencies need to acquire the knowledge and skills to address urinary incontinence. 


\section{INTRODUCTION}

$\mathrm{U}$ rinary incontinence (UI) is a major health problem affecting mostly older people and women. It is associated with embarrassment, anxiety and lower self-esteem, which may in-turn negatively affect social participation. UI is also an important cause of skin vulnerability 1,2 and it also increases the risk of institutionalisation ${ }^{3}$.

There are several different types of UI, including stress, urge, mixed and functional incontinence. Stress incontinence is any involuntary loss of urine that occurs during physical exertion causing a sudden rise in abdominal pressure. Urge incontinence occurs when a person has a sudden desire to void, followed by an involuntary loss of urine. Persons suffering from mixed incontinence have a combination of stress and urge incontinence. Functional incontinence is caused by factors outside the urinary tract and refers to urine loss resulting from the inability (or sometimes unwillingness) to get to a toilet due to, for example, a stroke, severe arthritis or dementia.

As higher age is a risk factor for UI, the prevalence of UI is expected to increase because of the aging of the population. In addition, the numbers of persons suffering from chronic diseases might increase. With the shift toward healthcare delivery in the home setting, it is necessary for home healthcare workers to be acquainted with treatment and management strategies to help patients suffering from UI. Treatment strategies are patient-oriented and aimed at changing the functioning of the lower urinary tract [e.g. pelvic floor exercises (PFME) and bladder retraining]. Management strategies are caregiver-oriented, and include strategies that improve or even reverse incontinence, but do not change urinary tract functioning (e.g. toileting regimes) ${ }^{4}$.

The elderly should be given the opportunity to achieve continence irrespective of their frailty or disability. Various studies ${ }^{5-7}$ have shown that in older adults treatment strategies, such as PFME, prompted voiding and bladder training, can reduce utinary accidents. The treatment of mixed UI requires consideration of the contribution of each of its components.

Nurses can play an important role in the care for patients suffering from UI. With the appropriate communicative and technical skills and an informal approach, they can offer or advice services that are tailored to the patients' needs.

Assessment is the key for effective treatment and management of incontinence. However, several studies have shown that many geriatric patients suffering from UI are undiagnosed and go untreated ${ }^{8,9}$. In a study by Mardon et al. only $56 \%$ of noninstitutionalised respondents aged $\geq 65$ years received treatment for UI 9 . They state that healthcare professionals often do not ask about UI, even in high-risk patients.

The aim of this study was to gain insight into the prevalence and type of UI 
in older adults receiving homecare and to gain insight into the strategies for treating or managing UI. The following questions were addressed:

- What is the prevalence of UI in older patients receiving homecare?

- For how many patients is a diagnosis regarding type of incontinence made and which healthcare worker is making this diagnosis?

- Which client characteristics are associated with whether or not a diagnosis is made?

- What strategies are used to treat or manage UI, and do they differ among the types of UI?

\section{METHOD}

Design

A cross-sectional survey was conducted to answer the research questions.

\section{Data collection}

Data were obtained from the Dutch National Prevalence Measurement of Health Care Problems ${ }^{10}$, which is a nation-wide cross-sectional study. Each year, all Dutch healthcare organisations (hospitals, nursing homes and homecare agencies) are invited to participate in the National Prevalence Measurement of Health Care Problems. Participating organisations are free to choose which care problem(s) they want to have surveyed for their organisation.

Before participating, each healthcare organisation appoints a co-ordinator who is responsible for organising and implementing the study. Nurses responsible for collecting the data are trained to apply the standardised data collection method and use the forms. After being informed about the study, patients are asked to participate. Only patients who present informed consent are included. All patients have the right to refuse to participate and to withdraw from the study at any moment without any consequences. The healthcare organisations that participated in this study were hospitals, nursing homes, institutions for the people with physical and learning disabilities, and homecare agencies.

Collection of the data used in the present study took place on one fixed day in April 2005. The present study used the data on incontinence collected from the homecare agencies. Patients of the homecare agencies were examined by the nurses during their regular visits. Ethical approval was given by the ethics committee of the University Hospital
Maastricht.

\section{Population and setting}

The population of this study consisted of adults aged $\geq 65$ years who were living at home and receiving care from a homecare agency. To receive homecare from such an agency in the Netherlands, a person must first apply to an independent 
assessment agency (called CIZ) to apply for homecare approval, based on indications. First the assessment agency assesses the person's need for care based on their mobility, self-care agency, living conditions and social network. Based on this assessment, it is determined which care (e.g. domestic or personal care) and how much care this person needs (ranging from one visit by a nurse each week to 8 hours of intensive care per day). After the approval has been granted by $\mathrm{CIZ}$, the person can contact a homecare agency for help.

\section{Data collection}

Based on a standardised questionnaire, patients were examined by the homecare nurse of the agency involved. To identify whether patients were suffering from UI, they were asked about the frequency of involuntary loss of urine ("never," "3 or 4 times a month," "a few times a week" or "every day"), which is in accordance with other studies ${ }^{11-14}$. Patients who were rated by the homecare nurse as "never" were regarded as continent. The questionnaire also included questions regarding the amounts of urine lost ("drops," "small splashes" or "entire bladder content") and the time of urine loss ("at night," "during the day" or "day and night").

To answer these questions the nurse collected information from the patient, as well as from his/her medical record. For patients who were unable to answer the questions, the informal caregiver, which in most cases was a close relative, was approached.

To identify the type of incontinence ("stress incontinence: the involuntary loss of urine during episodes of raised intra-abdominal pressure such as when laughing, sneezing or coughing," "urge incontinence: involuntary loss of urine accompanied by or immediately preceded by urgency," "mixed incontinence: having complaints of both stress and urge incontinence," or "functional incontinence: involuntary loss of urine caused by factors outside the urinary tract such as impaired mobility, medication or cognitive impairment") the nurse retrieved data from the patient record.

Dichotomous variables ("yes" or "no") were scored to measure which treatment strategies were used ("bladder training/PFME," "medication").

To gain insight into the management strategies, dichotomous variables ("yes" or "no") were scored on the use of absorbent products ("pads," "pants" or "underpads"), scheduled toileting, environmental modifications, special clothing, special skin care and catheter. It was possible to score more than one option.

Other data collected from the patient's record were age, gender, the healthcare worker who diagnosed the type of UI ("urologist/gynecologist", "GP" or "continence nurse"), time of onset of UI ("before admission to homecare services" or "after admission to homecare services"), number of reasons for admission to homecare services, and total number of treatment and management strategies. 


\section{Analysis}

Analyses were performed using SPSS. $\mathrm{P}<0.05$ was considered to be statistically significant. The prevalence of UI was calculated using the homecare nurse's rating and reported as a percentage. Differences between patients with and without a diagnosis regarding type of UI were analysed using the t-test for continuous variables and the $\chi^{2}$-test for categorical variables.

For each strategy, differences in patient and urine loss characteristics were analysed using the $\chi^{2}$-test and Mann-Whitney test. Backward elimination logistic regression was used to identify predictors that explained whether a diagnosis regarding type of UI was made or not.

Only variables that had a statistically significant association $(p<0.20)$ were included in the model.

\section{RESULTS}

In 2005 a total of 19 homecare agencies participated in the Dutch National Prevalence Measurement of Health Care Problems, with 2866 patients being screened for UI. The mean age of the study sample was 80 years (SD 7.2) and $65 \%$ were women. The most important reason for admission to homecare services was impaired Activitics of Daily Living (17\%), disease of the heart and vascular system $(9.9 \%)$, and Diabetes Mellitus (9.6\%). Other reasons were, for example, disease of the musculoskcletal system $(8.6 \%)$, dementia $(7.1 \%)$ and Cerebrovascular Attack (5.4\%).

\section{Diagnosis and strategies}

Of the 2866 patients $46 \%$ ( $n=1319)$ were suffering from UI. For $615(49.8 \%)$ of the 1319 patients suffering from UI, the type of incontinence was diagnosed (84 missing). It was determined that $13.1 \%$ of these patients had stress incontinence, $33.4 \%$ had urge incontinence, $18.1 \%$ had mixed incontinence and $35.4 \%$ had functional incontinence. Patients who were diagnosed regarding type of UI more often lost entire bladder contents, more often lost urine night and day, and had a higher frequency compared with patients without a diagnosis (see Table 1). Also male patients, patients who suffered from UI before being admitted to homecare services, and patients with a higher number of reasons for homecare services were more often diagnosed regarding type of UI. On average patients were offered 1.9 strategies (range 0-8, SD 1.2). Patients with a diagnosis regarding type of UI were offered more strategies than patients without a diagnosis $(2.1$ vs. $1.8, \mathrm{p}=0.001)$.

No differences were found in the numbers of strategies between age categories (range 1.78-2.1, $\mathrm{p}=0.466$ ). The more severe the loss of urine, the more strategies were offered. Patients losing large amounts of urine were offered a mean of 2.24 (SD 1.4) strategies, which is more than for patients losing 
moderate or little amounts of urine (mean 1.96 and 1.45 respectively, $\mathrm{p}<0.001$ ).

The use of pads was the most common strategy in both groups (59.2 and $55.8 \%$ respectively). Besides the use of disposable pants for patients without a diagnosis $(31.1 \%)$, scheduled toileting was also frequently adopted to manage UI in both groups (32.8 and 29.8\% respectively). Furthermore, patients who were diagnosed regarding type of UI more often had a catheter and were more often given medication when compared to patients without a diagnosis.

Table 1 Patient characteristics and urinary symptoms by whether or not a diagnosis regarding type of urinary incontinence is made $(n=1319)$

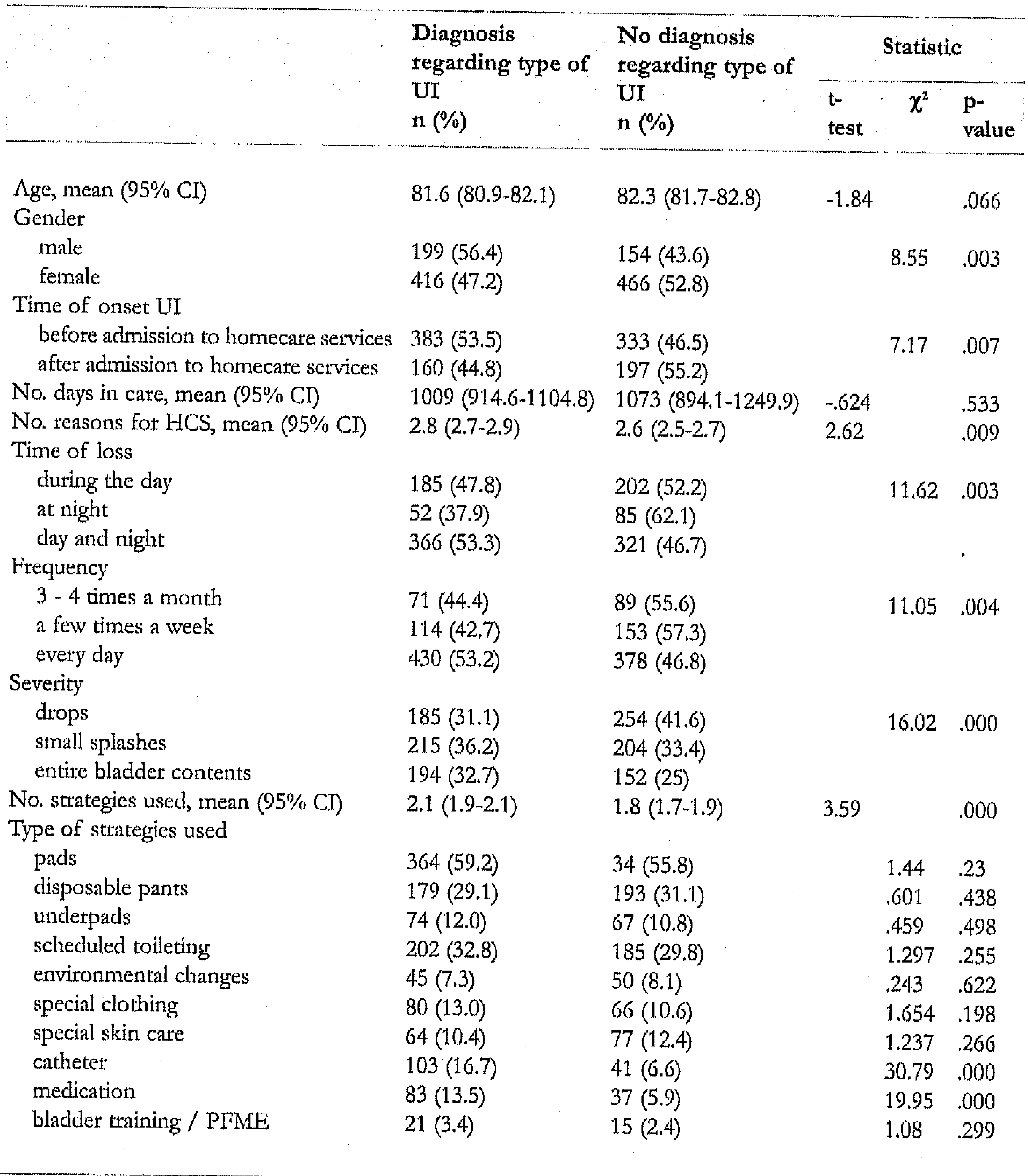

HCS, homecare services; PFME, pelvic floor muscle exercises; CI, confidence interval

\section{Factors associated with whether or not a diagnosis is made}

Multivariate logistic regression showed that patients who were already 
incontinent before being admitted to homecare services were more likely to have a diagnosis regarding type of UI as compared with patients who became incontinent after being admitted to homecare services (Table 2). Patients losing drops and patients losing urine during the night were less likely to have a diagnosis. Finally, patients without a catheter or without medication were also less likely to have a diagnosis.

Table 2 Odds of whether or not a diagnosis is made

\begin{tabular}{|c|c|c|c|c|}
\hline \multirow[b]{2}{*}{ Variables in the model } & \multirow[b]{2}{*}{ OR } & \multicolumn{2}{|c|}{$95 \%$ CI for OR } & \multirow[b]{2}{*}{ p-value } \\
\hline & & Lower & Upper & \\
\hline $\begin{array}{l}\text { No. strategies used } \\
\text { Time of onset UI }\end{array}$ & 1.11 & .981 & 1.251 & .099 \\
\hline $\begin{array}{l}\text { before admission to HCS } \\
\text { after admission to HCS (teferent) }\end{array}$ & 1.36 & 1.04 & 1.78 & .025 \\
\hline \multicolumn{5}{|l|}{ Time of loss } \\
\hline $\begin{array}{l}\text { during the day } \\
\text { at night } \\
\text { day and night (referent) }\end{array}$ & $\begin{array}{l}1.16 \\
.63\end{array}$ & $\begin{array}{l}.858 \\
.41\end{array}$ & $\begin{array}{l}1.57 \\
.984\end{array}$ & $\begin{array}{l}.333 \\
.042 \\
.044\end{array}$ \\
\hline \multicolumn{5}{|l|}{ Severity } \\
\hline drops & .699 & .484 & 1.009 & .056 \\
\hline $\begin{array}{l}\text { small splashes } \\
\text { entire bladder contents (referent) }\end{array}$ & 1.03 & .731 & 1.448 & $\begin{array}{l}.872 \\
.036\end{array}$ \\
\hline \multicolumn{5}{|l|}{ Catheter } \\
\hline $\begin{array}{l}\text { no } \\
\text { yes (referent) }\end{array}$ & .363 & .232 & .569 & .000 \\
\hline \multicolumn{5}{|l|}{ Medication } \\
\hline $\begin{array}{l}\text { no } \\
\text { yes (tefcrent) }\end{array}$ & .51 & .315 & .826 & .006 \\
\hline
\end{tabular}

OR, Odds Ratio; $\mathrm{CI}$, confidence interval; $\mathrm{HCS}$, homecare services

Table 3 presents the strategies by patient and urine-loss characteristics. Female patients more often were offered pads, scheduled toileting and bladder training/PFME, whereas male patients more often used pants or had a catheter. Patients aged $\geq 85$ years were less likely to receive a catheter, but scheduled toileting, pants and special skin care were more often adopted by this age group as compared with younger patients. Regarding incontinence symptoms, patients losing urine day and night, patients losing urine every day, and patients losing entire bladder contents more often used pants or underpads, more often received special skin care, and were more likely to have a catheter when compared with patients with less severe incontinence symptoms. Special clothing was more used by patients losing urine day and night, and patients losing entire bladder contents. Furthermore, patients losing entire bladder contents were less likely to use pads than patients losing smaller amounts of urine. Also, patients with urine leakage at night were less likely to use pads when compared with patients losing urine during the day, or day and night. 


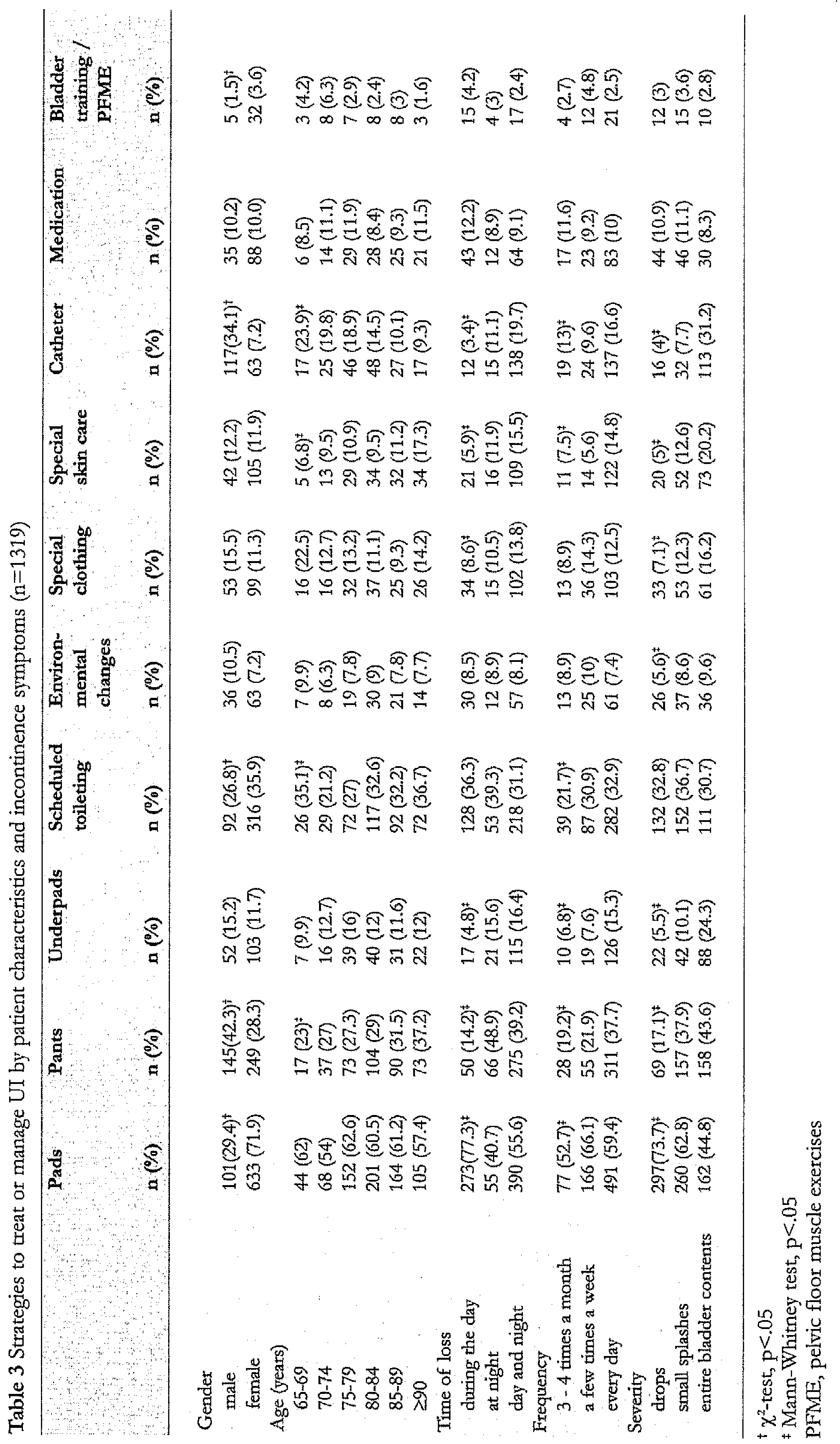


Health care worker diagnosing type of UI

For most patients a diagnosis regarding type of Ul was made by the GP (58\%), followed by the urologist (30.2\%) and the continence nurse (11.8\%). The most common diagnosis made by the urologist was functional incontinence $(54.1 \%)$, while urge incontinence was more common for the GP and the continence nurse (33.2 and $41.9 \%$ respectively).

In Table 4 the strategies by incontinence type and healthcare worker are presented. No differences in the numbers of strategies were found between the healthcare workers diagnosing type of UI (GP 2.0, urologist 2.0 and continence nurse 2.1, $\mathrm{p}=0.876$ ). Patients suffering from mixed incontinence were offered the highest number of strategies, whereas patients suffering from stress incontinence were offered the fewest strategies ( 2.13 vs. $1.51, \mathrm{p}=0.001)$.

Table 4 Strategies to treat or manage UI by health care worker and type of incontinence

\begin{tabular}{|c|c|c|c|c|c|}
\hline$\therefore \therefore$ & $\begin{array}{l}\text { GP } \\
\mathrm{n}(\%)\end{array}$ & $\begin{array}{l}\text { Urologist } \\
\text { n }(\%)\end{array}$ & $\begin{array}{l}\text { Continence } \\
\text { nurse } \mathrm{n}(\%)\end{array}$ & Total & $\begin{array}{l}\mathrm{p} \\
\text { value }\end{array}$ \\
\hline Stress & $\mathrm{n}=47(15.4 \%)$ & $\mathrm{n}=9(5.7 \%)$ & $\mathrm{n}=12(19.4 \%)$ & $68(12.9)$ & \\
\hline No. strategies (mean, CI) & $1.6(1.4-1.9)$ & $1.3(.9-1.7)$ & $1.4(1.1-1.7)$ & $1.51(1.4-1.8)$ & .465 \\
\hline Pads & $39(82.9)$ & $5(55.6)$ & $8(66.7)$ & $52(76.5)$ & \\
\hline Disposable pants & $8(17)$ & $1(11.1)$ & $1(8.3)$ & $10(14.7)$ & \\
\hline Underpads & - & $-\rightarrow$ & $1(8.3)$ & $1(1.5)$ & \\
\hline Scheduled toileting & $12(25.5)$ & -- & $3(25)$ & $15(22.1)$ & \\
\hline Environmental modifications & $1(2.1)$ & $-\cdots$ & - & $1(1.5)$ & \\
\hline Special garments & $6(12.8)$ & $1(11.1)$ & $-\cdots$ & $7(10.3)$ & \\
\hline Special skin care & $2(4.3)$ & $1(11.1)$ & -- & $3(4.4)$ & \\
\hline Catheter & $1(2.1)$ & $1(11.1)$ & $-\infty$ & $2(2.9)$ & \\
\hline Medication & $3(6.4)$ & $2(22.2)$ & - & $5(7.4)$ & \\
\hline Bladder training / PFME & $4(8.5)$ & $1(11.1)$ & $1(8.3)$ & $6(8.8)$ & \\
\hline Urge & $\mathrm{n}=101(33.2 \%)$ & $\mathrm{n}=42(26.4 \%)$ & $\mathrm{n}=26(41.9 \%)$ & $169(32.1)$ & \\
\hline No. strategies (mean, CI) & $2.0(1.8-2.2)$ & $2.4(1.9-2.9)$ & $1.9(1.6-2.2)$ & $2.0(1.9-2.3)$ & .117 \\
\hline Pads & $76(75.2)$ & $23(54.8)$ & $18(69.2)$ & $117(69.2)$ & \\
\hline Disposable pants & $22(21.8)$ & $17(40.5)$ & $10(38.5)$ & $49(28.9)$ & \\
\hline Underpads & $12(11.9)$ & $5(11.9)$ & $3(11.5)$ & $20(11.8)$ & \\
\hline Scheduled toileting & $37(36.6)$ & $18(42.9)$ & $6(23.1)$ & $61(36.1)$ & \\
\hline Environmental modifications & $6(5.9)$ & $3(7.1)$ & - & $9(5.3)$ & \\
\hline Special garments & $13(12.9)$ & $7(16.7)$ & $4(15.4)$ & $24(14.2)$ & \\
\hline Special skin care & $9(8.9)$ & $3(7.1)$ & $1(3.8)$ & $13(7.6)$ & \\
\hline Catheter & $2(2)$ & $7(16.7)$ & $1(3.8)$ & $10(5.9)$ & \\
\hline Medication & $14(13.9)$ & $12(28.6)$ & $2(7.7)$ & $28(16.6)$ & \\
\hline Bladder training / PFME & $5(5)$ & $4(9.5)$ & - & $9(5.3)$ & \\
\hline Mixed & $\mathrm{n}=70(22.9 \%)$ & $n=22(13.8 \%)$ & $\mathrm{n}=11(17.7 \%)$ & $103(19.6)$ & \\
\hline No. strategies (mean, $\mathrm{CI}$ ) & $2.4(2.1-2.7)$ & $2.1(1.7-2.6)$ & $2.3(1.4-3.1)$ & $2.13(2.0-2.5)$ & .755 \\
\hline Pads & $46(65.7)$ & $12(54.5)$ & $7 \cdot(63.6)$ & $65(63.1)$ & \\
\hline Disposable pants & $25(35.7)$ & $7(31.8)$ & $3(27.3)$ & $35(33,9)$ & \\
\hline Underpads & $7(10)$ & $1(4.5)$ & $1(9.1)$ & $9(8.7)$ & \\
\hline Scheduled toileting & $35(50)$ & $8(36,4)$ & $4(36.4)$ & $47(45.6)$ & \\
\hline Environmental modifications & $4(5.7)$ & - & $3(27.3)$ & $7(6.8)$ & \\
\hline Special garments & $10(14.3)$ & $-m$ & $2(18.2)$ & $12(11.7)$ & \\
\hline Special skin care & $12(17.1)$ & $2(9.1)$ & $1(9.1)$ & $15(14.6)$ & \\
\hline
\end{tabular}




\begin{tabular}{|c|c|c|c|c|c|}
\hline$\because$ & $\begin{array}{l}\text { GP } \\
\text { in }(\%)\end{array}$ & $\begin{array}{l}\text { Urologist } \\
\text { n }(\%)\end{array}$ & $\begin{array}{l}\text { Continence } \\
\text { nurse } n(\%)\end{array}$ & $\begin{array}{l}\text { Total } \\
\text { n }(\%)\end{array}$ & $\begin{array}{c}\mathrm{p} \\
\text { value }\end{array}$ \\
\hline Catheter & $1(1,4)$ & $7(31.8)$ & $1(9,1)$ & $9(8.7)$ & \\
\hline Medication & $16(22.9)$ & $7(31.8)$ & $3(27.3)$ & $26(25.2)$ & \\
\hline Bladder training / PFME & -- & $2(9.1)$ & -- & $2(1.9)$ & \\
\hline Functional & $\mathrm{n}=87(28.5 \%)$ & $\mathrm{n}=86(54.1 \%)$ & $\mathrm{n}=13(21 \%)$ & $186(35.4)$ & \\
\hline No. strategies (mean, CI) & $2.0(1.8-2.3)$ & $2.0(1.7-2.3)$ & $2.7(1.7-3.7)$ & $2.05(1.9-2.3)$ & .229 \\
\hline Pads & $46(52.9)$ & $22(25.6)$ & $9(69.2)$ & $77(41.4)$ & \\
\hline Disposable pants & $29(33.3)$ & $20(23.3)$ & $6(46.2)$ & $55(29.6)$ & \\
\hline Underpads & $16(18.4)$ & $14(16.3)$ & $7(53.8)$ & $37(19.9)$ & \\
\hline Scheduled toileting & $28(32.2)$ & $13(15.1)$ & $3(23.1)$ & $44(23.7)$ & \\
\hline Envitonmental modifications & $5(5.7)$ & $10(11.6)$ & $2(15.4)$ & $17(9,1)$ & \\
\hline Special gatments & $7(8.0)$ & $11(12.8)$ & $4(30.8)$ & $22(11.8)$ & \\
\hline Special skin care & $11(12.6)$ & $9(10.5)$ & $2(15.4)$ & $22(11.8)$ & \\
\hline Catheter & $20(22.9)$ & $53(61.6)$ & $1(7.7)$ & $74(39.8)$ & \\
\hline Medication & $6(6.9)$ & $13(15.1)$ & $1(7.7)$ & $20(10.8)$ & \\
\hline Bladder training / PFME & $2(2.3)$ & $2(2.3)$ & -- & $4(2.2)$ & \\
\hline Total & $\mathrm{n}=305(100)$ & $n=159(100)$ & $\mathrm{n}=62(100)$ & $526(100)$ & \\
\hline
\end{tabular}

PFME, pelvic floor muscle exercises; $\mathrm{CI}$, confidence interval

For patients suffering from stress or urge incontinence, the use of pads was the most common strategy, whereas, on average, $<10 \%$ of these patients were recommended bladder training or PFME. Pads were also the most commonly used strategy for patients suffering from mixed incontinence (63.1\%) and scheduled toileting was the second most used strategy (45.6\%). Finally, most patients suffering from functional incontinence diagnosed by the urologist had a catheter $(61.6 \%)$, whereas in cases where a GP or a continence nurse had made this diagnosis, pads were the most common strategy.

No strategies were offered by home healthcare workers for 58 patients $(4.4 \%)$ of the 1319 patients suffering from UI.

\section{DISCUSSION}

This study shows that the prevalence of UI in patients receiving homecare is high (46\%) and that the type of incontinence is diagnosed for only half of the patients suffering from UI.

The high prevalence we found in this study was consistent with another study using data on frail older people receiving home health care ${ }^{15}$. They report that $51 \%$ of the frail elderly suffered from UI. In light of the aging population and the growing number of community-dwelling persons suffering from UI, homecare agencies need to recognize the relevance of this problem.

The results of this study also show that of the patients suffering from UI, a diagnosis regarding type of incontinence was made for only $49 \%$. Patients who 
became incontinent after being admitted to homecare services were less likely to have a diagnosis. These results are more or less in line with another study that was conducted on special care units with older adults with dementia ${ }^{16}$. They found that at least one continence-related nursing diagnosis was established for only $55 \%$ of those cases suffering from UI. One explanation might be that healthcare workers find investigating or treating UI in older people not worth the effort ${ }^{17}$. However, to improve the lives of older people with UI, an evaluation and accurate diagnosis of UI is required, and this is the key for effective treatment and management of UI ${ }^{18}$.

Results also revealed that patients losing drops were less likely to have a diagnosis when compared with patients losing large amounts of urine. However, to prevent a worsening of UI, diagnosing the type of UI in less severely affected patients also requires the full attention of home healthcare workers. UI can have a detrimental effect on daily life, as it may cause patients to avoid social contacts. This may seriously affect the quality of life, especially for the elderly.

Our results show that the strategies for treating or managing UI do not differ much between patients with and patients without a diagnosis regarding type of UI. For both groups the majority of the patients used pads, with disposable pants and scheduled toileting frequently used as well. This was also reported by others who conducted a study on the frail elderly receiving homecare services ". They found that $66 \%$ of the subjects used diaper service. Considering the high age, and the physical and mental impairments of some of the patients, sometimes using pads can be appropriate to gain dependent (dry with the assistance from a caregiver) or social (dry with use of continence aids or appliances) continence. However, pads do not contribute to treating incontinence and should be the last option after all other options have been exhausted.

We were surprised to find that $13 \%$ of the patients not diagnosed regarding type of UI were prescribed medication or had a catheter. As urge incontinence is the predominant indication for drug therapy ${ }^{18}$, the decision to prescribe medication without having diagnosed the type of UI was intriguing. Without an assessment to determine the proper management strategies, prescribing medication may unnecessarily burden or harm the patients because of the sideeffects (e.g. dry mouth, nausea, urinary retention or insomnia). Similar if the case for the use of catheters, which can cause infections or bladder spasms. In fact, incontinent patients with long-term urinary catheters may actually be good candidates for bladder training ${ }^{20}$.

We found that, irrespective of the type of UI, most patients used pads to manage their UI, and $<10 \%$ of the patients suffering from stress, urge or mixed incontinence were offered bladder training or PFME. This is more or less comparable with the findings of a study assessing the quality of care provided to vulnerable, older community-based patients ${ }^{21}$. They reported that a 
behavioural intervention was recommended only for $13 \%$ of the patients. In light of research reporting the success of behavioural interventions aimed at elders with UI 5, 6, 22-24, the choice of strategies in our study population is of concern. The use of pads and pants should be limited to those elderly for whom it is not possible to regain continence or who do not wish active treatment.

According to our results, for only $8 \%$ of the patients suffering from UI were environmental changes adopted to manage UI. However, the environment of patients can have a tremendous effect on continence status. It has been found that environmental hazards may increase the prevalence of UI by $>50 \%{ }^{15}$. Adequate lighting, rails and grab bars in suitable positions, appropriate footwear to aid mobility and self-confidence, plus chairs and beds with the right height are some of the factors that can have a positive effect on continence status. Considering the high age, and the physical and/or cognitive impairments of our study population, we believe that full attention should be provided to possible hazards in the environment by home healthcare workers.

In addition, data have also shown that only $11 \%$ of the patients with a diagnosis regarding type of UI received special skin care. UI is an important cause of skin vulnerability, and older patients are especially at risk for skin damage as the barrier function of the skin is diminished in the elderly ${ }^{25}$. Using absorbent pads may also cause irritation or skin breakdown. As the majority of the patients in our study were losing urine day and night, taking care of the skin should be given full attention by home healthcare workers.

Homecare nurses can play an important role in the care for patients with UI As these nurses often visit patients on a regular basis, it will be easier for patients to talk about UI. Patients will have less shame to discuss the negative consequences of UI on their lives. Identifying treatable, potentially reversible conditions that can cause or contribute to UI may ameliorate the UI. By paying attention to potential environmental hazards (e.g., inadequate lighting and inaccessible toilets) nurses can help to prevent UI. As many people often think that UI is part of the ageing process for which no treatment exist, nurses need to inform them about treatment options. However, because of the multifactorial nature of UI, collaboration among various healthcare workers (e.g. primary care physicians and physiotherapists) often is necessary.

Finally, some methodological issues should be considered when interpreting the results. This study had a cross-sectional design and, therefore, only documented the strategies being offered at a fixed point in time. Strategies that had been used in the past were unknown. One of the strengths of this study was that only homecare nurses who knew the patient well filled in the questionnaire. 


\section{CONCLUSION}

Almost $50 \%$ of patients aged $\geq 65$ years receiving homecare suffered from UI. No diagnosis regarding type of incontinence was made for $49 \%$ of them, and pads and scheduled toileting were the most commonly used strategies. Despite studies reporting the success of behavioural interventions aimed at elders with UI, only a small number of patients were offered bladder training or PFME.

These results emphasise the need for future studies focusing on the improvement of the diagnostic process and the use of effective interventions, and focusing on the improvement of knowledge and skills of nurses. These studies should also focus on the patients' perceptions of UI and its consequences on their quality of life and other important patient outcomes, and should contribute to the development of knowledge and (nursing) theories guiding clinical nursing practice. 


\section{REFERENCES}

1. Ersser SJ, Getliffe K, Voegeli D, Regan S. A critical review of the interrelationship between skin vulnerability and urinary incontinence and related nursing intervention. International Journal of Nursing Studies. In Press, Corrected Proof.

2. Ersser SJ, Getliffe K, Voegeli D, Regan S. A critical review of the interrelationship between skin vulnerability and urinary incontinence and related nursing intervention. International Journal of Nursing Studies. 2005;42(7):823-835.

3. Nuotio M, Tammela TLJ, Luukkaala T, Jylhä M. Predictors of institutionalization in an older population during a 13-year period: the effect of urge incontinence. Journals of Gerontology, Series A, Biological sciences and Medical sciences. 2003;58(8):756-762.

4. Ouslander JG, Schnelle J. Assessment, treatment and management of urinary incontinence in the nursing home. In: Rubenstein LZ, Wieland D, eds. Improving care in the nursing home: comprehensive reviews of clinical research. Newbury Park: Sage; 1993:131-159.

5. Burgio KL, Locher JL, Goode PS, et al. Behavioral vs drug treatment for urge urinary incontinence in older women: a randomized controlled trial. Journal of the American Medical Association. 1998;280(23):1995-2000.

6. Engberg S, Sereika SM, McDowell BJ, Weber E, Brodak I. Effectiveness of prompted voiding in treating urinary incontinence in cognitively impaired homebound older adults. Journal of Wound, Ostomy and Continence Nursing. 2002;29(5):252-265.

7. Teunissen TA, de Jonge $A$, Van Weel $C$, Lagro Janssen TL. Treating urinaty incontinence in the elderly - conservative therapies that work: a systematic review. Journal of Family Practice. 2004;53(1):25-30.

8. Gibbs $\mathrm{CF}$, Johnson MT, Ouslander JG. Office management of geriatric urinary incontinence. The American Journal of Medicine. 2007;120:211-220.

9. Mardon RE, Halim S, Pawlson LG, Haffer SC. Management of urinary incontinence in Medicare Managed Care Beneficiaries. Archives of Internal Medicine. 2006;166:1128-1133.

10. Halfens R, Janssen M, Meijers J, Mistiaen P. Rapportage resultaten Landelijke Prevalentiemeting Zorgproblemen 2005. Maastricht: Universiteit Manstricht; November 2005.

11. Sandvik H, Seim A, Vanvik A, Hunskaar S. A severity index for epidemiological surveys of female urinary incontinence: comparison with 48-hour pad-weighing tests. Neurourology and Urodynamics. 2000;19(2):137-145.

12. O'Brien J, Austin M, Sethi P, O'Boyle P. Urinary incontinence: prevalence, need for treatment, and effectiveness of intervention by nurse. BMJ Clinical research ed. 1991;303(6813):1308-1312. 
13. Lagro-Janssen TL, Smits AJ, Van Weel C. Women with urinary incontinence: self-perceived worries and general practitioners' knowledge of problem. British Journal of General Practice. 1990;40(337):331-334.

14. Ju CC, Swan LK, Merriman A, Choon TE, Viegas O. Urinary incontinence among the elderly people of Singapore. Age and Ageing. 1991;20(5):387.

15. Landi F, Cesari M, Russo A, Onder G, Lattanzio F, Bernabei R. Potentially reversible risk factors and urinary incontinence in frail older people living in community. Age and Ageing. 2003;32:194-199.

16. Specht JK, Salsbury Lyons S, Maas ML. Patterns and treatments of urinary incontinence on special care units. Journal of Gerontological Nursing. 2002;25(5):13-21.

17. Fonda D, Benvenuti F, Castleden M. Management of incontinence in older people. Paper presented at: Incontinence: Proceedings of the First International Consultation on Incontinence, 1999; Plymouth.

18. Zarowitz BJ, Ouslander JG. The application of evidence-based principles of care in older persons (issue 6): urinary incontinence. Journal of the American Medical Directors Association. 2007;8(1):35-45.

19. Shimanouchi S, Kamei T, Hayashi M. homecare for the frail elderly based on urinary incontinence level. Public Health Nursing. 2000;17(6):468-473.

20. Emr K, Ryan R. Best practice for indwelling catheter in the home setting. Home Healthcare Nurse. 2004;22(12).

21. Gnanadesigan N, Saliba D, Roth CP, et al. The quality of care provided to vulnerable older community-based patients with urinary incontinence. Journal of the American Medical Directors Association. 2004;5:141-146.

22. Dougherty MC, Dwyer JW, Pendergast JF, et al. A randomized trial of behavioral management for continence with older rural women. Research in Nursing \& Health. 2002;25(1):3-13.

23. McDowell BJ, Engberg S, Sereika SM, et al. Effectiveness of behavioral therapy to treat incontinence in homebound older adults. Journal of the American Geriatrics Society. 1999;47:309-318.

24. Adkins VK, Mathews RM. Prompted voiding to reduce incontinence in community-dwelling older adults. Journal of Applied Behavior Analysis. 1997;30:153-156.

25. Doughty DB. Urinary and fecal incontinence; current management concepts. third ed. Atlanta: Mosby Elsevier; 2006. 


\section{Chapter}

Quality systems to improve care in elderly patients with urinary incontinence receiving homecare: do they work?

M.F.M.T. Du Moulin, M.N. Chenault, F.E.S. Tan, J.P.H. Hamers, R.H.G. Halfens

Submitted for publication 


\section{ABSTRACT}

bjective: (1) to gain insight into the use of quality systems to improve urinary incontinence (UI) care in older adults receiving homecare; and (2) to assess the associations between these quality systems and UI-related process and patient outcomes.

Design: cross-sectional survey

Setting: 19 homecare agencies in the Netherlands comprising 155 homecare teams

Sample: 3480 adults aged 65 and older, screened for UI

Main outcome measures: (1) percentage of patients with UI; (2) percentage of patients with a diagnosis regarding type of UI; (3) mean amount of urine loss; (4) mean frequency of urine loss.

Results: The quality systems most commonly used involved appointing a continence nurse (at the homecare agency level) and documenting UI-related actions in the patient's record (homecare teams). Mixed model analyses revealed no associations between the quality systems and the UI process or patient outcomes.

Conclusion: Most homecare agencies and homecare teams state to adopt quality systems to improve UI care for older adults. However, no associations were found between these quality systems and the UI process or patient outcomes. More research is therefore needed to gain insight into the content of the quality systems and their applicability to the homecare setting. 


\section{INTRODUCTION}

$\mathrm{U}$ rinary incontinence (UI) is a common, debilitating problem mainly affecting older people ${ }^{1-4}$. It can have adverse effects on physical health, psychological and social wellbeing ${ }^{5.8}$ and increase the risk of institutionalisation". As advancing age is a risk factor, ${ }^{10,11}$ the ageing of the population is expected to drastically increase the number of adults with UI. As older adults prefer to live in their own homes for as long as possible, the demand for homecare is also likely to increase. Studies show that about half of the patients receiving homecare have UI ${ }^{11,12}$. Addressing the problem adequately will therefore be a challenge for homecare agencies.

In spite of available treatment options, research shows that the management of UI often is inconsistent with what is considered optimal care for the

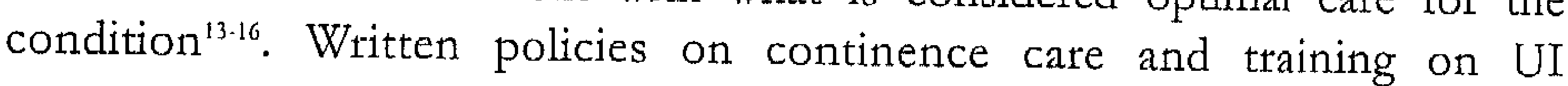
management are sparse, and behavioural treatments rarely prescribed ${ }^{17 \cdot 21}$. Rodriguez and colleagues ${ }^{22}$ report a knowledge-practice gap among qualified care staff who would benefit from training to increase their knowledge and alertness to clients' needs regarding UI care. In the Netherlands, too, it seems that UI management in daily general practice and nursing homes ${ }^{23-26}$ as well as for patients receiving homecare ${ }^{27}$ is not always adequate.

To improve UI care, several quality systems can be implemented. A quality system can be described as 'all the management activities explicitly designed to monitor, assess and improve the quality of care ${ }^{128}$. These systems can impact the care process or patient outcomes; several have been described that are used specifically to improve the quality of UI care. For example, Ouslander and colleagues $^{30}$ identified steps to use as a base for a quality initiative on incontinence; these included a focused history, the identification and treatment of potentially reversible causes, and chart documentation. Other quality systems concern UI education and the appointment of a healthcare worker dedicated to UI care ${ }^{31}$. Proper assessment of UI and documentation of the patient's continence status also help provide good care ${ }^{32,33}$.

Wagner et al. ${ }^{28}$ reviewed the effectiveness of quality systems in nursing homes and found some evidence that training and guidelines significantly reduce the prevalence of UI. However, little is known about the use and the effects of quality systems to improve UI care for older adults receiving care from homecare agencies. Indeed, it is unclear which quality system(s) homecare agencies tend to adopt, and whether they are effective. To measure effectiveness, process and outcome measures can be analysed ${ }^{28}$. Process measures have to do with the process of care (e.g. making a diagnosis), while outcome measures relate to UI outcomes (e.g. prevalence and frequency). These quality indicators are expected to positively influence the process of UI care and UI outcomes.

The aim of this study is to gain insight into the use of quality systems by homecare agencies to improve UI care in the Netherlands. Our second aim is to 
evaluate the relationship between these quality systems on UI outcomes (the prevalence and frequency of UI and amount of urine loss) and processes (whether a diagnosis as to UI type is made). The following questions are addressed:

1. What quality systems do homecare agencies use to improve UI care, and how many such agencies use these systems?

2. What is the relationship between these quality systems and UI prevalence and the number of patients diagnosed regarding UI type?

3. What is the relationship between these quality systems and UI severity in terms of the amount and frequency of urine loss?

\section{METHOD}

Design

This study is part of the Annual National Prevalence Measurement of Care Problems of Maastricht University. The design is a cross-sectional survey conducted during routine examination of patients by homecare nurses. The data were collected in April 2006.

\section{Dutch National Prevalence Measurement of Healib Care Problems}

Each year, all Dutch healthcare organisations are invited to participate in the National Prevalence Measurement of Health Care Problems ${ }^{34}$. Participating organisations include hospitals, nursing homes, homes for the elderly, institutions for the physically and mentally handicapped, and homecare agencies. Each organisation appoints a coordinator responsible for organising and implementing the study. Data collection is conducted by nurses trained to use the standardised forms; patients are included after providing informed consent. They have the right to refuse to participate and to withdraw from the study at any time without consequence.

The present study used the data pertaining to UI collected from 19 homecare agencies (14\% of the total number of homecare agencies in the Netherlands).

\section{Population and setting}

Adults aged 65 years or older who were living at home and receiving care from a homecare agency were eligible to participate. Only people who have applied to an independent assessment agency (CIZ) for homecare approval can receive homecare from a homecare agency. The assessment agency assesses the person's needs to determine the type and amount of care required. After the CIZ has granted the approval, the person can contact a homecare agency.

\section{Data collection}

Every homecare agency comprises homecare teams responsible for a geographically defined subset of patients. Therefore, data collection took place 
at three levels: the homecare agency, the homecare team and the patient.

Quality systems used at the level of the homecare agency differ from those of the homecare teams. Also, even if a homecare agency has no quality systems, individual teams can still adopt one or more quality systems. At the homecare agency level, the availability of quality systems ('continence nurse', 'UI protocol', 'updating of protocol', 'UI education') was scored (yes/no) using a list set up by a multidisciplinary team of experts. Likewise, at the homecare team level availability was scored (yes/no) using a list ('presence of a nurse with special UI focus', 'documentation in patient record', 'check as to whether UI protocol is used', 'UI brochure').

At the patient level a standardised questionnaire was used by the homecare nurses who examined the patients. To answer the questions the nurse collected information both from the patient and his or her patient record. For patients unable to answer the questions, the informal caregiver (in most cases a close relative) was approached. Data on the following patient characteristics were collected: age, sex, body mass index (BMI) and mobility ('bed-ridden', 'confined to chair', 'walks now and then', 'walks regularly').

To identify whether patients had UI, nurses asked about the frequency of involuntary urine loss $(1=$ never, $2=$ three or four times a month, $3=$ a few times a week, $4=$ every day). Patients rated as 'never' were regarded as continent. The nurse also rated the amount of urine loss $(1=$ drops, $2=$ small splashes, 3 $=$ entire bladder contents) and whether or not a diagnosis had been made regarding type of UI (yes/no).

\section{Analysis}

Analyses were performed using SPSS 15 . The relationship between patient characteristics and continence status was analysed using the $\chi^{2}$-test for categorical variables and the t-test for continuous variables. As the data has a multilevel structure in which homecare teams are embedded within agencies, random intercept models were defined to estimate outcome values relative to quality systems. For this, the data were aggregated at team level. The outcome variables then became mean percentage of patients with UI, mean percentage of patients who had been diagnosed as to UI type, mean amount of urine loss, and mean frequency of urine loss. Patient characteristics such as age, sex, mobility and BMI were also aggregated at team level and considered covariates.

It appeared that when a quality system was indeed present, it was often combined with one or more other quality systems. Therefore, all observed combinations of quality systems were classed as separate groups for comparison purposes. Comparisons were made between teams with (combinations of) quality system(s) and teams without quality systems, as well as between individual quality systems. To simplify the analysis, the combinations of systems at homecare agency level were considered separately from those at team level. 


\section{RESULTS}

In 2006 a total of 19 homecare agencies participated in the Dutch National Prevalence Measurement of Health Care Problems. These agencies consisted of 155 homecare teams caring for 3480 patients aged 65 years or older who were screened for UI. Table 1 presents patient characteristics by continence status. Being female and having high age or BMI and less mobility were related to incontinence.

Table $1 \mathrm{UI}$ status and patient characteristics

\begin{tabular}{llll}
\hline Patient characteristics & $\begin{array}{l}\text { Incontinent } \\
\mathbf{n}(\%)\end{array}$ & $\begin{array}{l}\text { Continent } \\
\mathbf{n}(\%)\end{array}$ & $\begin{array}{l}\text { p-valie } \\
\text { Sex }\end{array}$ \\
$\quad$ male & $421(34.9)$ & $785(65.1)$ & $\mathrm{p}<.001$ \\
$\quad$ female & $1154(51.0)$ & $1109(49.0)$ & \\
Age (mean, SD) & $82.1(7.1)$ & $80.1(7.0)$ & $\mathrm{p}<.001$ \\
BMI' (mean, SD) & $26.8(5.6)$ & $25.5(4.8)$ & $\mathrm{p}<.001$ \\
Mobility & & & \\
$\quad$ bed-ridden & $61(65.6)$ & $32(34.4)$ & $\mathrm{p}<.001$ \\
$\quad$ confined to chair & $153(65.9)$ & $79(34.1)$ & \\
$\quad$ walks now and then & $533(51.9)$ & $493(48.1)$ & \\
$\quad$ walks regularly & $770(38.8)$ & $1212(61.2)$ & \\
& & & \\
\hline
\end{tabular}

${ }^{1}$ Body Mass Index

The number of teams per homecare agency varies from 1 to 21 , and the number of patients per team from 2 to 117 . Of the 19 homecare agencies, a total of 10 $(53 \%)$ used one or more quality systems: $3(16 \%)$ used a UI protocol; $7(37 \%)$ employed a continence nurse; $4(21 \%)$ used UI education; and $4(21 \%)$ updated their protocols.

Of the 155 teams, 79 (51\%) appointed a nurse with a special UI focus, 29 $(18.7 \%)$ checked whether the UI protocol was used, 121 (78.1\%) documented UI-related actions in the patient's record, and $10(6.5 \%)$ used brochures on UI.

\section{UI prevalence}

To identify the quality systems associated with UI prevalence, all quality systems (separate and combined as had been observed) were entered into models: one for the quality systems at homecare agency level and one for the systems at team level. Table 2 shows the adjusted estimated mean prevalence of UI. No relationship between the mean percentage of UI in teams using quality systems (separate or combined) was observed compared to teams without quality systems. 
Table 2 Mean percentage incontinence by availability of quality systems

\begin{tabular}{|c|c|c|c|c|c|}
\hline Quality systems & $\begin{array}{l}\text { Number of } \\
\text { teams with } \\
\text { quality } \\
\text { system(s) }\end{array}$ & $\begin{array}{l}\text { Adjusted } \\
\text { estimated } \\
\text { mean \% of } \\
\text { Ur }\end{array}$ & s.e. & $95 \%$ CI interval & p-value \\
\hline \multicolumn{6}{|l|}{ Agency level* } \\
\hline A & 9 & 38.9 & 6.5 & $23.7-54.2$ & .207 \\
\hline$A B$ & 18 & 53.3 & 5.5 & $35.5-67.1$ & .664 \\
\hline$A C D$ & 7 & 58.5 & 7.3 & $42.5-74.5$ & .223 \\
\hline $\mathrm{BCD}$ & 29 & 40.4 & 4.1 & $29.5-51.3$ & .147 \\
\hline C & 17 & 42.5 & 4.4 & $32.7-52.3$ & .262 \\
\hline $\mathrm{D}$ & 2 & 68.7 & 11.2 & $46.3-91.1$ & .083 \\
\hline $\mathrm{BC}$ & 1 & 56.9 & 15.2 & $26.8-87.0$ & .586 \\
\hline none (reference) & 72 & 48.5 & 2.4 & $42.7-54.3$ & \\
\hline \multicolumn{6}{|l|}{ Team level** } \\
\hline a & 6 & 51.6 & 6.3 & $39.1-64.1$ & .706 \\
\hline $\mathrm{ab}$ & 4 & 53.9 & 8.0 & $38.2-70.0$ & .567 \\
\hline $\mathrm{ac}$ & 48 & 47.7 & 2.7 & $42.2-53.2$ & .795 \\
\hline$a b c$ & 11 & 48.6 & 4.9 & $38.8-58.3$ & .962 \\
\hline acd & 1 & 33,0 & 15.2 & $2.9-63.1$ & .313 \\
\hline$b$ & 1 & 32.8 & 15.2 & $2.6-62.9$ & .303 \\
\hline $\mathrm{bc}$ & 4 & 42.1 & 7.7 & $27.0-57.3$ & .424 \\
\hline c & 48 & 43.9 & 3.0 & $37.7-50.1$ & .282 \\
\hline abed & 9 & 51.9 & 6.3 & $39.0-64.7$ & .684 \\
\hline none (reference) & 23 & 48.9 & 3.8 & $41.2-56.6$ & \\
\hline
\end{tabular}

$A=$ protocol on incontinence, $B=$ updating of protocol, $C=$ continence nurse, $D=U I$ education $\mathrm{a}=$ nurse with special UI focus, $\mathrm{b}=$ check as to whether UI protocol is used, $\mathrm{c}=$ documentation in patient record, $\mathrm{d}=$ UI brochurc

$\S$

(within homecare agencies) without quality systems

* adjusted for mobility ( $\%$ bedridden): $b=0.47, p=.021$

** adjusted for mobility (\% bedridden): $b=0.62, p=.004$ and mean BMr: $b=1.63, p=.043$

Pair-wise comparisons (data not shown) of (combinations of) the quality systems showed that teams from homecare agencies providing UI education had a higher percentage of UI compared to teams from homecare agencies with a UI protocol $(p=.029)$, a continence nurse $(p=.035)$, or a combination of a continence nurse, education and protocol updating $(p=.023)$. Pair-wise comparisons of the teams' quality system combinations revealed no statistically significant differences.

\section{Diagnosis regarding type of UI}

The data showed that 16 teams never made diagnoses as to UI type, whereas 17 teams always did. These were excluded from analysis. Mixed model analysis was performed to measure the associations between the quality systems and mean number of diagnoses as to UI type. No associations were found (see Table 3). 
Table 3 Mean percentage of patients with UI diagnoses by availability of quality systems

\begin{tabular}{|c|c|c|c|c|c|}
\hline Quality systems" & $\begin{array}{l}\text { Number of } \\
\text { teams with } \\
\text { quality } \\
\text { system(s) }\end{array}$ & $\begin{array}{l}\text { Adjusted } \\
\text { estimated } \\
\text { mean } \% \text { of } \\
\text { diagnoses }\end{array}$ & s.e. & $95 \%$ CI interval & p-value \\
\hline \multicolumn{6}{|l|}{ Agency level } \\
\hline$\Lambda$ & 8 & 39.3 & 10.3 & $15.9-6.3 .7$ & .468 \\
\hline$A B$ & 14 & 50.4 & 8.9 & $27.4-73.4$ & .794 \\
\hline $\mathrm{ACD}$ & 6 & 53.1 & 11.3 & $28.6-77.5$ & .662 \\
\hline B & 16 & 39.3 & 7.0 & $24.2-54.4$ & .319 \\
\hline $\mathrm{BCD}$ & 22 & 41,4 & 6.7 & $25.1-57.6$ & .445 \\
\hline $\mathrm{BC}$ & 1 & 51.5 & 23.4 & $5.1-97.9$ & .872 \\
\hline none (reference) & 55 & 47.7 & 4.0 & $38.7-56.7$ & \\
\hline \multicolumn{6}{|l|}{ Tenm level } \\
\hline a & 5 & 54.7 & 10.3 & $34.2-75.2$ & .387 \\
\hline ac & 40 & 48.5 & 4.1 & $40.2-56.8$ & .561 \\
\hline $\mathrm{abc}$ & 9 & 52.2 & 7.9 & $36.4-68.0$ & .425 \\
\hline acd & 1 & 58.1 & 22.8 & $12.9-103.4$ & .562 \\
\hline abcd & 7 & 52,6 & 9.7 & $32.5-72.6$ & .478 \\
\hline b & 1 & 60.9 & 22.8 & $15.6-106.1$ & .485 \\
\hline $\mathrm{bc}$ & 3 & 47.3 & 13.2 & $21.2-73.5$ & .839 \\
\hline c & 39 & 36.8 & 4.4 & $27.3-46.2$ & .286 \\
\hline none (reference) & 17 & 44.4 & 5.9 & $32.3-55.2$ & \\
\hline
\end{tabular}

$A=$ protocol on incontinence, $B=$ updating of protocol, $C=$ continence nurse, $D=$ UI education $\mathrm{a}=$ nurse with special UI focus, $\mathrm{b}=$ check as to whether UI protocol is used, $\mathrm{c}=$ documentation in patient record, $\mathrm{d}=$ UI brochurc

$\S$ when compared to teams (within homecare agencies) without quality systems

Pair-wise comparison (data not shown) of (combinations of) the quality systems revealed no differences in the outcome measure. In other words, no (combinations of) quality systems performed better than any other on the outcome measure (\% of diagnoses).

\section{Frequency and amount of urine loss}

To identify which quality systems were associated with mean frequency of UI loss, all quality systems (separate and combined) were entered into models: one for the quality systems at agency level and one for those at team level. This was also done for mean amount of urine loss. Tables 4 and 5 show no relationship between the availability of the quality systems (separate or combined) and these two outcome variables. 
Quality systems to improve UI care: do they work?

Table 4 Mean frequency of UI loss by availability of quality systems

\begin{tabular}{|c|c|c|c|c|c|}
\hline Quality systems & $\begin{array}{l}\text { Number of } \\
\text { teams with } \\
\text { quality } \\
\text { system(s) }\end{array}$ & $\begin{array}{l}\text { Adjusted } \\
\text { estimated } \\
\text { mean } \\
\text { frequency** }\end{array}$ & s.e. & $95 \%$ CI interval & p-value \\
\hline \multicolumn{6}{|l|}{ Agency level* } \\
\hline$A$ & 9 & 3.57 & 0.11 & $3.3-3.8$ & .911 \\
\hline $\mathrm{AB}$ & 18 & 3.51 & 0.08 & $3.3-3.7$ & .625 \\
\hline $\mathrm{ACD}$ & 7 & 3.37 & 0.13 & $3.1-3.6$ & .165 \\
\hline $\mathrm{BC}$ & 1 & 3.34 & 0.30 & $2.7-3.9$ & .485 \\
\hline $\mathrm{BCD}$ & 29 & 3.59 & 0.06 & $3.4-3.7$ & .696 \\
\hline $\mathrm{C}$ & 17 & 3.51 & 0.08 & $3.4-3.7$ & .602 \\
\hline$D$ & 2 & 3.31 & 0.22 & $2.9-3.7$ & .260 \\
\hline none (teference) & 72 & 3.56 & 0.04 & $3.5-3.6$ & \\
\hline \multicolumn{6}{|l|}{ Team level } \\
\hline a & 6 & 3.62 & 0.12 & $3.4-3.9$ & .384 \\
\hline$a b$ & 4 & 3.56 & 0.15 & $3.3-3.9$ & .576 \\
\hline $\mathrm{ac}$ & 48 & 3.56 & 0.04 & $3.5-3.7$ & .415 \\
\hline$a b c$ & 11 & 3.59 & 0.09 & $3.4-3.8$ & .430 \\
\hline acd & 1 & 3.89 & 0.30 & $3.3-4.5$ & .301 \\
\hline abcd & 9 & 3.34 & 0.11 & $3.3-3.5$ & .215 \\
\hline $\mathrm{b}$ & 1 & 3.19 & 0.30 & $2.6-3.8$ & .320 \\
\hline$b c$ & 4 & 3.60 & 0.15 & $3.3-3.9$ & .563 \\
\hline c & 48 & 3.54 & 0.04 & $3.5-3.6$ & .576 \\
\hline none (reference) & 23 & 3.50 & 0.06 & $3.4-3.6$ & \\
\hline
\end{tabular}

$A=$ protocol on incontinence, $B=$ updating of protocol, $C=$ continence nurse, $D=U I$ education $a=$ nurse with special UI focus, $b=$ check as to whether UI protocol is used, $c=$ documentation in patient record, $\mathrm{d}=\mathrm{UI}$ brochure

$\S$ when compared to teams (within homecare agencies) without quality systems

$*$ adjusted for mobility (\% bedridden): $b=001, p=.038$

** range 2-4

\section{Frequency of UI loss}

Pair-wise comparisons (data not shown) of (combinations of) the quality systems used at homecare agency level revealed no differences in mean frequency of UI. Pair-wise comparisons of the (combinations of) quality systems at team level showed that, though not statistically significant, teams using all four quality systems seemed to have better outcomes (lower mean frequency of UI) than those using two (a nurse with a UI focus and documentation in patient record; $\mathrm{p}=.056$ ) or three (a nurse with a UI focus, documentation in patient record and check as to whether UI protocol was used; $\mathrm{p}=0.075)$. 
Table 5 Mean amount of urine loss by availability of quality systems

\begin{tabular}{|c|c|c|c|c|c|}
\hline Quality systems & $\begin{array}{l}\text { Number of } \\
\text { teams with } \\
\text { quality } \\
\text { system(s) }\end{array}$ & $\begin{array}{l}\text { Adjusted } \\
\text { estimated } \\
\text { mean utine } \\
\text { loss*** }\end{array}$ & s.e. & $95 \% \mathrm{Cl}$ interval & $p$-value \\
\hline \multicolumn{6}{|l|}{ Agengy level* } \\
\hline $\mathrm{A}$ & 9 & 1.96 & 0.12 & $1.7-2.2$ & .102 \\
\hline$A B$ & 18 & 1.70 & 0.08 & $1.5-1.9$ & .071 \\
\hline $\mathrm{ACD}$ & 7 & 2.02 & 0.13 & $1.8-2.3$ & .521 \\
\hline $\mathrm{BC}$ & 1 & 1.92 & 0.33 & $1.3-2.8$ & .644 \\
\hline$B C D$ & 29 & 1.91 & 0.07 & $1.8-2.1$ & .100 \\
\hline C & 17 & 1.82 & 0.08 & $1.7-2.0$ & .322 \\
\hline D & 2 & 2.16 & 0.24 & $1.7-2.6$ & .056 \\
\hline none (reference) & 72 & 1.90 & 0.04 & $1.8-2.0$ & \\
\hline \multicolumn{6}{|l|}{ Tenm lenel** } \\
\hline a & 6 & 1.86 & 0.14 & $1.6-2.1$ & .510 \\
\hline $\mathrm{ab}$ & 4 & 2.05 & 0.17 & $1.7-2.4$ & .699 \\
\hline $\mathrm{ac}$ & 48 & 1.81 & 0.05 & $1.7-1.9$ & .095 \\
\hline$a b c$ & 11 & 1.97 & 0.10 & $1.8-2.2$ & .991 \\
\hline acd & 1 & 1.98 & 0.34 & $1.3-2.6$ & .969 \\
\hline abcd & 9 & 1.92 & 0.12 & $1.7-2.2$ & .765 \\
\hline b & 1 & 1.67 & 0.34 & $1.0-2.3$ & .397 \\
\hline$b c$ & 4 & 1.87 & 0.17 & $1.5-2.2$ & .599 \\
\hline c & 48 & 1.90 & 0.06 & $1.8-2.0$ & .473 \\
\hline none (reference) & 23 & 1.97 & 0.08 & $1.8-2.1$ & \\
\hline
\end{tabular}

$A=$ protocol on incontinence,$B=$ updating of protocol, $C=$ continence nurse, $D=$ UI education $\mathrm{a}=$ nurse with special UI focus, $\mathrm{b}=$ check as to whether UI protocol is used, $\mathrm{c}=$ documentation in patient record, $\mathrm{d}=\mathrm{UI}$ brochure

$\S$ when compared to teams (within homecare agencies) without quality systems

$*$ adjusted for $\operatorname{sex}(\%$ female): $b=-.001, p=.001$

** adjusted for sex (\% female): $\mathrm{b}=-.006, \mathrm{p}=.001$

**** range $1-3$

\section{Amount of UI loss}

Pair-wise comparisons (data not shown) of (combinations of) quality systems at homecare agency level revealed a trend showing a lower mean amount of UI loss in teams from homecare agencies with both a UI protocol and updating of the protocol, compared to teams in agencies using UI education $(\mathrm{p}=.071)$ or in agencies with a combination of UI protocol, a continence nurse and education $(p=.056)$. Pair-wise comparison of (combinations) of quality systems at team level revealed no differences.

\section{DISCUSSION}

This study showed that $53 \%$ of the homecare agencies and $86 \%$ of the homecare teams used one or more quality systems to improve care for patients with UI. Documentation in patient's records (78\% of the teams) and use of a continence nurse $(37 \%$ of the homecare agencies) were the most common 
systems. However, results showed no associations between the quality systems as measured in our study and UI outcomes.

Some methodological issues should be mentioned when interpreting the results. This study had a cross-sectional design and cannot be used to make claims about cause-effect relationships between the outcome measures and quality systems used. It also provides no insight into the effects on UI outcomes of quality systems used in the past. Furthermore, it was not possible to check whether the homecare agencies and teams which indicated using quality systems in fact did so; research in other settings shows occasional discrepancies between documentation about care-process delivery in the patient's record and care that is actually provided ${ }^{35}$. How far this played a role in our study is not known. Finally, which quality systems other than those measured by the prevalence measurement are being used to improve UI care also remains unknown.

We were surprised to find no associations between the quality systems and the process and outcome measures. After all, studies in other settings report several quality systems as having positive effects on UI. For instance, one study with a pretest-posttest design conducted in seven nursing homes revealed that staff training significantly reduced incontinence prevalence from $43 \%$ to $21 \%{ }^{36}$. On the basis of a quasi-experiment, Collette et al. ${ }^{19}$ also reported that an educational programme for nursing staff significantly improved nurses' knowledge, skills and attitudes. Randomised controlled trials, too, have showed continence nurses to bring about positive results for community-dwelling women $^{37.39}$. Finally, using a prospective evaluation study, Sampselle et al. ${ }^{40}$ found that using an evidence-based protocol benefited women's continence status.

In spite of these results, we found no associations between the quality systems and our outcome measures. However, as a result of the low number of teams adopting certain (combinations of) quality systems, our mixed model analyses may have been under-powered to find any such associations. In addition, most of the studies mentioned above were not conducted in the home healthcare setting. Unlike in hospitals or nursing homes, patients receiving homecare are not under the constant surveillance of, for example, a nurse. There is also a possibility that homecare agencies or teams using one or more quality systems may be the very ones with relatively large proportions of patients with UI.

Many patients receiving homecare services are old, and most suffer from multiple medical conditions and disabilities. Therefore, quality systems to improve UI care in the home healthcare setting must address aspects specifically related to UI in this group (e.g. greater support may be required to ensure compliance and sustain motivation, and the assessment process may take longer as all relevant information may not be obtained at once) ${ }^{41}$. However, whether these aspects are included in the quality systems is not known, as our study only investigated whether a certain system (e.g., a protocol) was available in the 
homecare agency or team. No data were gathered on the content of protocols, for example, or the way in which the systems were adopted by the home healthcare workers.

The fact that we found no associations between the quality systems and UI outcomes may also result from certain staff or patient characteristics. Research has shown that healthcare workers may have negative attitudes about the effectiveness of treatment for $\mathrm{UI}^{42}$. Time constraints, too, may force them to focus care on more urgent problems, ${ }^{13}$ and patients, who tend to view UI as part of the ageing process, may be reluctant to ask for help or follow treatment ${ }^{44-46}$. Thus, despite the availability of quality systems to improve UI care, healthcare workers may not use them because of their own or the patient's lack of motivation.

Another factor that may have influenced our findings is that we do not know how the quality systems are implemented in home healthcare. The implementation of new working methods may be hampered by several factors (e.g. insufficient knowledge of the healthcare worker's experience, values, attitude, needs and priorities, as well as economic and administrative factors ${ }^{47}$. Therefore, the extent to which the quality systems are accepted and carried out by home healthcare workers remains unknown.

\section{CONCLUSION}

homecare agencies are confronted with caring for a growing number of older people with UI who also suffer from physical and/or mental impairments. There are several quality systems that home health care workers can adopt in order to improve UI care; however, our study revealed only limited use of such systems. Remarkably, we found no associations between quality systems and UI outcomes. Factors like inadequate implementation of quality systems or lack of motivation to address UI on the part of either the home healthcare worker or the patient may have influenced our results. Therefore, more insight is needed into the content of quality systems to improve UI care and their applicability in the homecare setting. 


\section{REFERENCES}

1. Rohr G, Stovring H, Christensen K, Gaist D, Nybo H, Kragstrup J. Characteristics of middle-aged and elderly women with urinary incontinence. Scandinavian Journal of Primary Health Care, 2005;23:203208.

2. Espino DV, Palmer RF, Miles TP, Mouton CP, Lichtenstein MJ, Markides $K P$. Prevalence and severity of urinary incontinence in elderly MexicanAmerican women. Journal of the American Geriatrics Society. 2003;51:1580-1586.

3. Danforth K, Townsend M, Lifford K, Curhan G, Resnick N, Grodstein F. Risk factors for urinary incontinence among middle-aged women. American Journal of Obstetrics and Gynecology. 2006;194:339-345.

4. Melville JL, Katon W, Delany K, Newton K. Urinary incontinence in US women - a population-based study. Archives of Internal Medicine. 2005;165(5):537-542.

5. Ko Y, Lin S, Salmon J, Bron M. The impact of urinary incontinence on quality of life of the elderly. American Journal of Managed Care. 2005;11(4):S103-111.

6. Engberg S, Sereika SM, Weber E, Engberg R, McDowell BJ, Reynolds CF. Prevalence and recognition of depressive symptoms among homebound older adults with urinary incontinence. Journal of Geriatric Psychiatry and Neurology. 2001;14(3):130-139.

7. van der Vaart $\mathrm{CH}$, de Leeuw JR, Roovers JP, Heintz AP. De invloed van urine-incontinentie op de kwaliteit van leven bij thuiswonende Nederlandse vrouwen van 45-70 jaar. Nederlands tijdschrift voor geneeskunde. 2000;144(19):894-897.

8. Fultz NH, Burgio K, Diokno AC, Kinchen KS, Obenschain R, Bump RC. Burden of stress urinary incontinence for community-dwelling women. American Journal of Obstetrics and Gynecology. 2003;189(5):1275-1282.

9. Thom DH, Haan MN, Van den Eeden SK. Medically recognized urinary incontinence and risks of hospitalization, nursing home admission and mortality. Age and Ageing. 1997;26(5):367-374.

10. Hannestad YS, Rortveit G, Sandvik H, Hunskaar S, the Norwegian EPINCONT study. Epidemiology of Incontinence in the County of N-T. A community-based epidemiological survey of female urinary incontinence: the Norwegian EPINCONT study. Epidemiology of Incontinence in the County of Nord-Trondelag. Journal of Clinical Epidemiology. 2000;53(11):1150-1157.

11. Landi F, Cesari M, Russo A, Onder G, Lattanzio F, Betnabei R. Potentially reversible risk factors and urinary incontinence in frail older people living in community. Age and Ageing. 2003;32:194-199. 
12. Du Moulin MFMT, Hamers JPH, Ambergen AW, Janssen MAP, Halfens RJG. Prevalence of urinary incontinence among community-dwelling adults receiving homecare. Research in Nursing \& Health. 2008; DOI:10.1002/nur.20291.

13. Gibbs $\mathrm{CF}$, Johnson MT, Ouslander JG. Office management of geriatric urinary incontinence. The American Journal of Medicine. 2007;120:211-220.

14. Mardon RE, Halim S, Pawlson LG, Haffer SC. Management of urinary incontinence in Medicare Managed Care Beneficiaries. Archives of Internal Medicine. 2006;166:1128-1133.

15. Penning-van Beest FJA, Sturkenboom MCJM, Bemelmans BLH, Herings RMC. Undertreatment of urinary incontinence in general practice. Annals of Pharmacotherapy. 2005;39(1):17-21.

16. Engberg S, Kincade J, Thompson D. Future directions for incontinence research with frail elders. Nursing Research. November/December 2004;53(6S):S22-S28.

17. Watson N, Brink CA, Zimmer J, Mayer R. Use of the Agency for Health Care Policy and Research Urinary Incontinence Guideline in nursing homes. Journal of the American Geriatrics Society. 2003;51(12):1779-1786.

18. Schnelle J, Cadogan M, Grbic D, et al. A standardized quality assessment system to evaluate incontinence care in the nursing home. Journal of the American Geriatrics Society. 2003;51(12).

19. Collette $C$, Leclerc $G$, Tu IM. Effectiveness of a geriattic urinary incontinence educational program for nursing staff. Canadian Journal of Nursing Leadership. 2003;16(4):99-109.

20. Mayor S. Incontinence management is inadequate, UK audit shows. British Medical Journal. 26 November 2005;331:1226.

21. Gnanadesigan N, Saliba D, Roth CP, et al. The quality of care provided to vulnerable older community-based patients with urinary incontinence. Journal of the American Medical Directors Association. 2004;5:141-146.

22. Rodriguez NA, Sackley CM, Badger FJ. Exploring the facets of continence care: a continence survey of care homes for older people in Birmingham. Journal of Clinical Nursing. 2005;16:954-962.

23. Inspectie voor: de Gezondheidszorg. Verpleeghuiszorg: kwaliteitsslag is gaande. Resultaat van geintensiveerd toezicht 2005-2006. Den Haag, December 2006.

24. Teunissen D, Bosch van den W, Weel C, Lagro Janssen TL. Urinary incontinence in the elderly: attitudes and experiences of general practitioners; a focus group study. Scandinavian Journal of Primary Health Care. 2006;24(56-61).

25. Albers-Heitner P, Berghmans LCM, Nieman F, Lagro Janssen TL, Winkens R. How do patients with urinary incontinence perceive care given by their general practitioner? A cross-sectional study. International Journal of Clinical Practice. 2008;62(3):508-515. 
26. Albers-Heitner P, Berghmans LCM, Nieman F, Lagro Janssen TL, Winkens R. Adherence to professional guidelines for patients with urinary incontinence by general practitioners: a cross-sectional study. Journal of Evaluation in Clinical Practice. 2007; in press.

27. Du Moulin MFMT, Hamers JPH, Ambergen AW, Halfens RJG. Urinary incontinence in older adults receiving homecare; diagnosis and strategies. Scandinavian Journal of Caring Sciences. 2008;doi: 10.1111/j.14716712.2008.00610.x.

28. Wagner C, Wal van der G, Groenewegen P, Bakker de D. The effectiveness of quality systems in nursing homes: a review. Quality \& Safety in Health Care. 2001;10:211-217.

29. Institute of Medicine IOM. http://www.iom.edu/cms/8089.aspx. 2008.

30. Ouslander JG. Quality improvement initiatives for urinary incontinence in nursing homes. Journal of the American Medical Directors Association. 2007;8(3):S6-S11.

31. Mueller $\mathrm{C}$, Cain $\mathrm{H}$. Comprehensive management of urinary incontinence through quality improvement efforts. Geriatric Nursing. 2002;23(2):82-87.

32. Awad L. Verantwoorde zorg bij toiletgang en incontinentie. Zeist: SCA hygiene products Nederland B.V.; 2006.

33. Lagro Janssen TL, Breedveldt Boer HP, Dongen JJAM, Lemain TJJ, Teunissen D, Pinxteren B. NHG-Standaard Incontinentie voor urine. Huisarts \& Wetenschap. 2006;49(10):501-510.

34. Halfens R, Janssen M, Meijers J, Mistiaen P. Rapportage resultaten Landelijke Prevalentiemeting Zorgproblemen 2005. Maastricht: Universiteit Maastricht; November 2005.

35. Schnelle J, Bates-Jensen B, Chu L, Simmons S. Accuracy of nursing home medical record information about care-process delivery: implications for staff management and improvement. Journal of the American Geriatrics Society. 2004;52:1378-1383.

36. Schnelle J, Newman D, White M, et al. Maintaining continence in nursing home residents through the application of industrial quality control. The Gerontologist. 1993;33(1):114-121.

37. Borrie MJ, Bawden M, Speechley M, Kloseck M. Interventions led by nurse continence advisers in the management of urinary incontinence: a randomized controlled trial. Canadian Medical Association Journal. May 1, 2002 2002;166(10):1267-1273.

38. Williams K, Assassa P, Cooper N, et al. Clinical and cost-effectiveness of a new nurse-led continence service: a randomised controlled trial. British Journal of General Practice. 2005;55(518):696-703.

39. Du Moulin MFMT, Hamers JPH, Paulus A, Berendsen C, Halfens R. Effects of introducing a specialized nurse in the care of community-dwelling women suffering from urinary incontinence. Journal of Wound, Ostomy, and Continence Nursing. 2007;34(6):631-640. 
40. Sampselle CM, Wyman J, Thomas C, et al. Continence for women: a test of AWHONN's evidence-based protocol in clinical practice. Journal of Wound, Ostomy, and Continence Nursing. 2000;27:109-117.

41. Getliffe K, Dolman M, eds. Promoting continence; a clinical and research resource. second ed: Baillière Tindall; 2003.

42. Resnick B, Keilman L, Calabrese B, et al. Nursing staff beliefs and expectations about continence care in nursing homes. Journal of Wound, Ostomy, and Continence Nursing. 2006;33(6):610-618.

43. Cheater FM, Baker R, Gillies $C$, et al. The nature and impact of urinary incontinence experienced by patients receiving community nursing services: a cross-sectional cohort study. International Journal of Nursing Studies. 2006; doi:10.1016/j.ijnurstu.2006.09.006.

44. Hägglund D, Wadensten B. Fear of humiliation inhibits women's careseeking behaviour for long-term urinary incontinence. Scandinavian Journal of Caring Sciences. 2007;21:305-312.

45. Teunissen D, Weel C, Lagro Janssen TL. Urinary incontinence in older people living in the community: examining help-seeking behaviour. British Journal of General Practice. 2005;55(519):776-782.

46. Dugan E, Roberts CP, Cohen SJ, et al. Why older community-dwelling adults do not discuss urinary incontinence with their primary care physicians. Journal of the American Geriatrics Society. 2001;49(4):462-465.

47. Grol R, Wensing M. Implementatie; effectieve verandering in de patiëntenzorg. 2 ed. Maarssen: Elsevier gezondheidszorg; 2001. 


\section{Chapter}

The role of the nurse in community
continence care: a systematic review

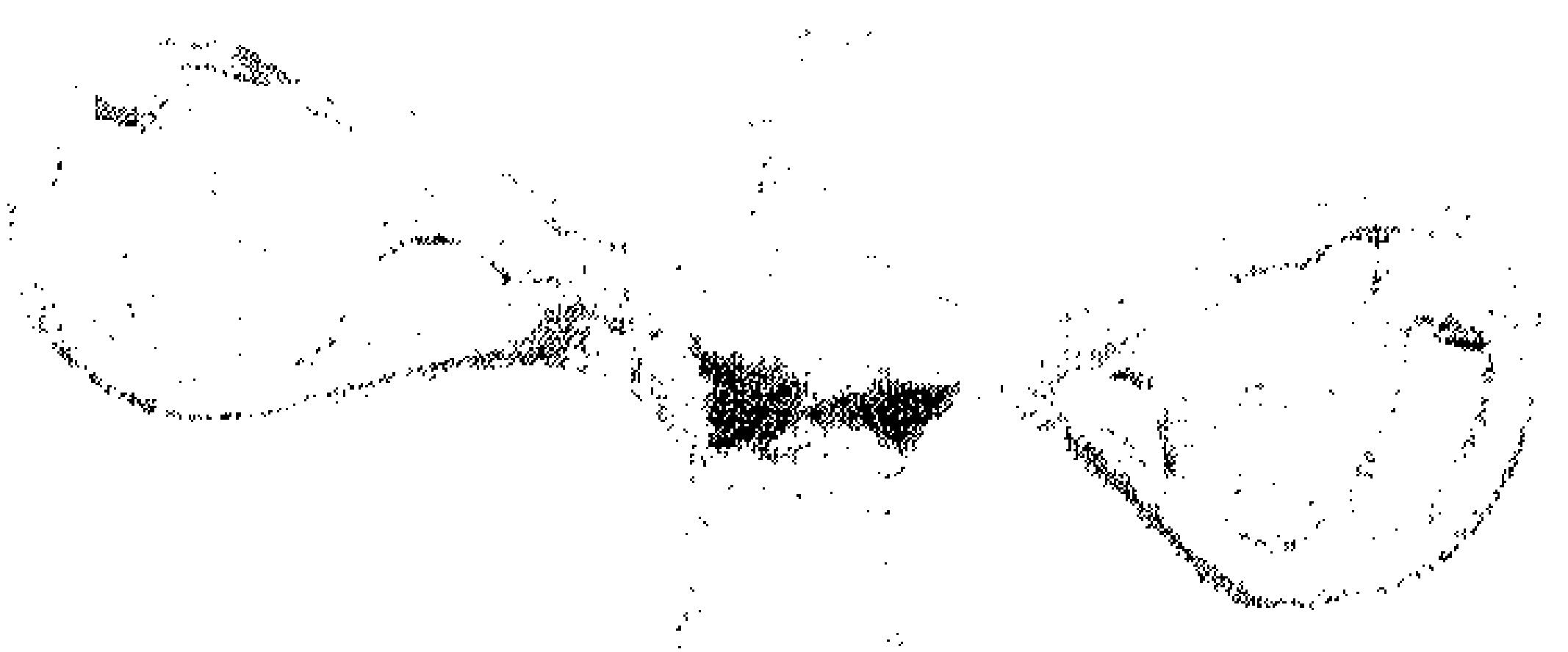

M.F.M.T. Du Moulin, J.P.H. Hamers, A.T.G. Paulus, C.L. Berendsen, R.J.G. Halfens

Published in International Journal of Nursing Studies, 2005 May;42(4):479-92 
ABSTRACT

Trinary incontinence (UI) is a condition that is associated with decreased quality of life. Apart from this impact on quality of life, UI is also a very costly problem. It is recognised that 'usual care' for patients suffering from UI is not optimal. Specialised nurses can play an important tole in the care for community-dwelling incontinent patients, as they have the appropriate interpersonal and technical skills to provide patient-tailored care. This systematic review analyses the effect of treatment by nurses on clinical and economic outcomes. A total of 12 randomised controlled trials (RCTs) were found, varying in terms of population, setting, outcome measurement and control/ intervention. There is limited evidence that treatment by nurses results in a decrease in incontinence. No evidence was found for cost reduction. Recommendations are made for future studies. 


\section{INTRODUCTION}

Trinary incontinence (UI) is a major health problem that affects mainly women. Its reported prevalence rates range from $9 \%$ to $34 \%{ }^{1-6}$. It is expected that the prevalence of incontinence will increase over the next decade, as the proportion of people older than 60 years grows. The problem of the high associated costs ${ }^{7}$ is also expected to rise with the increasing number of incontinent patients.

Although there are established services for patients suffering from urinary incontinence, the provision of treatment remains inconsistent 8.9. Many clinicians fail to diagnose the underlying cause of incontinence symptoms or to recommend treatment ${ }^{10-12}$. In addition, consultation time constraints, delayed referrals and conflicting advices have been reported ${ }^{13}$.

It is recognised that nurses can play an important role in the care for patients suffering from incontinence ${ }^{14,15}$. They have the appropriate interpersonal and technical skills and they use an informal approach that makes this type of service provision attractive to patients. By providing patient-tailored care and using evidence-based treatment options, it is expected that these nurses can adequately diagnose and treat patients suffering from incontinence, which may ultimately result in reduced costs. The aim of the present systematic review is to find evidence of the effectiveness of treatment by nurses in continence care. More specifically, the following question will be addressed:

What is the effect of nurses treating patients with urinaty incontinence when compared to 'usual care' in terms of clinical and economic outcomes as well as patient satisfaction?

\section{Background}

Though not a life-threatening condition, incontinence is associated with decreased quality of life ${ }^{16-18}$. Patients suffering from urinary incontinence are often anxious, have lower self-esteem or feel socially isolated ${ }^{10,20}$. In some cases, UI causes patients to feel depressed ${ }^{21}$ or to give up their job. In addition, patients suffering from incontinence have an increased tisk of skin breakdown, recurrent urinary tract infections, and falls, especially when they have symptoms of urgency, urge UI or nocturia ${ }^{22}$. Furthermore, UI has been shown to increase the risk of admission to nursing homes ${ }^{23}$. Unfortunately, urinary incontinence is often perceived as 'not a major problem' or as a normal part of the ageing process for which no treatment is needed ${ }^{24}$. In many cases, there is a lack of knowledge of treatment options, and instead of seeking professional help, patients often use incontinence products.

Apart from its impact on quality of life, urinary incontinence is a very costly condition, with part of the costs relating to the use of pads. In many countries, incontinence pads are prescribed by doctors and paid for by the national 
insurance. Results of a study conducted in western Norway show a median use of 1.8 pads per patient per day, with total cost amounting to $\$ 1.1$ million ${ }^{7}$. In the UK, National Health Service purchases of absorbent products amount to around $\$ 148$ million a year. In these times of cost containment in health care, it seems crucial to provide care that is patient-tailored in order to reduce the number of incontinence leaks, as this would ultimately lead to a decrease in the use of pads. If treatment is not possible, it is of great importance that patients receive pads that are adapted to their personal needs and leakage volume. And since leakage patterns may change over time, it is necessary to re-assess patients ${ }^{25}$. Pads that are not individually adapted to the patient or that are incorrectly applied may lead to inefficiency and unnecessarily increased costs.

Over the past decade, the role of specialist nurses has been rapidly expanding ${ }^{15,26}$. It is recognised that nurses can take over tasks from doctors ${ }^{27.27}$ and that they can improve the quality of care for patients ${ }^{30}$. Nurse specialists can also play an important role in the assessment and treatment of urinary symptoms in a primary care setting $9,14,31,32$. The literature reports on several lowrisk treatments that can be administered by continence nurses. Some of these options are lifestyle interventions (e.g., weight loss, decreased caffeine intake or dietary interventions), behavioural therapy (e.g., bladder training or pelvic muscle rehabilitation) or conservative treatment (e.g., medication and fluid schedules). These therapies have proved to be successful, with improvement/cure rates between $68 \%$ and $74 \%{ }^{33.35}$.

\section{METHOD}

\section{Literature search}

To answer the research question, we conducted a systematic review. Only studies that met the following criteria were included:

1. the study had to be a randomised controlled trial (this design is considered optimal for intervention studies because it can provide a good assessment of the efficacy of the intervention);

2. the intervention had to involve a nurse playing an important tole in the care for patients suffering from incontinence (versus 'usual care' or no treatment);

3. the study population had to include community-dwelling adults suffering from urinaty incontinence;

4. only studies were included that provided data about one or more of the following outcome measures: incontinence episodes (leaks), numbers of pads used, pad test, quality of life, patient satisfaction, costs.

We conducted a search for original articles published up to Aptil 1, 2004, using the following databases: Medline, CINAHL and EMBASE. Additional articles were identified from references cited in the articles retrieved by the search. All languages were included. 


\section{Selection criteria}

The following key words were used. The definition of the design ('randomised controlled trial') was combined with 'incontinence' or 'continence' and with varying descriptions of the nursing intervention ('nurse', 'continence advisor', 'consultant', 'management', 'nurse-led', 'treatment', 'conservative', 'behavioural', 'assessment', 'model', 'care'). To ensure that all forms of words were included, we used wild card characters.

\section{Methodological quality}

$\Lambda$ total of 12 studies meeting the selection criteria were rated for methodological strength using a list of quality criteria (see Table 1$)^{36}$.

Table 1 Criteria for assessing methodological quality'

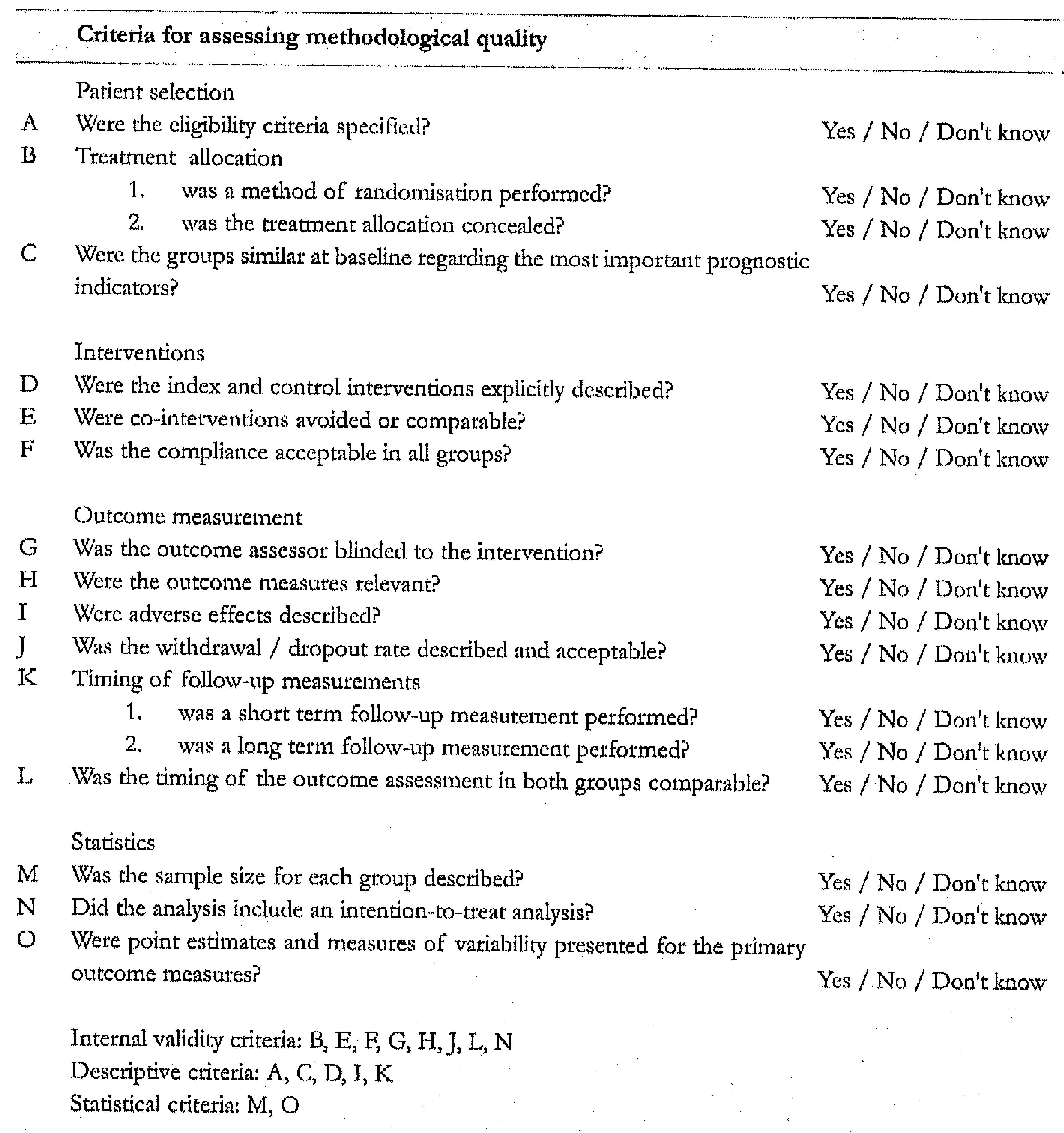

${ }^{1}$ Adapted from: Tulder M, Furlan A, Bombardier C, et al. Updated method guidelines for systematic reviews in the Cochrane Collaboration Back Review Group. Spine. 2003;28(12):1290-1299. 
As can be seen from Table 1, this validated list contains seventeen items, measuring internal validity (nine items), descriptive criteria (six items) and statistical criteria (two items). Items were scored 'yes' if sufficient information was available and/or bias was considered unlikely, 'no' if information was not available and bias was considered likely and 'don't know' if the information given was unclear. Given the type of intervention studied in the present review, 'blinding the care provider' and 'blinding the patient' for the intervention would not be possible. It was therefore decided to exclude these criteria from the original list.

The methodological quality of each study was rated by the first author. These ratings were compared with those of five other reviewers who each rated two or three studies. There was consensus between the reviewers in $80 \%$ of the ratings. Disagreements were caused by reading errors or different interpretations of the criteria. However, all disagreements could be resolved by discussion. After assessment a hierarchical list of the studies was generated. The larger the number of criteria rated 'yes', the greater the methodological quality. Studies that met less than $50 \%$ of the quality criteria were considered to be of poor quality ${ }^{36}$; therefore studies with a quality score less than 9 were excluded.

Table 2 presents the methodological scores of the studies in descending order. Scores ranged from 8 to 13 (average $11 \pm 1.6$ ) on a total score of 17 . Only one study was of poor quality (score $8{ }^{35}$. This study was excluded from the review.

Table 2 Methodological scores of the reviewed trials

\begin{tabular}{|c|c|c|c|c|c|c|c|c|c|c|c|c|c|c|c|c|c|c|}
\hline Author & $\mathbf{A}$ & $\begin{array}{l}B \\
1\end{array}$ & $\begin{array}{l}\mathbf{B} \\
2\end{array}$ & $\mathrm{C}$ & $\mathrm{D}$ & $\mathbf{E}$ & $\mathbf{F}$ & $\mathbf{G}$ & $\mathbf{H}$ & I & $\mathbf{J}$ & $\begin{array}{c}K \\
1\end{array}$ & $\begin{array}{l}K \\
2\end{array}$ & & & $\mathrm{~N}$ & $\mathrm{O}$ & $\begin{array}{l}\text { total scotes } \\
(\max =17)\end{array}$ \\
\hline 43 & $Y$ & $\mathrm{Y}$ & $\mathrm{D}$ & $\mathrm{Y}$ & $\mathrm{Y}$ & D & $Y$ & $\mathrm{Y}$ & $Y$ & $N$ & $\mathrm{Y}$ & $\mathrm{N}$ & $Y$ & $Y$ & $Y$ & $Y$ & $\mathrm{Y}$ & 13 \\
\hline 47 & $\mathrm{Y}$ & $\mathrm{Y}$ & $\mathrm{Y}$ & $\mathrm{Y}$ & $Y$ & $\mathrm{~N}$ & $Y$ & $\mathrm{~N}$ & $Y$ & $N$ & $\mathrm{Y}$ & $Y$ & $\mathrm{Y}$ & $\mathrm{Y}$ & Y I & $N$ & $Y$ & 13 \\
\hline 37 & $\mathrm{Y}$ & $\mathrm{Y}$ & $\mathrm{D}$ & $Y$ & $Y$ & $D$ & $\mathrm{D}$ & $\mathrm{Y}$ & $\mathrm{Y}$ & $Y$ & $Y$ & Y I & $\mathrm{N}$ & $Y$ & $Y$ & $\mathrm{Y}$ & $Y$ & 13 \\
\hline 41 & $Y$ & $\mathrm{Y}$ & $\mathrm{Y}$ & $\mathrm{Y}$ & $\mathrm{Y}$ & $\mathrm{N}$ & $\mathrm{D}$ & $N$ & $Y$ & $Y$ & $Y$ & Y I & $\mathrm{N}$ & Y & XI & $N$ & $\mathrm{Y}$ & 12 \\
\hline 45 & $Y$ & $Y$ & $Y$ & $\mathrm{Y}$ & $\mathrm{Y}$ & $\mathrm{D}$ & $\mathrm{N}$ & $\mathrm{D}$ & $\mathrm{Y}$ & $N$ & $\mathrm{~N}$ & $\mathrm{Y}$ & $Y$ & Y & $\mathrm{Y}$ & $\mathrm{Y}$ & $\mathrm{Y}$ & 12 \\
\hline 38 & $\mathrm{Y}$ & $\mathrm{Y}$ & $D$ & $Y$ & $\mathrm{Y}$ & $N$ & $Y$ & $D$ & $\mathrm{Y}$ & $\mathrm{N}$ & $Y$ & $Y 1$ & $\mathrm{~N}$ & $Y$ & $Y$ & $Y$ & $Y$ & 12 \\
\hline 39 & $\mathrm{Y}$ & $\mathrm{Y}$ & $\mathrm{D}$ & $Y$ & $\mathrm{Y}$ & $\mathrm{D}$ & $\mathrm{D}$ & $\mathrm{D}$ & $Y$ & $Y$ & $\mathrm{~N}$ & $\mathrm{Y}$ & $\mathrm{N}$ & $Y$ & $Y$ & $\mathrm{Y}$ & $\mathrm{Y}$ & 11 \\
\hline 42 & $\mathrm{Y}$ & $Y$ & $\mathrm{~N}$ & $Y$ & $Y$ & $\mathrm{~N}$ & $\mathrm{D}$ & $\mathrm{D}$ & $\mathrm{Y}$ & $N$ & $\mathrm{Y}$ & $\mathrm{Y}$ & $\mathrm{N}$ & Y & $\mathrm{Y}$ & $\mathrm{Y}$ & $Y$ & 11 \\
\hline 40 & $Y$ & $\mathrm{Y}$ & $\mathrm{N}$ & $\mathrm{Y}$ & $\mathrm{Y}$ & $\mathrm{N}$ & $N$ & $\mathrm{~N}$ & $Y$ & $Y$ & $\mathbf{N}$ & $\mathrm{N}$ & $Y$ & $Y$ & $\mathrm{Y}$ & $Y$ & $\mathrm{~N}$ & 10 \\
\hline 46 & $Y$ & $\mathrm{D}$ & $Y$ & $Y$ & $Y$ & $N$ & $\mathrm{~N}$ & $\mathrm{D}$ & $Y$ & $N$ & $\mathrm{Y}$ & $N$ & $\mathrm{Y}$ & Y & $\mathrm{Y} 1$ & $N$ & $\mathrm{Y}$ & 10 \\
\hline 44 & $\mathrm{D}$ & $Y$ & $D$ & $\mathrm{Y}$ & $\mathrm{Y}$ & $D$ & $\mathrm{D}$ & $\mathrm{D}$ & $\mathrm{Y}$ & $N$ & $\mathrm{X}$ & $N$ & $\mathrm{~N}$ & $Y$ & $Y$ & $\mathrm{Y}$ & $\mathrm{Y}$ & 9 \\
\hline 35 & $Y$ & $\mathrm{Y}$ & $\mathrm{D}$ & $\mathrm{D}$ & $Y$ & $\mathrm{~N}$ & $D$ & $\mathrm{D}$ & $\mathrm{Y}$ & $\mathrm{N}$ & $Y$ & Y l & $\mathrm{N}$ & $\mathrm{Y}$ & Y I & $\mathrm{N}$ & $N$ & 8 \\
\hline Mean (SD) & & & & & & & & & & & & & & & & & & $11.4(1.6)$ \\
\hline
\end{tabular}

See Table 1 for an explanation of categories $A$ to $O, Y=$ yes, $N=$ no, $D=$ don't know 
The descriptions of index and control interventions (D), outcome measures $(\mathrm{H})$, comparability of the timing of the outcome assessment $(\mathrm{L})$ and sample size (M) were adequate for all trials. A number of studies failed to provide a description of co-interventions (E) and blinding of the outcome assessor $(G)$. Rather high dropout rates $(\sigma)$ were reported by Moore et al. ${ }^{45}$, with an overall dropout rate of $24 \%$, and by Goode et al. ${ }^{30}$, with $37 \%$ of the patients dropping out. Overall, the quality of the studies was satisfactory.

\section{RESULTS}

The literature search resulted in 11 RCT's of sufficient methodological quality (three conducted by the same research group) addressing an intervention with a nurse playing an important role in the care for patients suffering from incontinence. 'The main characteristics of these studies have been summarised in Table 3a; in 'Table 3b a description of the nurse's education and the setting is given.

\section{Patients}

All patients were aged 26 years or older. Different definitions were used to determine the severity of incontinence at inclusion, varying from incontinence 'occurring at least twice a week' to 'any involuntary loss of urine in the preceding month'. All studies except three included patients suffering from stress, urge or mixed incontinence. Two studies included only patients suffering from urge incontinence ${ }^{37,38}$ and one study focused on patients with stress incontinence ${ }^{39}$. The studies also differed in the way they defined the duration of the complaints, varying from no limitations at all to at least 3 or 6 months. Sample sizes ranged from 87 to 747 patients.

\section{Intervention}

The role of the nurse in the RCTs involved a combination of treatment elements, resulting in a great diversity of interventions. The most common treatments that were explicitly mentioned concerned pelvic floor muscles exercises, bladder training and giving instructions to patients. Other options involved electrostimulation therapy, anticholinergic treatment, biofeedback and teaching the patient about the anatomy of the urinary tract. Group sessions were used in two studies ${ }^{40,+1}$ and three studies made use of written instructions that were given to the patients ${ }^{38,30,41}$.

A total of eight trials explicitly mentioned that the nurses were skilled or specially trained in assessing and/or treating incontinence. The descriptions of the training or level of competence of the nurses varied from 'a nurse having a bachelor of science' ${ }^{42}$ to just 'a nurse' ${ }^{43}$. 

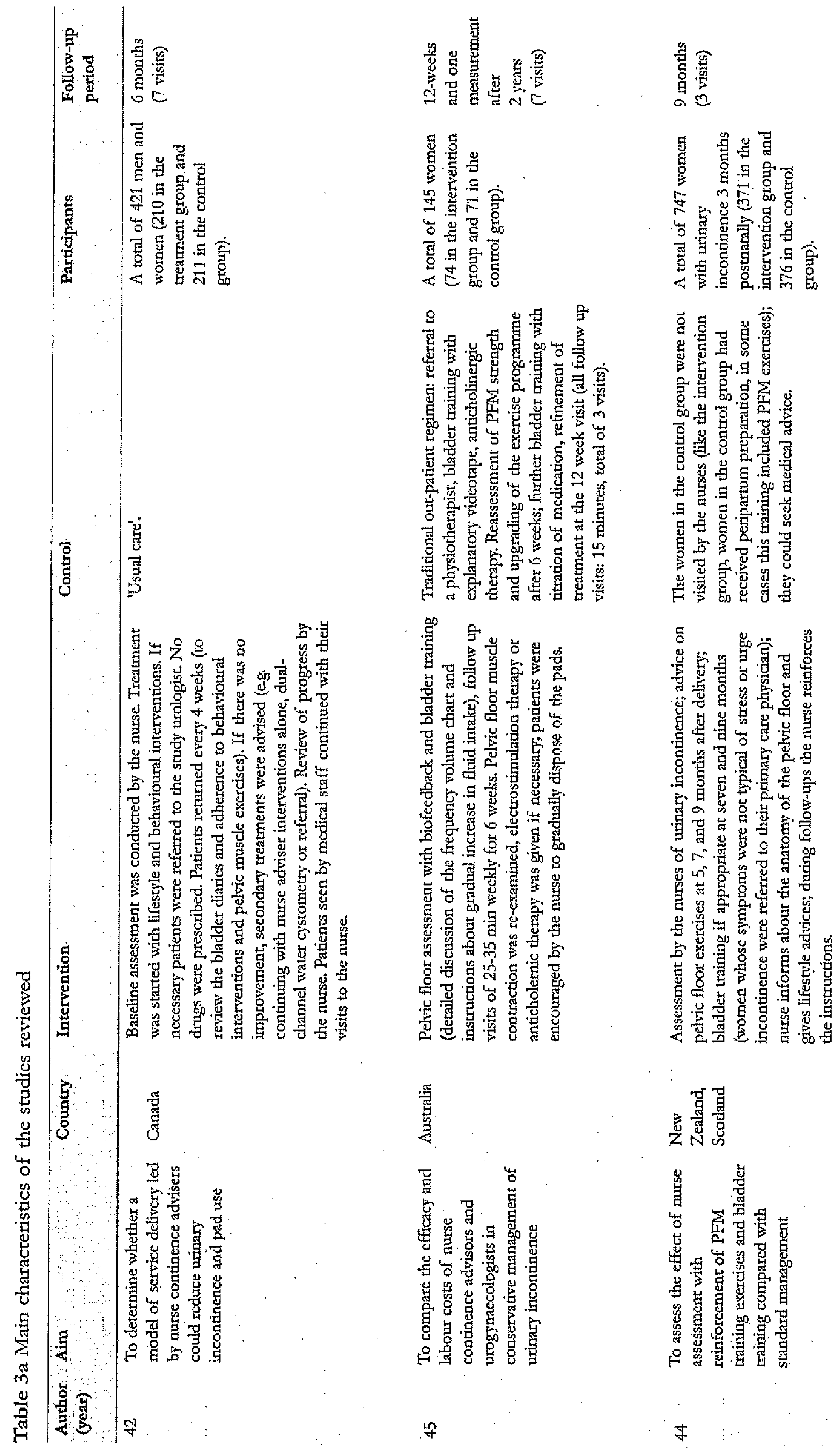

惡
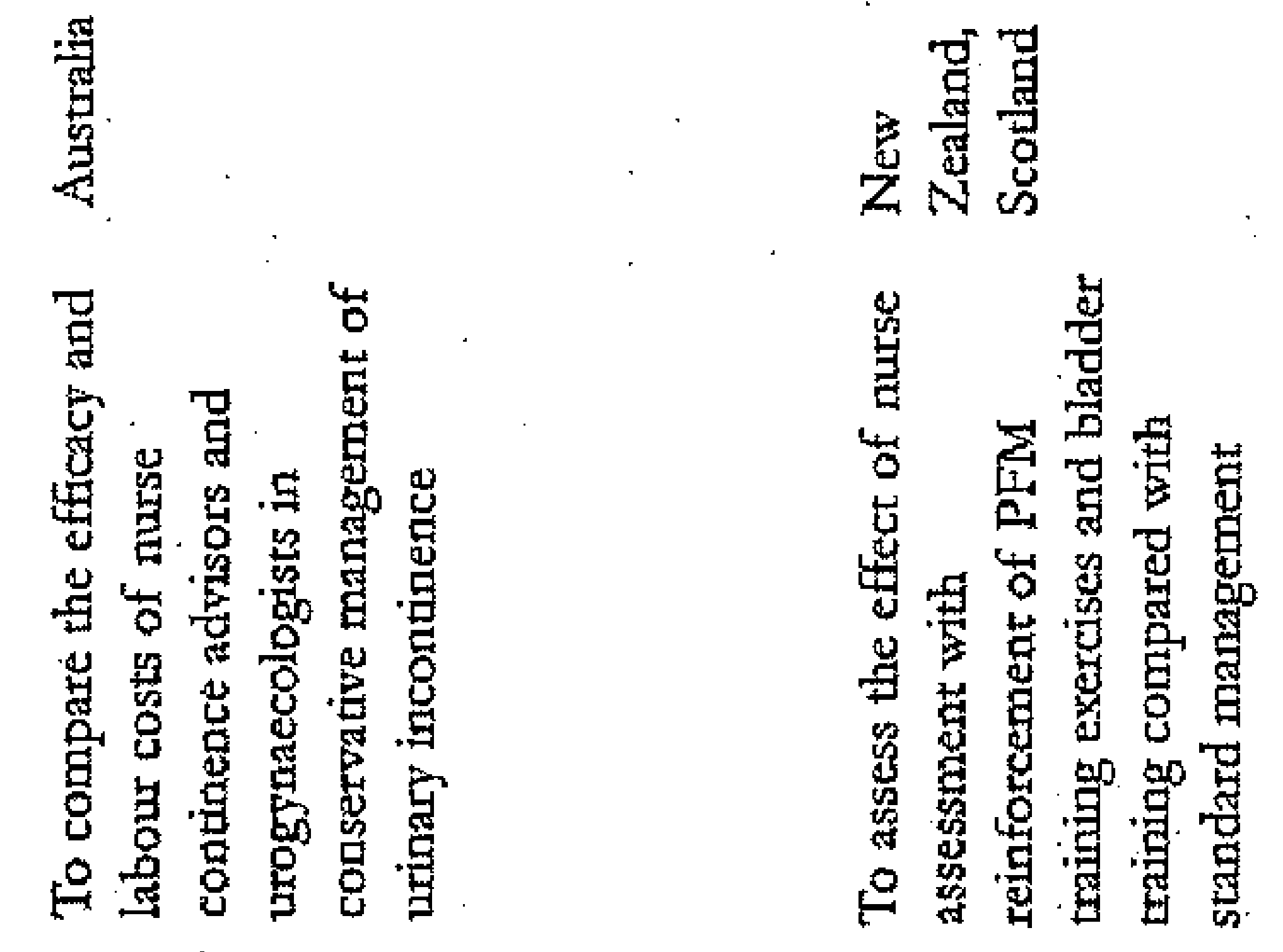

年

ఫ 
The role of the nurse in community continence care

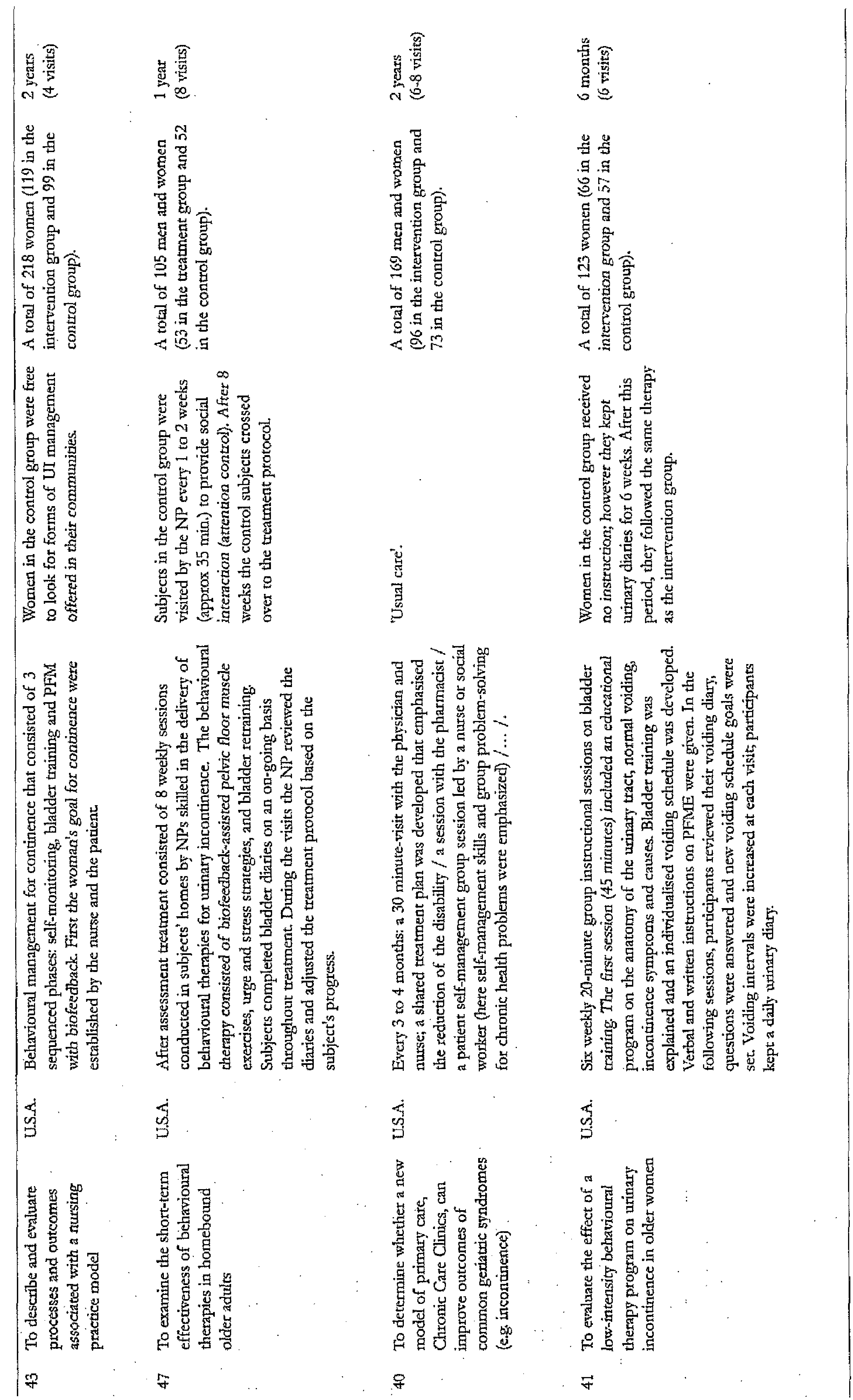




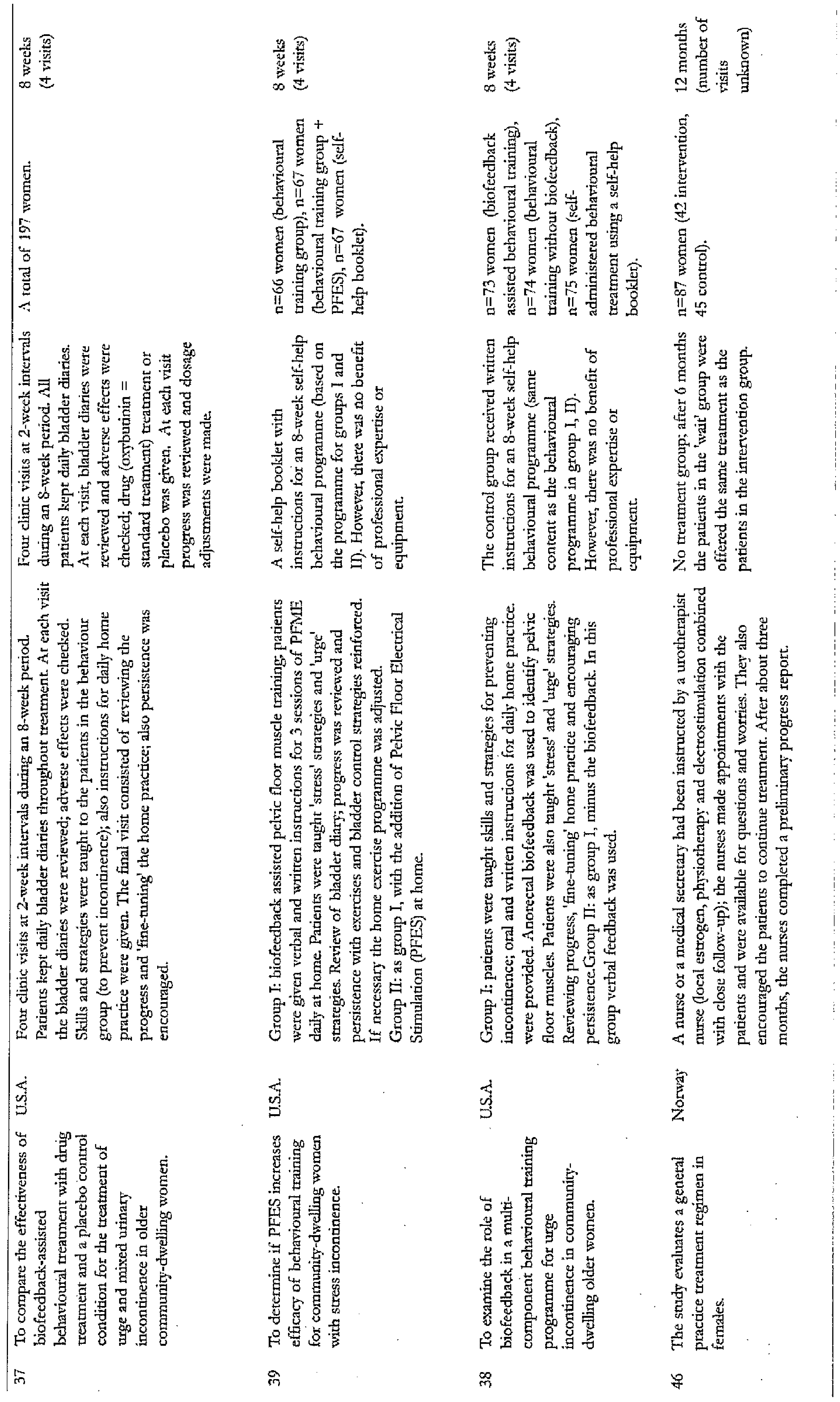


Table $3 \mathrm{~b}$ Description of the nursc's education and the setting of the studies reviewed

\begin{tabular}{|c|c|c|}
\hline Author (year) & Nurse's education & Setting \\
\hline 42 & $\begin{array}{l}\text { The nurse continence advisers were registered nurses who } \\
\text { had a bachelor of science in nursing degree. All the } \\
\text { nurses had received training that included both in-depth } \\
\text { small group education and hands-on supervised training } \\
\text { in an already established outpatient continence clinic. }\end{array}$ & Outpaticnt incontinence clinic \\
\hline 45 & $\begin{array}{l}\text { Two continence nurses who had completed a six-week } \\
\text { full-time diploma course in continence management; they } \\
\text { had worked in close partnership with the } \\
\text { urogynaecologists from } 1992 \text { to } 1996 \text {. }\end{array}$ & $\Lambda$ tertiary urogynaecolgy unit \\
\hline 44 & $\begin{array}{l}\text { The nurses (a midwife, a health visitor and a continence } \\
\text { advisor) followed a short course of specialised training in } \\
\text { conservative management given by local physiotherapists. }\end{array}$ & $\begin{array}{l}\text { Community intervention at } \\
\text { three centres }\end{array}$ \\
\hline 43 & A nurse. & $\begin{array}{l}\text { At the homes of older rutal } \\
\text { women }\end{array}$ \\
\hline 47 & $\begin{array}{l}\text { Nurse practitioners skilled in the delivery of behavioural } \\
\text { therapies for UI. }\end{array}$ & In-home visits \\
\hline 40 & $\begin{array}{l}\text { Team nurses trained in population-based medicine and } \\
\text { management strategies designed to enhance their } \\
\text { management of a selection of geriatric syndromes. They } \\
\text { also received individual on-the-job coaching from study } \\
\text { staff. }\end{array}$ & $\begin{array}{l}\text { Nine primary care physician } \\
\text { practices that comprise an } \\
\text { ambulatory clinic in a large } \\
\text { staff-model HMO }\end{array}$ \\
\hline 41 & Three nurse educators. & $\begin{array}{l}\text { A northern California health } \\
\text { maintenance organisation }\end{array}$ \\
\hline 37 & Nurse Practitioner. & $\begin{array}{l}\text { University-based outpatient } \\
\text { geriatric medicine clinic }\end{array}$ \\
\hline 39 & $\begin{array}{l}\text { Female nurse practitioners specially trained by the } \\
\text { behavioural psychologist and physician principal } \\
\text { investigator in behavioutal treatment of incontinence. }\end{array}$ & $\begin{array}{l}\text { A university-based outpatient } \\
\text { continence clinic }\end{array}$ \\
\hline 38 & Nurse practitioners. & $\begin{array}{l}\text { University-based outpatient } \\
\text { continence clinic }\end{array}$ \\
\hline 46 & $\begin{array}{l}\text { A nuise or medical secretary had been instructed in } \\
\text { treatment details by one of three urotherapist nurses. }\end{array}$ & $\begin{array}{l}\text { General practices in three } \\
\text { north-Norwegian } \\
\text { municipalities, in collaboration } \\
\text { with two local departments of } \\
\text { gynecology }\end{array}$ \\
\hline
\end{tabular}

\section{Measurements}

Various instruments for outcome measurement were used. To evaluate the effect of the intervention on incontinence episodes, nine studies used bladder diaries or frequency/volume charts (FVCs), and three studies also conducted a pad test. Others used questionnaires or a Visual Analogue Scale for patient assessment of the frequency or severity of incontinence $35,40,44$. 
Patient satisfaction with their care was measured using 'questions based on standardised instruments' ${ }^{\text {t0 }}$ or 'a patient satisfaction questionnaire' ${ }^{37-39}$.

Quality of life was measured with the Incontinence Impact Questionnaire (IIQ) or the Urogenital Distress Inventory (UDI) in five studies. Others (also) used items from the York Incontinence Perceptions Scale 12, a 20-point incontinence score ${ }^{45}$, the Hospital Anxiety and Depression score ${ }^{44}$ or other questionnaires to measure patient satisfaction ${ }^{37-39}$ and impact on daily life ${ }^{41,43,46}$.

One study mentioned a one-page self-administered questionnaire about personal costs of pads and other treatment or travel costs ${ }^{45}$.

Effects

- clinical / patient satisfaction

With the exception of three $38,40,45$ all studies reported a significantly greater reduction in incontinence episodes in the intervention group (see Table 4). As the interventions consisted of a complex of treatment elements, it is not possible to assess the contribution of each specific element to the positive outcome. Three studies reported that patient satisfaction had improved in the intervention group ${ }^{37.39}$. Some authors stated that, apart from the intervention, the attention from and interaction with the nurse may have also had a favourable influence on the patient ${ }^{38,45}$.

Two studies found that women who had more severe initial complaints benefited more from treatment by a nurse than women with less severe complaints ${ }^{44,46}$. These findings conflict with those of other studies, which found no relation between severity of initial symptoms and outcomes ${ }^{39,41}$.

- costs

One of the two RCTs reporting on costs found a significant reduction in costs relating to treatment, although no formal cost-utility analysis was conducted ${ }^{45}$. This result was found in spite of the fact that, when compared with the physician, the intervention by the nurse took longer (a median difference of over 50 minutes). A questionnaire regarding personal costs of incontinence proved to be impossible to complete by the patients in this study. Two other studies that did not report on costs did find a decrease in 'pads used' ${ }^{42,44}$. 


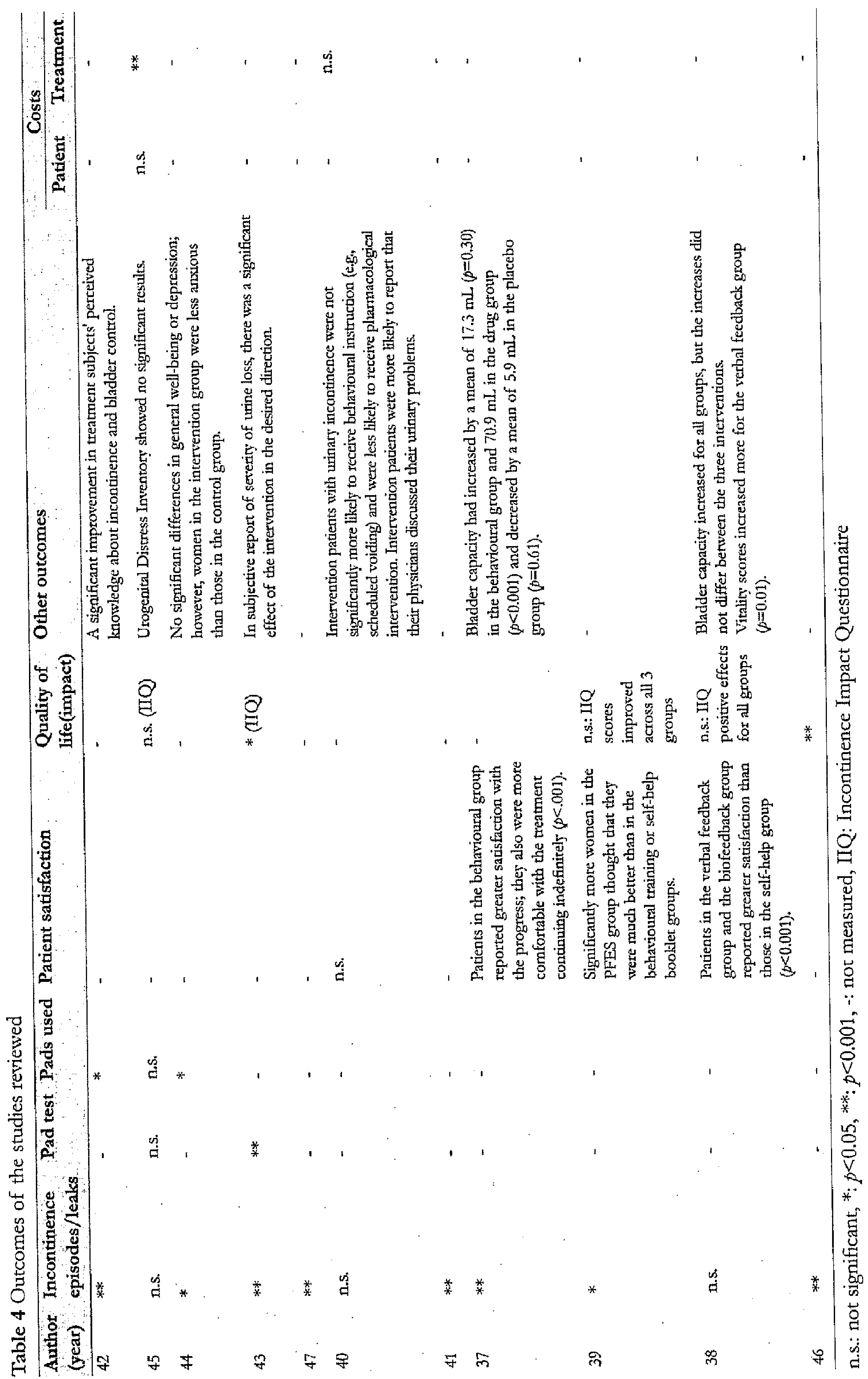




\section{DISCUSSION}

This review examined the clinical and economic impacts of continence care in which nurses play an important role. A total of 11 RCTs of sufficient quality were found meeting the eligibility criteria. Some limitations of the present systematic review should be mentioned. Small trials or trials with negative results that are difficult to get published might be underrepresented. Secondly, apart from the core element of each intervention (a nurse playing an important role in the care for patients suffering from incontinence) the studies were very heterogeneous (in terms of settings, age limits, effect measurement, etc.), which hampered comparisons.

Only one study was of poor methodological quality. No study exceeded 13 points (on a total score of 17). The item 'co-interventions avoided or comparable' was never met; this item seems to be irrelevant to these trials. Similarly, 'blinding of the outcome assessor' was rarely met; in most cases this was due to lack of information.

The effects of the intervention on clinical outcomes do not appear related to the number of visits paid to the nurse, to gender or to the type of incontinence. Two studies used group sessions led by a nurse ${ }^{40.41}$. The study by Coleman ${ }^{40}$ found no significant decrease in incontinence. This study introduced a new model of primary care to improve management of a selection of geriatric syndromes such as incontinence. Although no decrease in incontinence was found, patients were very satisfied. Subak ${ }^{41}$, on the other hand, did find a significant decrease in incontinence episodes. Unlike the study by Coleman "t), the study by Subak ${ }^{41}$ was set up for the sole purpose of treating incontinence, possibly leading to a more thorough approach to this health problem.

The interventions took place in various clinical settings. However, in two studies, the nurse visited the patients at their own homes ${ }^{43,17}$. Both studies resulted in a reduction in urinary incontinence. The authors stated that in spite of the presence of other chronic conditions and functional impairments among the population under study, significant reductions in urinary incontinence were achieved. These findings conflict with those of the study by Holtedahl, who stated that comorbidity made treatment difficult in several patients ${ }^{40}$.

Remarkably, in two studies that had not resulted in a significant decrease in incontinence episodes patients still reported greater satisfaction ${ }^{38,40}$. This may have resulted from the time and special attention given by an interested nurse; similar findings have been reported by other workers ${ }^{28,20}$.

A total of eight studies found a significant decrease in incontinence episodes in the intervention group. Of these, five studies used a follow-up period of less than one year $37,39,41,42,44$. However, it is questionable whether the favourable results found in these RCT's were still present after one year, as relapse rates of up to $60 \%$ after six months have been described ${ }^{48}$. It is also known that the 
greatest efficacy of pelvic muscle exercise is found after 11 to 12 weeks, after which it tends to decline ${ }^{4}$. Hence, long-term studies are 'critical to motivate women to undertake the behavioural change and to persist with the prescribed regimen for the several months required to achieve the greatest benefit ${ }^{50}$.

Findings about the benefit to patients in relation with the severity of initial complaints are conflicting. This may have been caused by the way in which 'severity' was measured. Two studies found that patients with more severe initial symptoms derived greater benefit from treatment by the nurse than patients having less severe complaints ${ }^{4+,}+6$. In these studies, 'severity' was measured using a questionnaire on severity ${ }^{4+}$ and a severity index ${ }^{4}$. Results of the studies that found no relation were based on bladder diaries ${ }^{39,4}$. Findings based on data from bladder diaries may be more precise.

One of the two studies reporting on costs found a reduction in treatment costs ${ }^{45}$. Although no formal cost-utility analysis was conducted, results showed that the median treatment cost of the nurse was significantly lower than that of the standard outpatient regimen. Moore ${ }^{45}$ believed that the greater amount of time spent with the nurse might be the main benefit of the intervention. These findings contradict those by Hopkins et al., who state that 'the task may take longer, and the nurse may spend more time on advising and counselling patients (...), but additional time means additional $\operatorname{costs}^{151}$. None of the studies reported cost reduction due to a decrease in the numbers of pads used. Also no formal economic analysis was conducted of the costs of nursing time spent. These limitations should be addressed in future research.

\section{CONCLUSION}

This review revealed some evidence that treatment of incontinent communitydwelling patients by a nurse is beneficial in terms of clinical outcomes. However, most of the evidence was derived from research with follow-up periods of less than one year. Therefore, future studies should focus on long-term follow-up, as it is known that short-term results may extinguish over time. Further, more research needs to focus on the impact of severity of urinary incontinence on outcomes. Research should assess who will benefit most from treatment by a nurse. Only one study found a decrease in costs, but these findings were not based on a formal cost-utility analysis. More studies are needed that focus on costs, as this is an important outcome in research examining the efficacy of interventions.

Finally, this review shows that nurses can care for patients suffering from incontinence leading to improved health outcomes and patient satisfaction. Other workers more or less found similar results in different patient groups e.g., type 2 diabetes ${ }^{52}, \mathrm{COPD}^{53}$ or rheumatology ${ }^{28}$. It seems justified that nurses play a central role in the care for patients for a variety of diseases. 


\section{REFERENCES}

1. Hagglund $D$, Olsson $H$, Leppert J. Urinary incontinence: an unexpected large problem among young females. Results from a population-based study. Family Practice. 1999;16(5):506-509.

2. Roe B, Doll H, Wilson K. Help seeking behaviour and health and social services utilisation by people suffering from urinary incontinence. International Journal of Nursing Studies. 1999;36(3):245-253.

3. Ushiroyama T, Ikeda A, Ueki M. Prevalence, incidence, and awareness in the treatment of menopausal urinary incontinence. Maturitas. 1999;33(2):127132.

4. Hannestad YS, Rortveit G, Sandvik H, Hunskaar S. A community-based epidemiological survey of female urinary incontinence: the Norwegian EPINCONT study. Epidemiology of Incontinence in the County of NordTrondelag. Journal of Clinical Epidemiology. 2000;53(11):1150-1157.

5. Perry S, Shaw C, Assassa P, et al. An epidemiological study to establish the prevalence of urinary symptoms and felt need in the community: the Leicestershire MRC Incontinence Study. Leicestershire MRC Incontinence Study Team. Journal of Public Health Medicine. 2000;22(3):427-434.

6. Thakar R, Stanton S. Regular review: Management of urinary incontinence in women. British Medical Journal. 2000;321(7272):1326-1331.

7. Sandvik $\mathrm{H}$, Hunskaar S. The epidemiology of pad consumption among community-dwelling incontinent women. Journal of Aging and Health. 1995;7(3):417-426.

8. Shields N, Thomas C, Benson K, Major K, Tree J. Development of a community nurse-led continence service. British Journal of Nursing. 1998;7(14):824-826, 828-830.

9. Williams K, Assassa R, Smith $\mathrm{N}$, et al. Development, implementation and evaluation of a new nurse-led continence service: a pilot study. Journal of Clinical Nursing. 2000;9(4):566-573.

10. Milne JL. The impact of information on health behaviors of older adults with urinary incontinence. Clinical Nursing Research. 2000;9(2):161-176.

11. Jones TV, Bunner SH. Approaches to urinary incontinence in a rural population: a comparison of physician assistants, nurse practitioners and family physicians. Journal of the American Board of Family Practice. 1998;11:207-215.

12. Dovey S, McNaughton T, Tilyard M, Gurr E, Jolleys J, Wilson D. General practitioners' opinions of continence care training. New Zealand Medical Journal. 1996;109:340-343.

13. Davis K, Kumar D. Pelvic floor dysfunction: a conceptual framework for collaborative patient-centred care. Journal of Advanced Nursing. 2003;43(6):555-568.

14. Wells $M$. The role of the nurse in urinary incontinence. Baillière's Clinical Obstetrics and Gynaecology. 2000;14(2):335-353. 
15. Shaw C, Williams KS, Assassa RP. Patients' views of a new nurse-led continence service. Journal of Clinical Nursing. 2000;9(4):574-582.

16. Chiaffarino F, Parazzini F, Lavezzari M, Giambanco V. Impact of urinary incontinence and overactive bladder on quality of life. European Urology. 2003;43(5):535-538.

17. Simeonova Z, Milsom I, Kullendorff AM, Molander U, Bengtsson C. The prevalence of urinary incontinence and its influence on the quality of life in women from an urban Swedish population. Acta Obstetricia et Gynecologica Scandinavica. 1999;78(6):546-551.

18. Temml C, Haidinger G, Schmidbauer J, Schatzl G, Madersbacher S. Urinary incontinence in both sexes: prevalence rates and impact on quality of life and sexual life. Neurourology and Urodynamics. 2000;19(3):259-271.

19. Grimby A, Milsom I, Molander U, Wiklund I, Ekelund P. The influence of urinary incontinence on the quality of life of elderly women. Age and Ageing. 1993;22(2):82-89.

20. Lin S-Y, Dougherty MC. Incontinence impact, symptom distress and treatment-seeking behavior in women with involuntary urine loss in Southern Taiwan. International Journal of Nursing Studies. 2003;40(3):227234.

21. Dugan E, Cohen SJ, Bland DR, et al. The association of depressive symptoms and urinary incontinence among older adults. Journal of the Ametican Geriatrics Society. 2000;48(4):413-416.

22. Hiser $\mathrm{V}$. Nursing interventions for urinary incontinence in home health. Journal of Wound, Ostomy, and Continence Nursing. 1999;26:142-160.

23. Thom DH, Haan MN, Eeden van den SK. Medically recognised urinary incontinence and risks of hospitalisation, nursing home admission and mortality. Age and Ageing. 1997;26:367-374.

24. Dugan E, Roberts CP, Cohen SJ, et al. Why older community-dwelling adults do not discuss urinary incontinence with their primary care physicians. Journal of the American Geriatrics Society. 2001;49(4):462-465.

25. Hellstrom L, Ekelund P, Larsson M, Milsom I. Adapting incontinent patients incontinence aids to their leakage volumes. Scandinavian Journal of Caring Sciences. 1993; 7:67-71.

26. Kernick D, Scott A. Economic approaches to doctor/nurse skill mix: problems, pitfalls, and partial solutions. British Journal of General Practice. 2002;52:42-46.

27. Richardson G, Maynard A, Cullum N, Kindig D. Skill mix changes: substitution or service development? Health Policy. 1998;45(2):119-132.

28. Hill J, Harmer R, Wright V, Lawton C. An evaluation of the effectiveness, safety and acceptability of a nurse practitioner in a rheumatology outpatient clinic. British Journal of Rheumatology. 1994;33:283-288.

29. Horrocks S, Anderson E, Salisbury C. Systematic review of whether nurse practitioners working in primary care can provide equivalent care to doctors. British Medical Journal. 2002;324:819-823. 
30. Vrijhoef HJM, Diederiks JPM, Spreeuwenberg C. Effects on quality of care for patients with type 2 diabetes or COPD when the specialised nurse has a central role: a literature review. Patient Education and Counselling. 2000;41:243-250.

31. O'Brien J. Evaluating primary care interventions for incontinence. Nursing Standard, Royal College of Nursing, Great Britain 1987. 1996;10(23):40-43.

32. Gallo ML, Fallon PJ, Staskin DR. Urinary incontinence: steps to evaluation, diagnosis, and treatment. The Nurse Practitioner. 1997;22(2):21-44.

33. Seim A, Sivertsen B, Eriksen B, Hunskaar S. Treatment of urinary incontinence in women in general practice: observational study. British Medical Journal. 8 June 1996;312:1459-1462.

34. Lagro-Janssen A, Debruyne F, Smits A, Weel C. The effects of treatment of urinary incontinence in general practice. Family Practice. 1992;9:284-289.

35. O'Brien J, Austin M, Sethi P, O'Boyle P. Urinary incontinence: prevalence, need for treatment, and effectiveness of intervention by nurse. BMJ Clinical research ed. 1991;303(6813):1308-1312.

36. Tulder M, Furlan A, Bombardier C, et al. Updated method guidelines for systematic reviews in the Cochrane Collaboration Back Review Group. Spine. 2003;28(12):1290-1299.

37. Burgio KL, Locher JL, Goode PS, et al. Behavioral vs drug treatment for urge urinary incontinence in older women: a randomized controlled trial. Journal of the American Medical Association. 1998;280(23):1995-2000.

38. Burgio K, Goode PS, Locher JL, et al. Behavioral training with and without biofeedback in the treatment of urge incontinence in older women; a randomized controlled trial. Journal of the American Medical Association. 2002;288(18):2293-2299.

39. Goode PS, Burgio K, Locher JL, et al. Effect of behavioral training with or without pelvic floor electrical stimulation on stress incontinence in women. Journal of the American Medical Association. July 16 2003;290(3):345-352.

40. Coleman EA, Grothaus LC, Sandhu N, Wagner EH. Chronic care clinics: a randomized controlled trial of a new model of primary care for frail older adults. Journal of the American Geriatrics Society. 1999;47:775-783.

41. Subak LL, Quesenberry J, Charles P., Posner SF, Cattolica E, Soghikian K. The effect of behavioral therapy on urinary incontinence: a randomized controlled trial. Obstetrics \& Gynecology. 2002;100(1):72-78.

42. Borrie MJ, Bawden M, Speechley M, Kloseck M. Interventions led by nurse continence advisers in the management of urinary incontinence: a randomized controlled trial. Canadian Medical Association Journal. 2002;166(10):1267-1273.

43. Dougherty MC, Dwyer JW, Pendergast JF, et al. A randomized trial of behavioral management for continence with older rural women. Research in Nursing \& Health. 2002;25(1):3-13. 
44. Glazener CMA, Herbison GP, Wilson PD, et al. Conservative management of persistent postnatal urinary and faecal incontinence: randomised controlled trial. British Medical Journal. 2001;323(7313):593-.

45. Moore KH, O'Sullivan RJ, Simons A, Prashar S, Anderson P, Louey M. Randomised controlled trial of nurse continence advisor therapy compared with standard urogynaecology regimen for conservative incontinence treatment: efficacy, costs and two year follow up. British Journal of Obstetrics and Gynaecology. 2003;110(7):649-657.

46. Holtedahl K, Verelst M, Schiefloe A. A population based, randomized, controlled trial of conservative treatment for urinary incontinence in women. Acta Obstetricia et Gynecologica Scandinavica. 1998;77(6):671-677.

47. McDowell BJ, Engberg S, Sereika SM, et al. Effectiveness of behavioral therapy to treat incontinence in homebound older adults. Journal of the American Geriatrics Society. 1999;47:309-318.

48. Mouritsen L. Pelvic floor exercises for female stress urinary incontinence. International Urogynecology Journal. 1994(5):44-51.

49. Wyman J, Fant J, McClish D, Bump RC. Comparative efficacy of behavioral interventions in the management of female urinary incontinence. American Journal of Obstetrics and Gynecology. 1998;179:999-1007.

50. Sampselle CM. Behavioral interventions in young and middle-age women. American Journal of Nursing. March 2003:9-19.

51. Hopkins A, Solomon J, Abelson J. Shifting boundaries in professional care. Journal of the Royal Society of Medicine. 1995;89:364-371.

52. Vrijhoef HJM, Diederiks JPM, Spreeuwenberg C, Wolffenbuttel BHR, van Wilderen LJGP. The nurse specialist as main care-provider for patients with type 2 diabetes in a primary care setting: effects on patient outcomes. International Journal of Nursing Studies. 2002;39(4):441-451.

53. Vrijhoef HJM. Is it justifiable to treat chronic patients by nurse specialists? Maastricht: Department of Health Care Studies, Universiteit Maastricht; 2002. 


\section{Chapter}

\section{Effects of introducing a specialized nurse in the care of community dwelling women suffering from urinary incontinence \\ - a randomized controlled trial -}

M.F.M.T. Du Moulin, J.P.H. Hamers, A.T.G. Paulus, C.L. Berendsen, R.J.G. Halfens

Published in Journal of Wound, Ostomy and Continence Nursing 2007; 34(6): 631-640 


\section{ABSTRACT}

Trinary incontinence (UI) often remains inadequately treated. In the literature, there are indications that continence nurses' diagnoses and treatment advices are beneficial in terms of clinical outcomes. However, the precise short-term and long-term effects are unclear. This study investigates the short-term and long-term effects of the introduction of a continence nurse in the care of community-dwelling women suffering from UI.

In a cluster randomised study, 38 women were referred to the continence nurse who, guided by a protocol, assessed and advised the patients about therapy, lifestyle, or medication. If progress was disappointing, therapy was revised. Results were compared to a group of 13 women who received 'usual care' by the General Practitioner. Data on frequency and volume of incontinence, quality of life, and patient satisfaction were collected at baseline and after 3, 6, and 12 months.

After 6 months, women in the intervention group reported a greater reduction in 'moderate' incontinent episodes when compared to women in the control group. No treatment effect was found after 12 months. Although there was a stronger improvement in scores as regards to quality of life in the intervention group, with the exception of the dimension 'physical', no treatment effect was found.

The introduction of a continence nurse demonstrates short-term benefit to community-dwelling women suffering from UI. However, the long-term effects should be further explored with larger study populations.

Trial registration number: ISRCTN15553880 


\section{BACKGROUND}

T rinary incontinence (UI) is a common problem, affecting an estimated $14 \%$ to $69 \%$ of community-dwelling women ${ }^{1,2}$. It reduces patients' quality of life and its physical consequences include cutaneous and urinary tract infections, falls, and skin lesions ${ }^{3}$. The psychosocial consequences of UI include lower selfesteem or isolation ${ }^{4,5}$ and depression, ${ }^{6.8}$ along with increasing expenses for pads, diapers, and treatment ${ }^{y, 10}$. Sandvik and Hunskaar ${ }^{11}$ indicated a median use of 1.8 pads per patient per day in a group of 122,516 Norwegian women, and the UK National Health Service spends approximately $£_{148}$ million a year (more than $\$ 300$ million US) on incontinence pads annually.

Although General Practitioners (GP) are typically the first contact for patients suffering from UI, UI often remains inadequately treated ${ }^{12-15}$. Clinicians may fail to diagnose the underlying cause of incontinence symptoms or fail to recommend treatment ${ }^{16-18}$. Shah and Harris ${ }^{19}$ noted that GPs did not feel confident about managing incontinence. Another study reported consultation time constraints, delayed referrals, and conflicting advice ${ }^{20}$.

Over the past decade, specialized nurses have been integrated into the health care system of many countries including the Netherlands, ${ }^{21-23}$ and management of UI in particular lends itself to a nursing role ${ }^{24,25}$. Several treatments, such as lifestyle interventions, behavioral therapy, and pharmacotherapy are well within the expertise of the continence nurse. Williams and colleagues ${ }^{26}$ investigated the clinical and cost-effectiveness of a nurse-led continence service in a randomized clinical trial. Standard care comprised access to existing primary care and continence advisory services in the area. They reported a reduction in lower urinary tract symptoms including UI, urgency, frequency and nocturia at 6 months when continence nurse services were compared to existing primary care services. However, no long-term effects were described. A systematic review ${ }^{27}$ found evidence that treatment of community-dwelling incontinent women by a specialized nurse can be beneficial in terms of clinical outcomes. Favorable results were described in terms of numbers of incontinent episodes and patient satisfaction. The reviewers suggested that specialized nurses are capable of taking over tasks from doctors in the care of patients suffering from UI. However, most of the evidence was based on studies with a follow-up of less than 1 year. As favorable results may decline over time, it remains necessary to conduct studies on the effectiveness of specialized nurses with longer follow-up periods.

In the Netherlands most women who suffer from UI first visit their GP. However, in spite of UI guidelines that are issued by the Dutch College of General Practitioners, these patients remain under treated. For example, a study of 1663 women with newly identified UI found that $71 \%$ did not receive active treatment within 1 year after diagnosis ${ }^{15}$. The type of incontinence was reported in less than $50 \%$. In another study assessing GP attitudes to UI in elderly 
patients, lack of time, complexity of the problem and presence of comorbidities reduced their likelihood to treat UI ${ }^{28}$. In order to improve the care of patients with UI, a joint initiative was taken by an insurance company and Maastricht University to introduce a specialized nurse in the care of community-dwelling women with urinary incontinence. This is in line with other studies on specialized nurses in the care for patients with Chronic Obstructive Pulmonary Disease (COPD) or type II diabetes ${ }^{29,30}$.

Aims

The aim of this study was to investigate the short-term and long-term effect of introducing a continence nurse to the care of community-dwelling patients suffering from UI. It was expected that, based on the continence nurse's knowledge and experience and guided by a protocol, outcomes would be comparable or better than care rendered by the GP. Outcomes measured were: (1) numbers of incontinent episodes, (2) numbers of pads used, (3) quality of life, and (4) patient satisfaction.

\section{METHOD}

\section{Design}

We completed a cluster randomized clinical trial in the southern region of the Netherlands. One hundred and one GPs were randomly allocated to the intervention $(n=50)$ and control $(n=51)$ groups using a random number table. Due to the nature of the intervention it was not possible for the GP or patient to be blinded to the allocation group. Depending on the GP allocation, eligible subjects either saw the continence nurse (intervention group) or received standard care from the GP (control group) (Figure 1).

\section{Intervention}

The intervention group met with a registered nurse who specialized in the care of incontinent patients. Over a period of 1 year, the nurse advised and guided these patients and provided an assessment using history-taking and postvoid residual (PVR) urine measurement. To exclude urinary tract infection, urinalysis was completed by the subject's GP. Bladder diaries and quality of life questionnaires were completed by subjects and results were reviewed at subsequent visits. After assessment, the continence nurse advised the patient about treatment options guided by a protocol written by a multidisciplinary team comprising a GP, urologist, physiotherapist, and continence nurse (Figure 2).

The protocol provided a management plan including evidence-based interventions for the treatment of stress, urge, and mixed incontinence. Caregivers treating the patients, such as the physiotherapist, were asked to report findings and progress to the nurse, who acted as a coordinator. The nurse provided lifestyle and behavioral interventions tailored to the individual patient 


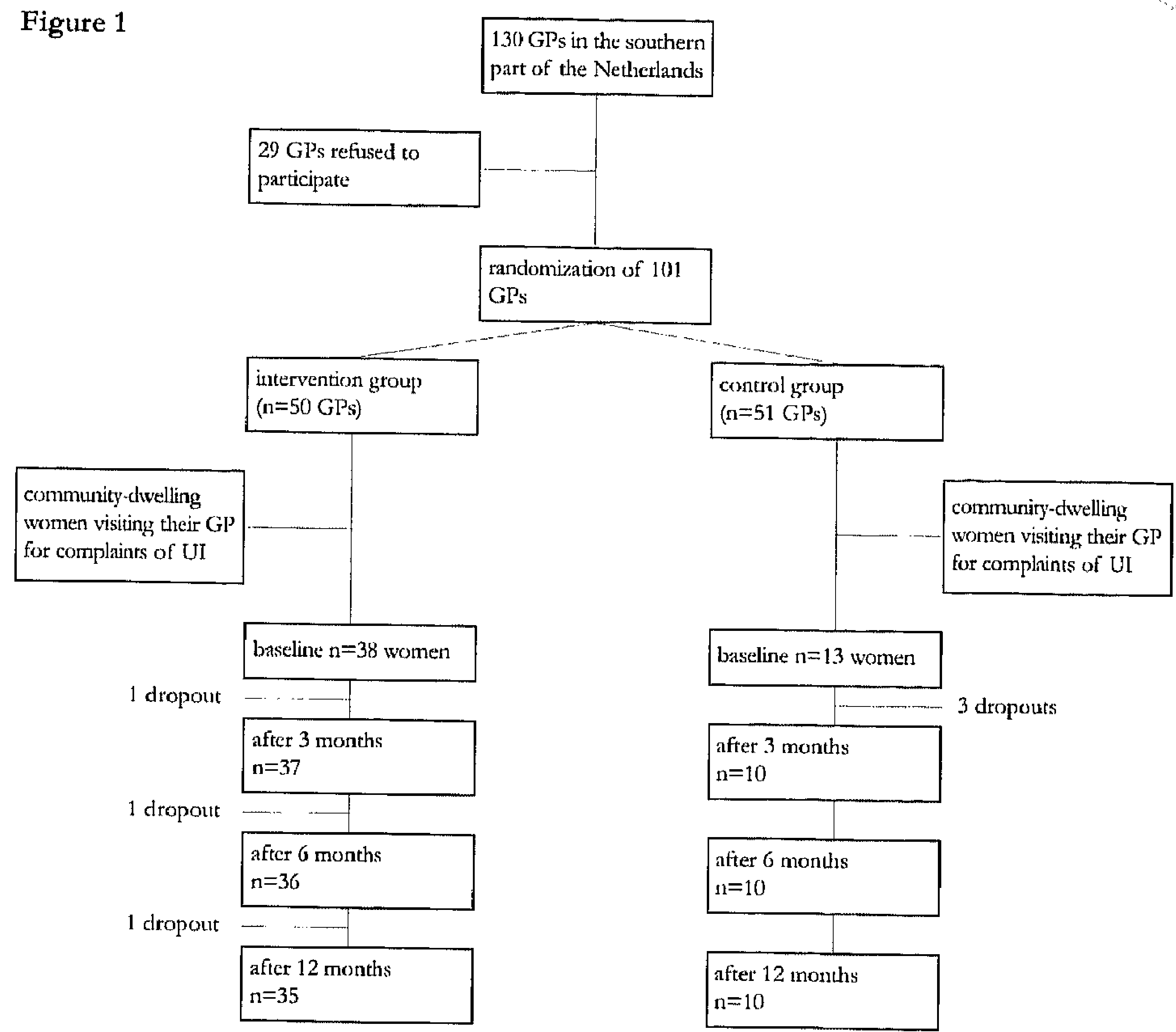

as well as information about pad use. During the 1-year follow-up, the nurse received information about treatment progress from the caregivers involved. All patients returned at 3,6 , and 12 months for follow-up including review of the bladder diaries and questionnaires they had received by mail 2 weeks prior to the appointment. When patients expressed dissatisfaction with their progress, treatment was reviewed and, if indicated, the nurse recommended referral to a urologist. After each visit, the nurse reported her findings to the subject's GP, who remained responsible for their overall care.

Usual care delivered by the GP also allowed access to health care workers in the field of continence care, such as a physiotherapist or urologist. In most cases pelvic floor muscle exercises were completed under the direction of a physiotherapist. Depending on the GP, women were asked to return after 3 or 6 months for follow up.

\section{Sample}

Community-dwelling women aged 18 years and older presenting to their GP for the first time with complaints of stress, urge, or mixed incontinence were included. Women were excluded if their urine tested positive for bacteria, if they had a PVR of $100 \mathrm{~mL}$ or more, if they had given birth within 3 months 


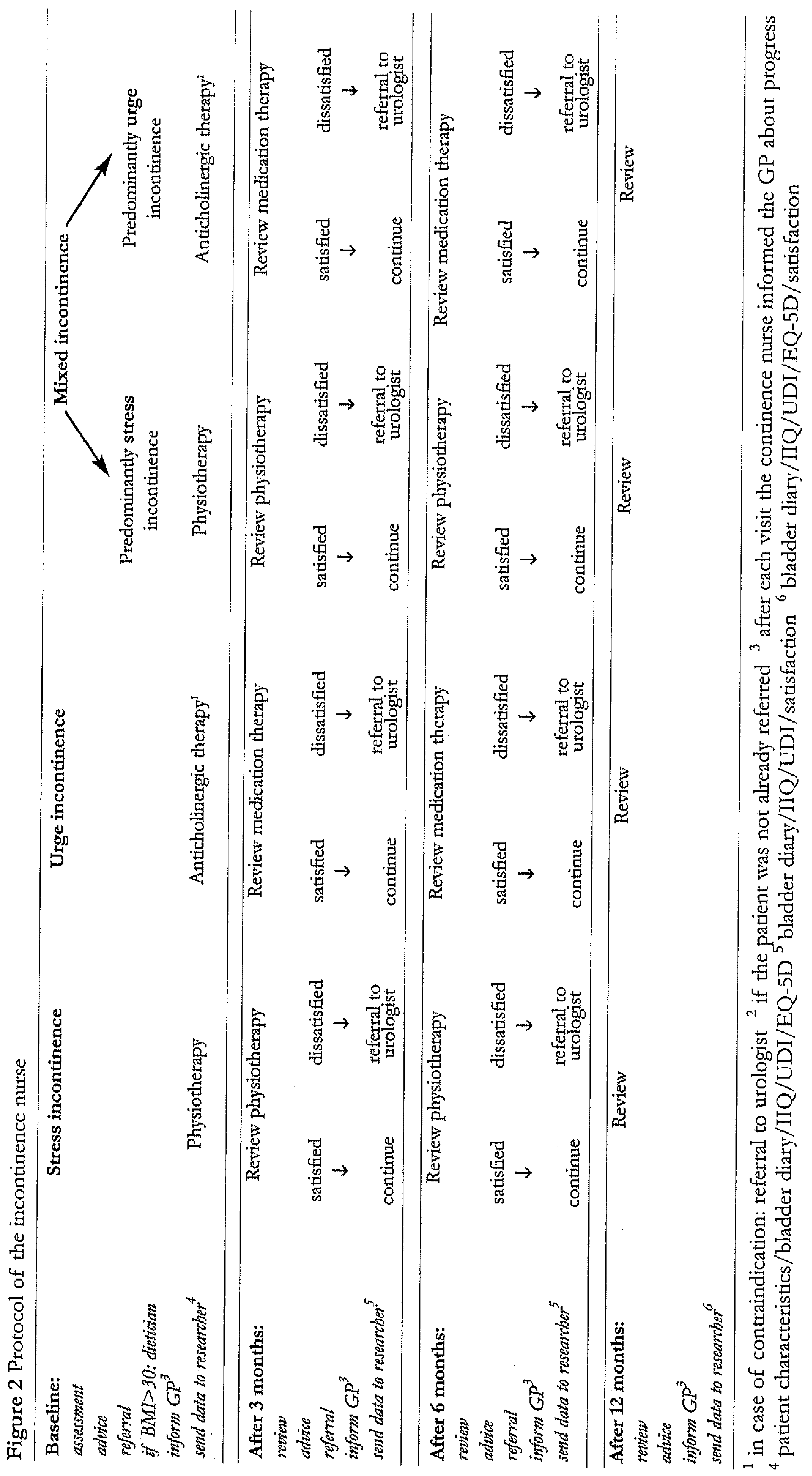


preceding recruitment, or if they suffered from bladder cancer, renal disease, or uterine prolapse past the introitus. A sample size of 228 (114 per group) was needed to provide at least $90 \%$ power to detect a minimum difference between intervention and control group of $25 \%$ in incontinent episodes $(p=.05)$ at 12 month follow-up.

\section{Outcome measures}

The primary outcome measure was the number of incontinent episodes. This was assessed by a 3-day bladder diary recording the frequency and volume (a few drops, moderate loss, or severe loss) of incontinent episodes throughout the day and night. Moderate loss was defined as losing a small volume of urine, and severe loss resulted in the need to change garments. Three-day bladder diaries have often been used in studies on incontinence ${ }^{31.34}$ and studies have shown that such diaries are as effective as 7-day diaries ${ }^{35,36}$.

Secondary outcome measures included: numbers of pads used, impact and bother of UI, quality of life, and satisfaction with treatment. The numbers of pads used were measured by the 3-day bladder diary. Women registered the number of pads they used over a period of 3 days. Incontinence pads as well as sanitary towels and panty liners were registered. The Incontinence Impact Questionnaire (IIQ) and the Urogenital Distress Inventory (UDI) ${ }^{37}$ are diseasespecific questionnaires that have been translated and validated for the Netherlands ${ }^{38}$. The IIQ consists of 30 items covering five subscales (mobility, emotional functioning, physical activity, social functioning, and embarrassment), with patients rating the extent to which urine leakage affects their functioning (from ' $1=$ not at all' to ' $4=$ very much'). The mean of responses is transformed to a score ranging from 0 to 100 with a higher score indicating greater impact on daily life. The UDI consists of 19 items covering 5 subscales (discomfort/pain, urinary incontinence, overactive bladder, genital prolapse, and obstructive micturition); each item assesses 2 aspects: whether or not a symptom is present and the amount of bother it causes (measured on a 4-point Likert scale ranging from ' $1=$ not at all' to ' $4=$ greatly'). As with IIQ scores the mean of responses is transformed to a score ranging from 0 to 100 with a higher score indicating greater impact on daily life.

A generic questionnaire designed to measure health related quality of life, the EuroQol (EQ-5D), was used. It has also been used in other studies on incontinence ${ }^{30.41}$. The EQ-5D defines health in terms of 5 dimensions: mobility, self-care, usual activities, pain/discomfort, and anxiety/depression. Each dimension is assessed at 3 levels, representing 'no problem', 'some problem', and 'extreme problem'. The EQ-5D questionnaire also includes a $20 \mathrm{~cm}$ visual analogue scale $\left(E Q-5 D_{\text {vas }}\right)$ ranging from 0 (indicating worst imaginable health state) to 100 (indicating best imaginable health state). Patient satisfaction with care was measured on a 10-point scale ranging from 'very poor' (1) to 'excellent' (10). 


\section{Ethical considerations}

Approval was given by the ethical committee of the Atrium Medical Centre. After having received written and verbal information about the study from their GP, patients were asked to sign an informed consent form. Anonymity and confidentiality were assured and patients were aware that they could withdraw at any time without adverse consequences.

\section{Procedure}

Women visiting their GP for complaints of UI were asked to participate in the study. After informed consent, the GP filled in a questionnaire on the following patient characteristics: age, type of incontinence, Body Mass Index, number of births, and duration of complaints. After this, the GP handed over the 3-day bladder diary and questionnaires to the subject for baseline measurement. Women who visited GPs and were allocated to the intervention group were referred directly to the continence nurse. Prior to the visit with the nurse, the women completed a 3-day bladder diary.

Women who were allocated to the control group visited their GP and received usual care which, depending on the GP, consisted of prescribing pads or referral. After 3, 6, and 12 months, all patients were sent a 3-day bladder diary and questionnaires by post. Women in the control group returned the completed information to the researcher by post. Women in the intervention group brought the completed information to their next appointment with the continence nurse.

\section{Problems with inclusion of patients}

During inclusion, several measures were taken to remind the GP to include patients for the study. Measures included telephone calls, personal visits, posters, and leaflets that promoted the study. Nevertheless recruitment was disappointing and the sample population comprised 38 patients in the intervention group (recruited by 19 GPs) and 13 patients in the control group (recruited by 9 GPs). GPs either had difficulty finding eligible subjects or they often failed to remember to offer study admission. The number of patients included by individual GPs tanged from 1 ( $n=15$ GPs) to 5 subjects ( $n=1$ GP) indicating small cluster sizes. Recruitment continued over a 2-year period.

\section{Data analysis}

Patient characteristics in the 2 groups were compared using the $\chi^{2}$-test (for 'duration of complaints') and the t-test (for 'age' and 'Body Mass Index'). Since group sizes were not equal and data were not normally distributed, nonparametric tests were used to analyze study outcomes. Only data from women who completed the study were analysed. Within-group changes were evaluated by the Wilcoxon signed-ranks test (for 'incontinent episodes', 'number of pads used', and 'quality of life' measures). Change scores were calculated by 
subtracting scores at 12 months from baseline scores. Between-group differences in effect were compared by applying the Mann-Whitney $U$ test to the change scores. Data were analyzed using SPSS 13 software program. A significance level of $\mathrm{p}<.05$ was used for all analyses.

\section{RESULTS}

A total of 28 GPs (28\%) enrolled 51 patients; 38 in the intervention group and 13 in the control group. Six subjects ( 3 in each group) dropped out because of the demands of study participation $(n=5)$ or intercurrent illness $(n=1)$. Data from these subjects were not included in the final analyses. The patient groups were comparable in terms of most characteristics, except that mixed incontinence was more frequent in the intervention group, whereas stress incontinence was more frequent in the control group (Table 1).

Table 1 Patient characteristics in the 2 groups

\begin{tabular}{|c|c|c|c|c|}
\hline $\begin{array}{l}\text { Characteristics } \\
\end{array}$ & $\begin{array}{l}\text { Intervention } \\
(\mathrm{n}=35) \\
\mathrm{n}(\%)\end{array}$ & $\begin{array}{l}\text { Control } \\
(t=10) \\
n(\%)\end{array}$ & $\begin{array}{l}\chi^{2} \\
\text { (p-value) }\end{array}$ & $\begin{array}{l}\text { t-test } \\
\text { (p-value) }\end{array}$ \\
\hline Age, mean (SD) & $51(13)$ & $54(10)$ & & 0.410 \\
\hline \multicolumn{5}{|l|}{ Incontinence } \\
\hline stress & $5(15)$ & $7(78)$ & & \\
\hline urge & $1(3)$ & $1(11)$ & & \\
\hline mixed & $27(82)$ & $1(11)$ & & \\
\hline Body Mass Index, mean (SD) & $27(5)$ & $27(4)$ & & 0.776 \\
\hline Number of births & 2 & 2 & & 0.054 \\
\hline \multicolumn{5}{|l|}{ Duration of complaints ${ }^{2}$} \\
\hline less than 3 years & $14(42)$ & $5(50)$ & 0.470 & \\
\hline more than 3 years & $19(58)$ & $4(50)$ & & \\
\hline
\end{tabular}

Intervention group: 2 missing; control group: 1 missing

${ }^{2}$ Intervention group: 2 missing; control group: 1 missing

\section{Primary outcome (reduction in UI episodes)}

After 6 months we found a lower 'moderate loss' in the intervention group $(p<.05)$ as well as a tendency for lower 'total loss' $(p=.049)$ (Table 2). The number of 'total loss' episodes for women in the intervention group decreased from 9.1 per 3 days at baseline to 4.8 per. 3 days after 12 months. Although women in the control group also had fewer UI episodes after 12 months ( 9 episodes per 3 days at baseline vs 8.6 episodes per 3 days at 12 months), the decrease was smaller than in the intervention group. Nevertheless, no statistically significant differences between the groups were found at 12 month follow-up.

Within-group analyses of the intervention group showed a statistically significant decrease in the number of 'total loss' episodes per 3 days $(p<.05)$ and 'severe loss' episodes per 3 days $(p<.05)$ after 6 months and 12 months $(p<.05)$. No statistically significant changes were found within the control group. 
Table 2 Numbers of incontinent episodes (per 3 days) and numbers of pads used (per 3 days) at baseline and after 6 and 12 months

\begin{tabular}{|c|c|c|c|c|c|c|c|c|}
\hline \multirow{2}{*}{$\begin{array}{cc} & : \\
\ddots & \\
\ddots & \\
\ddots & \vdots\end{array}$} & \multicolumn{3}{|c|}{$\begin{array}{l}\text { Intervention } \\
\qquad(\mathrm{n}=35)\end{array}$} & \multicolumn{3}{|c|}{$\begin{array}{l}\text { Control } \\
(\mathrm{n}=10)^{*}\end{array}$} & \multicolumn{2}{|c|}{$\begin{array}{l}\text { Mann-Whitney } U \\
\text { (p-value) }\end{array}$} \\
\hline & $\begin{array}{l}\text { Baseline } \\
\text { mean (SD) }\end{array}$ & $\begin{array}{l}\text { After } 6 \\
\text { months } \\
\text { mean (SD) }\end{array}$ & $\begin{array}{l}\text { After } 12 \\
\text { months } \\
\text { mean (SD) }\end{array}$ & $\begin{array}{l}\text { Baseline } \\
\text { mean (SD) }\end{array}$ & $\begin{array}{l}\text { After 6 } \\
\text { montlis } \\
\text { mean (SD) }\end{array}$ & $\begin{array}{l}\text { After } 12 \\
\text { months } \\
\text { mean (SD) }\end{array}$ & $\begin{array}{l}\text { After } 6 \\
\text { months }\end{array}$ & $\begin{array}{l}\text { After } 12 \\
\text { months }\end{array}$ \\
\hline \multicolumn{9}{|l|}{ Incontinent episodes } \\
\hline A few drops & $5.4(10.6)$ & $3.1(4.4)$ & $2.5(4.4)$ & $6.9(7.5)$ & $4.8(4.6)$ & $6.8(5.7)$ & 0.777 & 0.680 \\
\hline Moderate loss & $3.0(4.4)$ & $2,0(6.1)$ & $2.0(3.7)$ & $1.9(2.2)$ & $4.8(4.0)$ & $1.8(2.3)$ & 0,006 & 0.176 \\
\hline Severe loss & $0.7(2.0)$ & $0.2(0.5)^{\dagger}$ & $0.3(1.1)^{\ddagger}$ & $0.3(0.5)$ & $0.1(0.4)$ & $0.1(0.4)$ & 0.620 & 0.755 \\
\hline Total loss & $9.1(11.6)$ & $5.3(7.4)^{\dagger}$ & $4.8(7.5)^{\prime}$ & $9.0(7.2)$ & $9.6(7.7)$ & $8.6(5.6)$ & 0.049 & 0.283 \\
\hline \multicolumn{9}{|l|}{ Pods used } \\
\hline Panty liner & $2.9(4.4)$ & $1.9(3.0)$ & $1.2(2.2)^{\ddagger}$ & $3.3(4.1)$ & $3.1(3.7)$ & $3.3(3.6)$ & 1.00 & 0.396 \\
\hline Sanitary towel & $1.5(3.2)$ & $0.3(1.7)$ & $0.2(1.2)^{\ddagger}$ & $0.8(2.1)$ & $1.5(2.8)$ & $1.0(2.1)$ & 0.070 & 0.319 \\
\hline Incontinence pads & $2.7(5.8)$ & $2.9(4.0)$ & $2.7(4.1)$ & $1.9(3.5)$ & $1.8(3.3)$ & $1.5(3.9)$ & 0.465 & 0.795 \\
\hline Total use & $7.1(6.0)$ & $5.0(3.8)^{\dagger}$ & $4.2(4.2)^{\ddagger}$ & $5.9(5.3)$ & $6.4(3.9)$ & $5.8(4.1)$ & 0.250 & 0.136 \\
\hline
\end{tabular}

$\mathrm{SD}$, standard deviation

- 2 patients are missing from this group

${ }^{\dagger} \mathrm{p}<.05$ (based on Wilcoxon signed-ranks test for within-group changes after 6 months)

${ }^{t} \mathrm{p}<.05$ (based on Wilcoxon signed-ranks test for within-group changes after 12 months)

\section{Secondary outcomes}

After 12 months, a decrease in the total number of pads used was found in the intervention group ( 7.1 per 3 days at baseline vs 4.2 per 3 days at 12 months). In the control group the decrease in the total number of pads used was smaller (5.9 per 3 days at baseline vs 5.8 per 3 days at 12 months). No statistically significant differences between the intervention and control groups regarding pad use were found.

Within-group analyses identified a statistically significant decrease in the total use of pads in the intervention group after 12 months $(p<.05)$. After 12 months, women in the intervention group used fewer panty liners $(p<.05)$ and sanitary napkins $(\mathrm{p}<.05)$. No statistically significant changes were found within the control group.

Within-group analyses also revealed an improvement with respect to the dimensions 'mobility', 'emotional', 'embarrassment', and 'physical' $(p<.05)$ in the intervention group at 6 months. After 12 months, women in the intervention group experienced improvement on all dimensions of the IIQ $(\mathrm{p}<.05)$. Withingroup analyses of the control group revealed improvement with respect to the 'emotional' dimension at 6 months $(\mathrm{p}<.05)$. After 12 months, subjects achieved improvement in the 'mobility' and 'embarrassment' dimensions $(p<.05)$. Between-group analyses at 12 months revealed that women in the intervention group experienced significantly less impact on the 'physical' dimension of the IIQ $(\mathrm{p}<.05)$ (Table 3). 
Table 3 Quality of life and patient satisfaction at baseline and after 6 and 12 months

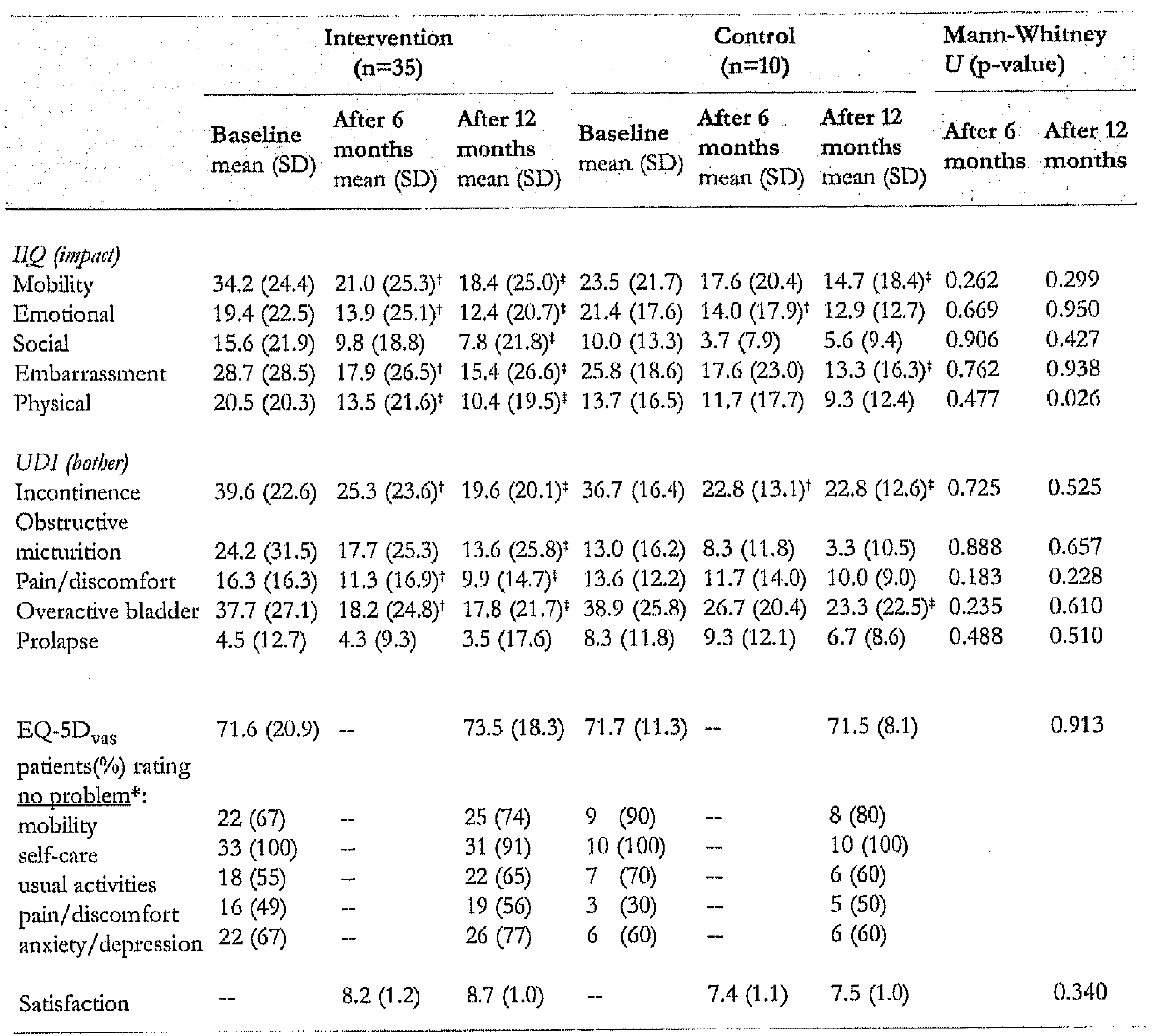

$\mathrm{SD}$, standard deviation

${ }^{\dagger} \mathrm{p}<.05$ (based on the Wilcoxon Test for within-group changes after 6 months)

$\neq p<, 05$ (based on the Wilcoxon Test for within-group changes after 12 months)

not measured

- because of small sample size no test for between-group changes was performed

Between-group analyses of the UDI scores revealed no statistically significant differences between the 2 groups. Within-group analyses found that after 6 months patients in the intervention group were less bothered by symptoms relating to 'incontinence', 'pain/discomfort', and 'overactive bladder' $(\mathrm{p}<.05)$. After 12 months these improvements had persisted together with a decreased bother relating to 'obstructive micturition' $(p<.05)$.

Among women in the control group, bother relating to 'incontinence' significantly diminished at 6 months $(p<.05)$. At 12 months, the magnitude of bother relating to both 'incontinence' and 'overactive bladder' decreased significantly $(p<.05)$.

At 12 month follow-up, no statistically significant differences in ratings were 
found between the groups as regards on the $E Q-5 D_{\text {vas }}$ scores. Although the mean satisfaction score was higher in the intervention group, the difference was not statistically significant when compared to the control group.

\section{DISCUSSION}

A nurse-led intervention appeared to improve the number of 'moderate' UI episodes after 6 months. As for the impact of UI on quality of life, an effect was found after 12 months for the 'physical' dimension measured by the IIQ questionnaire. In the current context of healthcare restraints and with the recent release of the Tag F315 in the United States, opportunities for expert nurses to positively impact continence care and market their skills are expanding rapidly ${ }^{42}$. Our study suggests that nurse-led continence interventions contribute to positive outcomes.

Our results must be interpreted with caution. Against our expectations, the number of patients included was disappointing. We believe that the strict exclusion criteria and possible low incidence of women with UI seeking care from GPs led to lower than expected recruitment. We also conclude that the greater number of subjects in the intervention group may be attributable to differences in physicians' efforts to include patients, and the attractiveness of admission to an intervention group associated with a novel treatment modality. The small sample size negatively affected both the power to detect changes in outcome measures and the ability to generalize results.

Despite the limitations, interesting findings were revealed. After 6 months, women in the intervention group reported a greater reduction in number of 'moderate' incontinent episodes when compared to women in the control group. During the 3 follow-up visits, the women may have gained confidence in discussing their UI problems, enabling the continence nurse to accurately assess the situation and offer appropriate individualized recommendations. ${ }^{43}$ Moore and coworkers ${ }^{44}$ described the 'development of a closer therapeutic relationship' between nurse and patient resulting from the greater amount of time invested by the continence nurse. The greater motivation of the women treated by the continence nurse to follow her advice and also to please the continence nurse may have positively biased results in the intervention group. A major limitation of the study was not using a 24-hour pad test to quantify the incontinence since our definitions of 'drops', 'moderate', and 'severe' are prone to subjective interpretation. Further research on the topic should include the pad test as a way to quantify urine loss. Although treatment effects cannot be attributed to the intervention, they are consistent with those of other studies involving long-term follow-up ${ }^{45-47}$. It is encouraging that the positive results in the intervention group after 6 months persisted after 12 months.

Similar to previous reports, we found that women used not only incontinence pads, they also used panty liners and sanitary pads to contain urine ${ }^{48.50}$. Further 
research might explore the choice of product and the personal struggles that may occur. Sanitary products are "normal", UI products are not. The higher costs of incontinence pads in comparison with other products may also be a reason for the purchase of items such as panty liners.

With the exception of the 'physical' dimension on the IIQ, no treatment effect was found when health-related quality of life scores were analyzed. The intervention group did show a stronger improvement in quality of life measured by the IIQ which was consistent with the decrease in the number of incontinent episodes. It is not surprising that less urine loss results in a higher quality of life. Similar findings reported by Dougherty and coworkers ${ }^{45}$ who studied a group of older, community dwelling women, also found a significant improvement in IIQ scores in combination with a decrease in incontinent episodes. Goode and associates ${ }^{51}$ also described a decrease in UI episodes without a statistically significant improvement in IIQ scores in a group of women with stress UI. The lack of statistically significant findings may be partly explained by the lesser impact associated with stress versus urgency incontinence on quality of life ${ }^{51.53}$.

No treatment effect was found after 1 year regarding scores on the UDI. However, after 1 year, a decrease in bother experienced by the women, as measured by the UDI, was found in the intervention group ('incontinence', 'obstructive micturition', 'pain/discomfort', and 'overactive bladder') and, to a lesser degree, in the control group ('incontinence', 'overactive bladder'). In a study comparing nurse continence advisor care with a standard urogynecological regimen for conservative incontinence treatment, an improvement in UDI scores in both groups was reported ${ }^{44}$. This is of note since Rodriguez and associates ${ }^{54}$ described that physicians tend to underestimate the bother experienced by UI patients. Others have suggested that improvement in the control group could be attributed to the self-insight and behavior changes associated with keeping a bladder diary ${ }^{55}$.

We found that patient satisfaction increased in both groups after 1 year, with no significant differences between the groups. We measured patient satisfaction using a 10-point VAS-scale. Other studies reporting favorable results in terms of patient satisfaction used another instrument where patients could rate satisfaction with their progress as 'completely', 'somewhat' or 'not at all' ${ }^{53,56}$. Coleman and coworkers ${ }^{56}$ reported that patients were satisfied even though the number of incontinent episodes had not decreased, perhaps owing the positive influence of the therapeutic relationship developed between patient and provider. 


\section{CONCLUSION}

This study was limited by a small sample owing to recruitment challenges. We found that the introduction of a continence nurse in primary care resulted in a decrease in 'moderate' incontinent episodes after 6 months. Based on knowledge and experience, and guided by a protocol, the nurse was able to recommend therapy and give information tailored to the patient's needs, potentially improving continence and reported quality of life. No intervention effect was found at 12 month follow-up, but within-group differences suggest that the introduction of a continence nurse might be beneficial for women suffering from UI. However, the effect of the intervention by the specialized nurse must be further explored with larger study populations. 


\section{REFERENCES}

1. Hunskaar S, Burgio K, Diokno AC, Herzog AR, Hjalmas K, Lapitan MC. Epidemiology and natural history of urinary incontinence in women. Urology. 2003;62(Suppl 4A):16-23.

2. Temml C, Haidinger G, Schmidbauer J, Schatzl G, Madersbacher S. Urinary incontinence in both sexes: prevalence rates and impact on quality of life and sexual life. Neurourology and Urodynamics. 2000;19:259-271.

3. Hiser V. Nursing interventions for urinary incontinence in home health. Journal of Wound, Ostomy and Continence Nursing. 1999;26:142-160.

4. Grimby A, Milsom I, Molander U, Wiklund I, Ekelund P. The influence of urinary incontinence on the quality of life of elderly women. Age and Ageing. 1993;22(2):82-89.

5. Lin S-Y, Dougherty MC. Incontinence impact, symptom distress and treatment-seeking behavior in women with involuntary urine loss in Southern Taiwan. International Journal of Nursing Studies. 2003;40(3):227-234.

6. Dugan E, Cohen SJ, Bland DR, et al. The association of depressive symptoms and urinary incontinence among older adults. Journal of the American Geriatrics Society. 2000;48(4):413-416.

7. Melville JL, Delany K, Newton K, Katon W. Incontinence severity and major depression in incontinent women. Obstetrics \& Gynecology. 2005;106(3):585-592.

8. Ko Y, Lin S, Salmon J, Bron M. The impact of urinary incontinence on quality of life of the elderly. American Journal of Managed Care. 2005;11(4):S103-111.

9. Hampel C, Artibani W, Espuna Pons M, et al. Understanding the burden of stress urinary incontinence in Europe: a qualitative review of the litcrature. European Urology. 2004;46(1):15-27.

10. Thom DH, Nygaard IE, Calhoun EA. Urologic diseases in America project: urinary incontinence in women - national trends in hospitalizations, office visits, treatment and economic impact. The Journal of Urology. 2005;173:1295-1301.

11. Sandvik H, Hunskaar S. The epidemiology of pad consumption among community-dwelling incontinent women. Journal of Aging and Health. 1995;7(3):417-426.

12. Shields N, Thomas C, Benson K, Major K, Tree J. Development of a community nurse-led continence service. British Journal of Nursing. 1998;7(14):824-826, 828-830.

13. Williams K, Assassa R, Smith $\mathrm{N}$, et al. Development, implementation and evaluation of a new nurse-led continence service: a pilot study. Journal of Clinical Nursing. 2000;9(4):566-573.

14. Brockelhurst JC. Urinary incontinence in the community: analysis of a MORI poll. British Medical Journal. 1993;306:832-834. 
15. Penning-van Beest FJA, Sturkenboom MCJM, Bemelmans BLH, Herings RMC. Undertreatment of urinary incontinence in general practice. Annals of Pharmacotherapy. 2005;39(1):17-21.

16. Dovey S, McNaughton T, Tilyard M, Gurr E, Jolleys J, Wilson D. General practitioners' opinions of continence care training. New Zealand Medical Journal. 1996;109:340-343.

17. Jones TV, Bunner SH. Approaches to urinary incontinence in a rural population: a comparison of physician assistants, nurse practitioners and family physicians. Journal of the American Board of Family Practice. 1998;11:207-215.

18. Milne JL. The impact of information on health behaviors of older adults with urinary incontinence. Clinical Nursing Research. 2000;9(2):161-176.

19. Shah S, Harris M. A survey of general practitioner's confidence in their management of elderly patients. Australian Family Physician. 1997 (26 Suppl 1):S12-17.

20. Davis K, Kumar D. Pelvic floor dysfunction: a conceptual framework for collaborative patient-centred care. Journal of Advanced Nursing. 2003;43(6):555-568.

21. Hill J, Harmer R, Wright V, Lawton C. An evaluation of the effectiveness, safety and acceptability of a nurse practitioner in a rheumatology outpatient clinic. British Journal of Rheumatology. 1994;33:283-288.

22. Horrocks S, Anderson E, Salisbury C. Systematic review of whether nurse practitioners working in primary care can provide equivalent care to doctors. British Medical Journal. 2002;324:819-823.

23. Richardson G, Maynard A, Cullum N, Kindig D. Skill mix changes: substitution or service development? Health Policy. 1998;45(2):119-132.

24. Shaw C, Williams KS, Assassa RP. Patients' views of a new nurse-led continence service. Journal of Clinical Nursing. 2000;9(4):574-582.

25. Wells $M$. The role of the nurse in urinary incontinence. Baillière's Clinical Obstetrics and Gynaecology. 2000;14(2):335-353.

26. Williams $\mathrm{K}$, Assassa $\mathrm{P}$, Cooper $\mathrm{N}$, et al. Clinical and cost-effectiveness of a new nurse-led continence service: a randomised controlled trial. British Journal of General Practice. 2005;55(518):696-703.

27. Du Moulin MFMT, Hamers JPH, Paulus A, Berendsen C, Halfens R. The role of the nurse in community continence care: a systematic review. International Journal of Nursing Studies. 2005;42(4):479-492.

28. Teunissen D, Bosch van den W, Weel C, Lagro Janssen TL. Urinary incontinence in the elderly: attitudes and experiences of general practitioners; a focus group study. Scandinavian Journal of Primary Health Care. 2006;24(56-61).

29. Vrijhoef HJM, Diederiks JPM, Spreeuwenberg C. Effects on quality of care for patients with type 2 diabetes or COPD when the specialised nurse has a central role: a literature review. Patient Education and Counseling. 2000;41:243-250. 
30. Wilderen LJGP. The nurse specialist as main care-provider for patients with type 2 diabetes in a primary care setting: effects on patient outcomes. International Journal of Nursing Studies. 2002;39(4):441-451.

31. Boyington AR, Dougherty M, Phetrasuwan S. Effectiveness of a computerbased system to deliver a continence health promotion intervention. Journal of Wound, Ostomy and Continence Nursing. 2005;32(4):246-254.

32. Mattsson S, Gladh G. Urethrovaginal reflux - a common cause of daytime incontinence in girls. Pediatrics. 2003;111(1):136-139.

33. Schulte-Baukloh H, Weiss C, Stolze T, Sturzebecher B, Knispel H. Botulinum - a toxin for treatment of overactive bladder without detrusor overactivity: urodynamic outcome and patient satisfaction. Urology. 2005;66(1):82-87.

34. Heit M, Blackwell L, Ouseph R. Comorbidities affect the impact of urinary incontinence as measured by disease-specific quality of life instruments. International Urogynecology Journal and Pelvic Floor dysfunction. 2005;16(1):6-11.

35. Dmochowski RR, Sanders SW, Appell RA, Nitti VW, Davila GW. Bladderhealth diaries: an assessment of 3-day vs 7-day entries. British Journal of Urology international. 2005;96:1049-1054.

36. Brown J, McNaughton K, Wyman J, et al. Measurement characteristics of a voiding diary for use by men and women with overactive bladder. Urology. 2003;61(4):802-809.

37. Shumaker SA, Wyman JF, Uebersax JS, McClish D, Fantl JA. Health-related quality of life measures for women with urinary incontinence: the Incontinence Impact Questionnaire and the Urogenital Distress Inventory. Continence Program in Women (CPW) Research Group. Quality of Life Research. 1994;3(5):291-306.

38. Vaart van der C, Leeuw de J, Roovers J, Heintz A. Measuring health-related quality of life in women with urogenital dysfunction: the Urogenital Distress Inventory and Incontinence Impact Questionnaire revisited. Neurourology and Urodynamics. 2003;22:97-104.

39. Ward K, Hilton P. Prospective multicentre randomised trial of tension-free vaginal tape and colposuspension as primary treatment for stress incontinence. British Medical Journal. 2002;325:67-.

40. O'Brien J, Goeree R, Bernard L, Rosner A, Williamson T. Cost-effectiveness of tolterodin for patients with urge incontinence who discontinue initial therapy with oxybutynin: a Canadian perspective. Clinical Therapeutics. 2001;23(12):2038-2049.

41. Manca A, Schulpher MJ, Ward K, Hilton P. A cost-utility analysis of tensionfree vaginal tape versus colposuspension for primary urodynamic stress incontinence. International Journal of Obstetrics and Gynaecology. 2003;110(3):255-262.

42. Hurlow J. An opportunity for WOC Nurses. Journal of Wound, Ostomy and Continence Nursing. 2006;33(3):296-304. 
43. Hampton S. Importance of the appropriate selection and use of continence pads. British Journal of Nursing. 2005;14(5):265-266, 268-269.

44. Moore KH, O'Sullivan RJ, Simons A, Prashar S, Anderson P, Louey M. Randomised controlled trial of nurse continence advisor therapy compared with standard urogynaecology regimen for conservative incontinence treatment: efficacy, costs and two year follow up. International Journal of Obstetrics and Gynaecology. 2003;110(7):649-657.

45. Dougherty MC, Dwyer JW, Pendergast JF, et al. A randomized trial of behavioral management for continence with older rural women. Research in Nursing \& Health. 2002;25(1):3-13.

46. McDowell BJ, Engberg S, Sereika SM, et al. Effectiveness of behavioral therapy to treat incontinence in homebound older adults. Journal of the American Geriatrics Society. 1999;47:309-318.

47. Holtedahl K, Verelst M, Schiefloe A. A population based, randomized, controlled trial of conservative treatment for urinary incontinence in women. Acta Obstetricia et Gynecologica Scandinavica. 1998;77(6):671-677.

48. Diokno AC, Burgio K, Fultz NH, Kinchen K, Obenschain R, Bump RC. Medical and self-care practices reported by women with urinary incontinence. American Journal of Managed Care. 2004;10:69-78.

49. Palmer MH, Fitzgerald ST. Urinary incontinence in working women: a comparison study. Journal of Women's Health. 2002;11(10):879-888.

50. Saini J, Axelrod FB, Maayan C, Stringer J, Smilen SW. Urinary incontinence in familial dysautonomia. International Urogynecology Journal. 2003;14:209-213.

51. Goode PS, Burgio K, Locher JL, et al. Effect of behavioral training with or without pelvic floor electrical stimulation on stress incontinence in women. Journal of the American Medical Association. July 16 2003;290(3):345-352.

52. Sandvik H, Kveine E, Hunskaar S. Female urinary incontinence psychosocial impact, self care, and consultations. Scandinavian Journal of Caring Sciences. 1993;7(1):53-56.

53. Hunskaar S, Vinsnes A. The quality of life in women with utinary incontinence as measured by the sickness impact profile. Journal of the American Getiatrics Society. 1991;39(4):378-382.

54. Rodriguez LV, Blander DS, Dorey F, Raz S, Zimmern P. Discrepancy in patient and physician perception of patient's quality of life related to urinary symptoms. Urology. 2003;62(1):49-53.

55. Burgio K, Goode PS, Locher JL, et al. Behavioral training with and without biofeedback in the treatment of urge incontinence in older women; a randomized controlled trial. Journal of the American Medical Association. 2002;288(18):2293-2299.

56. Coleman EA, Grothaus LC, Sandhu N, Wagner EH. Chronic care clinics: a randomized controlled trial of a new model of primary care for frail older adults. Journal of the American Geriatrics Society. 1999;47:775-783. 


\section{Chapter}

General discussion 


\section{GENERAL DISCUSSION}

This thesis examines urinary incontinence (UI) in community-dwelling adults in terms of how it is addressed and how care can be improved. In the first part, the prevalence, diagnosis and treatment of UI in older adults receiving homecare in the Netherlands was investigated, as was the use of quality systems to improve the UI care given by homecare agencies. In the second part, a systematic review into the effects of a continence nurse was described. Further, a randomised controlled trial was presented on the effects of introducing a continence nurse in the care of community-dwelling women with UI.

The following research questions have been answered:

- What is the prevalence of UI in older adults receiving homecare?

- How many patients receiving homecare are diagnosed as to UI type, and what strategies are used to treat or manage UI?

- To what extent do homecare agencies use quality systems to improve UI care, and what is the association between these quality systems and UI's prevalence, diagnosis and severity?

- What are the effects of introducing a continence nurse into the care of community-dwelling women suffering from UI?

This chapter summarises the main results and discusses some methodological reflections. Finally, it presents the implications for practice and recommendations for future research.

\section{MAIN RESULTS}

\section{Prevalence of UI in older adults receiving homecare}

This thesis shows that almost half of the older adults receiving homecare are incontinent; this is more or less in accordance with Landi et al.'s study, which reported $51 \%$ of the elderly receiving homecare as incontinent. Most UI patients lost moderate to large amounts of urine on a daily basis. Factors associated with UI were high BMI, high age and being female, as well as having many reasons for admission to homecare services, diabetes mellitus, faecal incontinence, and impaired mobility. Most of these were consistent with factors found in other studies ${ }^{1-7}$. Results also showed that $33 \%$ of the patients had become incontinent after being admitted to homecare. Clearly, it will be a challenge for homecare agencies to adequately address UI in the ageing population.

\section{Addressing UI in older adults receiving bomecare}

This study examined the number of patients diagnosed as to UI type, and strategies to address it. Results showed that for only half of the patients with UI, a diagnosis regarding type had been given. This is in line with other studies also 
reporting that little effort is made to diagnose type of $\mathrm{UI}^{8.10}$.

Compared to patients losing small amounts of urine, those losing larger amounts were more likely to have been diagnosed as to UI type. Most patients with UI in our study used absorbent pads, but few were offered bladder training or pelvic floor muscle exercises. However, research shows that even in elderly patients there are strategies to decrease or indeed cure UI., ${ }^{11}{ }^{12}$ and although absorbent products can be helpful, they will not cause UI symptoms to disappear. We conclude that to adequately address the problem, diagnosis of UI type is needed.

\section{Quality systems used by bomecure agencies to improve UI care}

In this study quality systems to improve UI care such as adopting a continence nurse or a UI protocol were investigated at the level of homecare agencies and teams. Our study revealed that $53 \%$ of the homecare agencies and $86 \%$ of the homecare teams used one or more of these quality systems in UI care. Appointing a continence nurse (37\% of the homecare agencies) and documenting UI in the patient's record (78\% of the homecare teams) were the most commonly used quality systems. No associations were found between the quality systems used and UI outcomes (prevalence, number of patients with a diagnosis as to type, frequency and amount of urine loss). This contrasts with studies in other settings which report positive outcomes on UI as a result of the use of quality systems ${ }^{13-15}$.

We presented some explanations underlying the lack of associations. First, we questioned whether the quality systems sufficiently address the specific needs of older adults with UI who also have physical and/or mental impairments. However, as we were only interested in whether a quality system was used by a homecare agency or team, no statements can be made about the quality system itself (e.g. protocol contents). Also, older adults living in their own homes are not under the constant surveillance of a healthcare worker, as they would be in a hospital or nursing home. Thus, keeping patients motivated to address their UI is more complicated, as home healthcare workers only see their patients during visits. According to the healthcare workers, time constraints, too, force them to focus attention on more emergent problems. Other factors may include the healthcare worker's or patient's negative attitude to UI care, and the way the quality system is implemented. Therefore, more insight is needed into the content of the quality systems and their applicability in the homecare setting.

\section{Effects of a continence nurse}

Based on a systematic review comprising 12 randomised controlled trials (RCT's), we found that care given by a nurse specialised in UI can be beneficial in terms of clinical outcomes. Still, as most trials used follow-up periods of less than one year, it is questionable whether these positive results are still present 
after one year, as high relapse rates after six months have been reported ${ }^{16}$. Thus, further research with long-term follow-up is needed to determine the effects of continence nurses.

Our RCT, which was hampered by a slow recruitment rate, showed that after six months women who were advised and guided by the continence nurse reported a greater reduction in 'moderate' incontinent episodes compared to women who received usual care. Guided by a protocol as well as her own knowledge and experience, the nurse was able to advise patients about treatment and give information tailored to their needs. Although no treatment effect between the groups was found after 12 months, within-group analyses showed that women in the intervention group showed a significant decrease in incontinent episodes after one year. Results also revealed that in the intervention group women experienced significantly less impact on the 'physical' dimension of the Incontinence Impact Questionnaire after 12 months. Hence, communitydwelling women with UI seem to benefit from care given by a continence nurse.

\section{Methodological reflections}

Several methodological issues of the studies have already been presented in the separate chapters. This section sets out the most important methodological strengths and limitations.

\section{UI in the bomecare setting}

For our studies on elderly UI patients receiving homecare, data from the Dutch National Prevalence Measurement of Health Care Problems were used. Every year hundreds of institutions participate in this measurement, generating large study populations. The standardised method of data collection by nurses in the home health care setting as well as the fact that these nurses are well-known to the patients are strengths of the studies. Consistency of the measurements was ensured by way of a second independent healthcare worker scoring the same patient in a random sample of 20 patients in each homecare agency; kappa values revealed good agreement. We also believe that, because of a trusting relationship, patients felt confident enough to discuss their UI and related problems with the nurse.

As these studies have cross-sectional designs, no statements can be made about the cause-effect relationships between variables. We are also aware that the number of variables in this prevalence measurement is limited; we did not measure other factors known to be associated with UI, such as cognitive status. However, the main aim of the Dutch National Prevalence Measurement of Health Care Problems is to measure UI's prevalence: involving too many variables would be too complicated and time-consuming. To what extent this omission influenced our results is not known.

Another limitation might be the voluntary nature of the prevalence 
measurement. Each year all homecare agencies are invited to participate, but are free to decide whether they do so or not. Also, participating agencies can decide which of the following care problem(s) is/are to be surveyed: pressure ulcers, urinary incontinence, malnutrition, fixation, intertrigo or falls. It may be that this led to a greater willingness to take part among homecare agencies with a policy on improving quality of UI care.

\section{Effects of a continence nurse}

To investigate the effects of a continence nurse we used an RCT, which is the most rigorous way to determine whether a cause-effect relation exists between an intervention and outcome measures. Detailed information was gathered on UI episodes and the amount and frequency of UI loss. Questionnaires that had been used to measure amount of bother of UI and its impact on the lives of those involved were validated for the Dutch setting. The intervention was carefully implemented and guided by a multidisciplinary team. However, from the start, patient inclusion was disappointing. Therefore, measures were taken to remind GPs to include patients for the study, including personal visits and telephone calls to their practices, reminders in the form of letters and faxes, and the distribution of posters and leaflets to promote the study. The total number of patients included nevertheless remained low.

One reason for this low recruitment rate might be the strict exclusion criteria (e.g. women who had been treated for UI in the past were excluded). However, these criteria were selected to maintain homogeneity within the groups. The incidence of women with UI seeking care from a GP for the first time was also low, and despite the carefully planned introduction of the continence nurse and the GPs' promises to participate, most were not actively involved in recruitment. Whether this was a result of little interest in the intervention, for instance, or an aversion to deviating from daily routine is not known. After the inclusion period, we interviewed some GPs on their participation. They reported that, in spite of the reminders, they had found it difficult to keep the study in mind and to find suitable women to include. The small sample size negatively affected the power to detect changes in outcome measures and, ultimately, our ability to generalise the results.

To measure the frequency and amount of urine loss (drops, moderate or severe), the women used a three-day bladder diary four times over a period of one year. This is prone to subjective interpretation. We are aware that a pad-weighing test would have been a more objective way to quantify the changes in urine loss over time, but a bladder diary has nevertheless been shown to correlate well with the 24-hour pad test ${ }^{17}$, 18. In addition, the self-insight and behaviour changes associated with keeping a bladder diary may also have led to an improvement in continence status. 
Our studies on the prevalence and treatment of UI in patients receiving homecare have demonstrated that care is not optimal. Results revealed that half of the UI patients are not diagnosed as to type of UI. Also, many patients use pads though few are actually being treated for UI (e.g. bladder training or pelvic floor muscle exercises). Given the negative consequences of UI on quality of life and the increased tisk of institutionalisation, it is therefore important to find ways to improve UI care in the community.

The literature ${ }^{15}$ describes quality systems focused on improving care for patients with UI. One such system concerns the appointment of a specialised continence nurse who can assess a patient to identify the underlying cause ${ }^{19}$ of $\mathrm{UI}$ and, guided by a protocol with evidence-based treatments, give advice tailored to the patient's needs (e.g. treatment by a physiotherapist, medication, or referral to a urologist). Our systematic review on the effects of appointing a continence nurse in the care for community-dwelling patients showed that this nurse could benefit UI patients in terms of clinical outcomes (e.g. incontinent episodes and quality of life). To gain more insight into the effects of a continence nurse in the care for community-dwelling women in the southern Netherlands, we conducted an RCT which, unfortunately, was hampered by a low recruitment rate. Results showed that community-dwelling women with UI seemed to benefit from the services of a continence nurse.

In view of these results, we think that patients receiving homecare could also benefit from a continence nurse's specific knowledge and skills. We are aware that many patients in our study are elderly and have physical and/or mental impairments that can interfere with proper management of UI, and indeed, in some cases absorbent pads can help manage UI in eldetly patients. However, the number of elderly receiving homecare who were offered pelvic floor muscle exercises or bladder training was low, despite research having shown that these therapies can benefit even elderly people ${ }^{12}$. Addressing UI in the elderly in particular can be complex, and requires the services of expert continence nurses who are able adequately to assess and guide patients.

Unfortunately, there is a general perception among both the public and healthcare workers that UI is part of the ageing process for which no treatment is available ${ }^{20-22}$. In our study, most patients receiving homecare used pads. The belief that pads are the only option is strengthened by pad commercials in the media that contribute to the belief that UI is a normal women's complaint after childbitth or with increasing age. For elderly patients receiving homecare, these perceptions may hamper proper treatment of UI. Continence nurses, however, can inform other healthcare workers and the general public about how to adequately address UI. Therefore, collaboration between home healthcare nurses and continence nurses is important. 
Although many elderly are not keen simply to 'put up' with their UI, ${ }^{23,24}$ they are often reluctant to mention it due to embarrassment or lack of awareness of available treatments ${ }^{22,25}$. Yet because home healthcare nurses pay their patients regular visits, a relationship based on trust may grow, facilitating the patients to discuss their UI problems. It is therefore important that home healthcare nurses encourage them to seek help by informing the continence nurse and/or a GP.

Our study on quality systems to improve UI care (e.g. appointing a continence nurse, documenting UI in the patient's record, providing education on UI) demonstrated that only half of the homecare agencies and $86 \%$ of the homecare teams used one or more of the quality systems measured in our study. We also found that these quality systems were not associated with positive UI outcomes. This seems inconsistent with the literature showing positive effects of quality systems on UI outcomes, ${ }^{11426,27}$ but can be explained in several ways. One reason may be that homecare agencies with high UI prevalence rates in particular adopt quality systems. We can also question whether the implementation of the quality systems in the homecare setting has been successful. Effective implementation requires good planning and preparation and a systematic approach; the target group and setting must be analysed and bottlenecks identified. We therefore advise homecare agencies and teams to critically evaluate their quality systems. Are all homecare workers familiar with the quality systems, and do they fit with their needs and knowledge? Do the quality systems sufficiently address the needs of the older adults with UI? More insight into the content and proper use of such systems may help home healthcare workers better gear them to UI care in the homecare setting.

We found no association between the appointment of a continence nurse and UI outcomes in the homecare setting. This stands in contrast with our trial on community-dwelling women who were advised and guided by a highly qualified and experienced continence nurse, and showed positive results after six months. One explanation might be the level of knowledge of the continence nurses. In the Netherlands, continence nurses may have followed a variety of educational progtammes, and their job responsibilities can vary between advising patients about treatment options and coordinating care on the one hand, and giving general information on absorbent materials on the other hand. Therefore, a critical evaluation of the educational programmes for continence nurses is recommended. Addressing UI is a complex matter requiring the input of qualified nurses; our trial showed that the input of a qualified and experienced continence nurse resulted in a decrease in incontinent episodes after six months. Although caution is warranted when interpreting the RCT results, we believe that community-dwelling women with UI can benefit from the services of a continence nurse. 


\section{Recommendations for future research}

Based on the results of this study, we recommend further research into the effects of a continence nurse. Our trial revealed that the introduction of a continence nurse resulted in a decrease in 'moderate' incontinence episodes after six months. Unfortunately, this study was limited by its small sample size. Thus, more research is needed with larger study populations on the long-term effects of involving such a nurse in the care for community-dwelling women with UI. We also recommend a cost-effectiveness study to evaluate the outcomes and costs, as well as a process evaluation. As patient recruitment in our study was hampered by, among other things, the strict in- and exclusion criteria, we would also advise reconsidering these criteria to facilitate recruitment. In addition, it is questionable whether recruiting patients through GPs is recommendable; other ways to recruit patients should therefore be explored.

In our study on elderly people receiving homecare, only half of the UI patients were diagnosed regarding type of UI. This raises questions about why relatively few are diagnosed. One reason might be a lack of knowledge on how to address the problem. Also, are the patients reluctant to undergo assessment and, if so, is this because they fear treatment or they lack motivation? Are the healthcare professionals themselves motivated enough to address UI in the elderly? Do structural factors such as lack of time hamper professionals in adequately assessing the elderly? Hence, more research is needed into why patients with UI are not properly diagnosed. The insights gained by answering these questions could help home healthcare workers more effectively address UI and reflect on the necessary skills to do so.

No associations were found between quality systems to improve UI care for older adults receiving homecare and UI outcomes. As we were only interested in whether or not a quality system was used by the homecare agency or team, no information is available on the content of these systems and their applicability in the homecare setting. Therefore, future research should focus on gaining indepth information on the implementation of the quality systems and their content. This may lead to the alteration of existing quality systems or the development of new ones, ultimately leading to positive UI outcomes for homecare patients. 


\section{REFERENCES}

1. Landi F, Cesari M, Russo A, Onder G, Lattanzio F, Bernabei R. Potentially reversible risk factors and urinary incontinence in frail older people living in community. Age and Ageing. 2003;32:194-199.

2. Jackson $R$, Vittinghoff $E$, Kanaya A, et al. Urinary incontinence in elderly women: findings from the health, aging, and body composition study. Obstetrics and Gynecology. 2004;104:301-307.

3. Espino DV, Palmer RF, Miles TP, Mouton CP, Lichtenstein MJ, Markides KP. Prevalence and severity of urinary incontinence in elderly MexicanAmerican women. Journal of the American Geriatrics Society. 2003;51:1580-1586.

4. Stenzelius K, Mattiasson A, Rahm Hallberg I, Westergren A. Symptoms of urinary and faecal incontinence among men and women $75+$ in relations to health complaints and quality of life. Neurourology and Urodynamics 2004(23):211-222.

5. Lewis CM, Schrader R, Many A, Mackay M, Rogers RG. Diabetes and urinary incontinence in 50- to 90-year-old women: a cross-sectional population-based study. American Journal of Obstetrics and Gynecology. 2005;193:2154-2158.

6. Nuotio M, Jylhä M, Luukkaala T, Tammela TLJ. Utinary incontinence in a Finnish population aged 70 and over. Scandinavian Journal of Primary Health Care. 2003;21:182-187.

7. Bliss D, Fischer LR, Savik k, Avery M, Mark P. Severity of fecal incontinence in community-living elderly in a health maintenance organization. Research in Nursing \& Health. 2004;27(3):162-173.

8. Penning-van Beest FJA, Sturkenboom MCJM, Bemelmans BLH, Herings RMC. Undertreatment of urinary incontinence in general practice. Annals of Pharmacotherapy. 2005;39(1):17-21.

9. Kinchen K, Lee J, Fireman B, Hunkeler E, Nehemiah J, Curtice T. The prevalence, burden, and treatment of urinary incontinence among women in a managed care plan. Journal of Women's Health. 2007;16(3):415-422.

10. Mayor S. Incontinence management is inadequate, UK audit shows. British Medical Journal. 26 November 2005;331:1226.

11. Perrin L, Dauphinee.S., Corcos J, Hanley JA, Kuchel GA. Pelvic floor muscle training with biofeedback and bladder training in elderly women: a feasibility study. Journal of Wound, Ostomy and Continence Nursing. May/June 2005;32(3):186-199.

12. Teunissen TA, de Jonge A, Van Weel C, Lagro Janssen TL. Treating urinary incontinence in the elderly - conservative therapies that work: a systematic review. Journal of Family Practice. 2004;53(1):25-30. 
13. Ouslander JG. Quality improvement initiatives for urinary incontinence in nursing homes. Journal of the American Medical Directors Association. 2007;8(3):S6-S11.

14. Mueller C, Cain H. Comprehensive management of urinary incontinence through quality improvement efforts. Geriatric Nursing. 2002;23(2):82-87.

15. Wagner $C$, Wal van der $G$, Groenewegen P, Bakker de $D$. The effectiveness of quality systems in nursing homes: a review. Quality \& Safety in Health Care. 2001;10:211-217.

16. Mouritsen L. Pelvic floor exercises for female stress urinary incontinence. International Urogynecology Journal. 1994(5):44-51.

17. Groutz A, Blaivas JG, Chaikin DC, et al. Noninvasive outcome measures of urinary incontinence and lower urinary tract symptoms: a multicenter study of micturition diary and pad tests. Journal of Urology. 2000;164(3 Pt 1):698-701.

18. Karantanis E, Fynes M, Moore KH, Stanton S. Comparison of the ICIQ-SF and 24-hour pad test with other measures for evaluating the severity of urodynamic stress incontinence. International Urogynecology Journal. 2004;15(2):111-116.

19. Getliffe $K$, Dolman $M$, eds. Promoting continence; a clinical and research resource. second ed: Baillière Tindall; 2003.

20. Teunissen D, Bosch van den W, Weel C, Lagro Janssen TL. Urinary incontinence in the elderly: attitudes and experiences of general practitioners; a focus group study. Scandinavian Journal of Primary Health Care. 2006;24(56-61).

21. Gibbs CF, Johnson MT, Ouslander JG. Office management of geriatric urinary incontinence. The American Journal of Medicine. 2007;120:211-220.

22. Mardon RE, Halim S, Pawlson LG, Haffer SC. Management of urinary incontinence in Medicare Managed Care Beneficiaries. Archives of Internal Medicine. 2006;166:1128-1133.

23. Cheater FM, Baker R, Gillies $C$, et al. The nature and impact of urinary incontinence experienced by patients receiving community nursing services: a cross-sectional cohort study. International Journal of Nursing Studies. 2006; doi:10.1016/j.ijnurstu.2006.09.006.

24. Palmer MH, Newman D. Bladder control educational needs of older adults. Journal of Gerontological Nursing. 2006;32(1):28-32.

25. Shaw C, Tansey R, Jackson C, Hyde C, Allan R. Barriers to help seeking in people with urinary symptoms. Family Practice. 2001;18(1):48-52.

26. Awad L. Verantwoorde zorg bij toiletgang en incontinentie. Zeist: SCA hygiene products Nederland B.V.; 2006.

27. Lagro Janssen TL, Breedveldt Boer HP, Dongen JJAM, Lemain TJJ, Teunissen D, Pinxteren B. NHG-Standaard Incontinentie voor urine. Huisarts \& Wetenschap. 2006;49(10):501-510. 


\section{Chapter}

Summary

Samenvatting

Dankwoord

Curriculum Vitae 
This thesis describes urinary incontinence (UI) in community-dwelling adults in terms of how it is addressed and how care can be improved. UI is a common condition, especially in older people, and is defined by the International Continence Society as 'the complaint of any involuntary loss of urine'. Several types of UI can be identified with stress, urge, mixed and functional UI being some of the most common. In the Netherlands, about 800,000 people suffer from UI, which is linked with negative physical, mental and social consequences and is also associated with high costs. With the ageing population and because high age is a risk factor for UI, the number of people with UI will increase drastically. In spite of available treatments, research shows that treatment often remains inadequate as healthcare workers and society often believe that UI is part of the ageing process and nothing can be done about it. The literature describes 'quality systems' (such as UI protocols or the adoption of a continence nurse) that can improve care for patients with UI.

This thesis first addresses UI in community-dwelling adults who receive care from a homecare agency. The aim was to gain insight into UI's prevalence, how it is addressed, and the quality systems used by homecare agencies to improve UI care. Second, the role of a specialized nurse in UI care is examined. Literature shows that continence nurses can play an important role in UI care. Thus, an intervention was set up to gain insight into the effects of introducing a continence nurse in the care for community-dwelling women with UI.

The research questions posed in this thesis were as follows:

- What is the prevalence of UI in older adults receiving homecare?

- How many patients receiving homecare are diagnosed as to UI type, and what strategies are used to treat or manage UI?

- To what extent do homecare agencies use quality systems to improve UI care, and what is the association between these quality systems and UI's prevalence, diagnosis and severity?

- What are the effects of introducing a continence nurse into the care of community-dwelling women with UI?

Chapter 1 presents a general introduction to the research topic. The most common types of UI are discussed, as well as their impact on patients' lives. This is followed by a description of how UI can be assessed and treated, and the suggestion that current UI care is not optimal. Finally, the thesis aims and outline are presented.

Chapters 2, 3 and 4 report on a cross-sectional study using data from the Dutch National Prevalence Measurement of Health Care Problems. This is a nationwide cross-sectional study that takes place each year. All Dutch healthcare organisations (hospitals, nursing homes, institutions for people with physical and learning disabilities, and homecare agencies) are invited to participate. Several 
care problems (pressure ulcers, incontinence, falls, malnutrition, fixation and intertrigo) are measured. To collect data, standardised forms are used by nurses who are well-known to the patients and trained to use the forms correctly. Data on incontinence collected from a sample of patients from the homecare agencies are used.

Chapter 2 describes a cross-sectional study examining the prevalence of UI in older adults with UI receiving homecare. The data included patient characteristics, frequency of UI loss, severity and type of UI, and risk factors. A total of 19 homecare agencies participated in the study, with 2866 patients screened for UI. Results revealed that $46 \%(\mathrm{n}=1319)$ of the patients had UI. Associated risk factors included being female, high body mass index and high age. Of the patients with UI, more than $50 \%$ were not diagnosed as to type.

Chapter 3 presents a study on the diagnosis of and strategies to address UI in older adults receiving homecare. Data were collected on patient sex and age, date of UI onset, frequency, severity, and time of loss, UI type, the healthcare worker who diagnosed it, and strategies to manage or treat it. Of the patients with UI, $50 \%(\mathrm{n}=615)$ were diagnosed as to type (most commonly functional incontinence; $35 \%)$, usually by the GP (58\%). Patients who had been diagnosed were more severely affected and offered more strategies to manage their UI than undiagnosed patients. Pads were used by over half of the patients, and scheduled toileting was adopted for about one third. In spite of studies reporting positive results of behavioural interventions for older adults with UI, only a small number of patients were offered bladder training or pelvic floor muscle exercises. Environmental changes and special skincare were offered in $8 \%$ and $11 \%$ of the cases respectively. We conclude that more attention should be paid to diagnosing UI and strategies to effectively treat or manage it in older persons.

Chapter 4 describes a study on quality systems (e.g. adopting a continence nurse, or using a UI protocol): we investigated whether homecare agencies use these systems to improve UI care. We also looked for associations between these systems and UI outcomes, such as prevalence as well as amount and frequency of UI loss. Data were collected from 19 homecare agencies comprising 155 homecare teams. Results showed that about one third of the homecare agencies adopted a continence nurse and, in the homecare teams, documentation in the patient record was the most commonly used quality system. Remarkably, there were no associations between the quality systems and UI outcomes. Therefore, we question whether the quality systems are well implemented, and whether they adequately meet the needs of this specific population. We conclude that further research is needed to investigate the content of the quality systems and their applicability in the homecare setting.

Cbapter 5 presents the results of a systematic review on the effects of introducing a continence nurse in the care for community-dwelling adults with UI. We found 12 randomised controlled trials (RCTs) that were heterogeneous 
in terms of population, setting, outcome measurements and control/intervention. We then assessed these studies for methodological quality and found only one to be of poor quality. Of the remainder, eight reported a significantly greater reduction in incontinence episodes in patients cared for by the nurse compared to patients receiving standard care. However, five of these used a follow-up period of less than one year. It is questionable whether positive results still exist after one year, as research shows relapse rates of $60 \%$ after six months. In light of this, we conclude that future studies should focus on the long-term effects of a continence nurse on community-dwelling patients with UI.

Chapter 6 describes the results of an RCT aimed to investigate the short- and long-term effects of introducing a continence nurse to the care of communitydwelling women with UI. For the purpose of this study, the nurse used a protocol with evidence-based UI treatments set up by a multidisciplinary team. Outcome measures were number of incontinent episodes, number of pads used, quality of life, and patient satisfaction; 101 GPs were randomised to the intervention $(n=50)$ and control groups $(n=51)$. Women who visited their $G P$ in the intervention group were sent to the continence nurse. Guided by the protocol as well as her knowledge and experience, this nurse advised the women about best treatment and aspects such as skincare and lifestyle interventions. The women visited the nurse again after 3,6, and 12 months to discuss the progress of the treatment. If necessary, the nurse would refer them to a urologist.

Women visiting their GP in the control group received usual care. Data were collected for both groups using, for example, bladder diaties, the Incontinence Impact Questionnaire and the Urogenital Distress Inventory. Data from 35 women in the intervention group and 10 women in the control group could be analysed. Results showed that after six months women in the intervention group experienced a lower 'moderate loss' compared to those in the control group. Within-group analysis further showed a statistically significant decrease in incontinent episodes in the intervention group after 12 months. However, no differences regarding incontinent episodes and number of pads used were found between the study groups after one year. As for impact on quality of life, women in the intervention group showed better results on the 'physical' dimension compared to women who had received usual care. We recommend that the effect of introducing a specialised nurse in the care for adults with UI be further investigated, as our study was limited by its small sample size.

Chapter 7 presents a general discussion of the studies described in this thesis. Besides a summary of the main findings, it also discusses theoretical and methodological reflections and concludes with implications for practice and future research. 


\section{SAMENVATTIING}

Dit proefschrift gaat over urine incontinentie bij volwassenen binnen de eerstelijn. Urine incontinentie is een veel voorkomend probleem, vooral bij ouderen. De International Continence Society (ICS) omschrijft het als: objectief aantoonbaar ongewild urineverlies. In Nederland hebben zo'n 800.000 mensen last van incontinentie. Verschillende soorten urine incontinentie kunnen worden onderscheiden waarvan stress, aandrang, gemengde en functionele incontinentie het meest voorkomen. Incontinentie kent veel negatieve psychische, sociale en lichamelijke gevolgen en het wordt vaak geassocieerd met hoge kosten.

Door de vergrijzing van de bevolking zal ook het aantal mensen met incontinentie toenemen aangezien hoge leeftijd een risicofactor is. Ondanks dat er verschillende behandelingen bestaan die incontinentie kunnen verhelpen, blijkt uit de (inter)nationale literatuur dat de behandeling van incontinentie vaak niet optimaal is. Zowel werkers in de gezondheidszorg als de samenleving denken nog vaak dat incontinentie een onoverkomelijk probleem is bij het ouder worden en dat hier niets aan gedaan kan worden. In de literatuur worden zogenaamde 'kwaliteitssystemen' (bijvoorbeeld een protocol voor de behandeling van incontinentie of het inzetten van een incontinentieverpleegkundige) beschreven, die de kwaliteit van zorg kunnen verbeteren.

Dit proefschrift beschrijft op de eerste plaats het voorkomen en behandelen van incontinentie bij volwassenen van 65 jaar of ouder die thuiszorg ontvangen. Het doel van deze studie was on inzicht te krijgen in de prevalentie van incontinentie en de manier waarop met dit probleem door de thuiszorg wordt omgegaan. Ook werd inzicht verkregen in kwaliteitssystemen die werden gebruikt door thuiszorginstellingen om de zorg voor ouderen met incontinentie te verbeteren. Op de tweede plaats is onderzocht wat de effecten waten van het inzetten van een incontinentieverpleegkundige binnen de zorg voor vrouwen met UI die hiervoor hun huisarts bezochten. Uit de literatuur blijkt dat incontinentieverpleegkundigen een belangrijke rol kunnen spelen in de zorg voor incontinente patiënten. Een interventiestudie werd opgezet om inzicht te krijgen in de effecten van het toevoegen van een incontinentieverpleegkundige aan de zorg voor patiënten met incontinentie.

De volgende vraagstellingen werden beantwoord:

- Wat is de prevalentie van incontinentie bij ouderen die thuiszorg ontvangen?

- Hoeveel incontinente patiënten binnen de thuiszorg zijn gediagnosticeerd wat betreft soort incontinentie en welke strategieën worden gebruikt om incontinentie te verbeteren?

- In welke mate maakt de thuiszorg gebruik van kwaliteitssystemen om de zorg tondom incontinentie te verbeteren en wat is de relatie tussen deze kwaliteitssystemen en de prevalentie en ernst van incontinentie alsook het aantal patiënten met een diagnose wat betreft soort incontinentie? 
- Wat zijn de effecten van het toevoegen van een incontinentieverpleegkundige aan de zorg voor incontinente vrouwen?

Hoofdstuk 1 is een algemene introductie waarin inzicht wordt gegeven in de achtergrond van dit proefschrift. Nadat de meest voorkomende vormen van incontinentic en de gevolgen hiervan voor de patiënten zijn weergegeven, volgt een beschrijving van de meest voorkomende behandelingen van incontinentie. Uit onderzoek blijkt echter dat de behandeling van incontinentie vaak niet optimaal is. Dit hoofdstuk wordt afgesloten met het doel van het proefschrift en een kort overzicht van de afzonderlijke hoofdstukken.

Hoofdstuk. 2, Hoofdstuk 3 en Hoofdstuk 4 beschrijven elk een cross-sectionele studie waarin gebruik is gemaakt van data van de Landelijke Prevalentiemeting Zorgproblemen. Aan deze jaarlijkse meting kunnen alle intramurale en extramurale gezondheidszorginstellingen in Nederland deelnemen. Tijdens de meting worden data vetzameld over decubitus, incontinentie, vallen, ondervoeding, fixatie en smetten. Instellingen kunnen zelf beslissen of zij aan deze meting willen participeren en welke zorgproblemen worden gemeten. Dataverzameling vindt plaats door geïnstrueerde verpleegkundigen die de patiënt goed kennen. Met behulp van gestandaardiseerde vragenlijsten worden de data, afkomstig van de patiënt en haar/zijn dossier, verzameld. Voor deze studies zijn data gebruikt van een steekproef van patiënten met incontinentie binnen de thuiszorg.

Hoofdstuk 2 presenteert een cross-sectionele studie naar de prevalentie van incontinentie bij ouderen die thuiszorg ontvangen. Data-verzameling had betreklking op onder andere patiëntkenmerken (bijvoorbeeld geslacht, leeftijd en Body Mass Index), frequentie en ernst van de incontinentie, risicofactoren en soort incontinentie. Negentien thuiszorginstellingen hebben deelgenomen aan deze studie met in totaal 2866 patiënten die zijn gescreend op incontinentie. Uit de resultaten blijkt dat $46 \% \quad(n=1319)$ van de patiënten last heeft van incontinentie. Factoren die samenhangen met incontinentie zijn onder andere het vrouwelijk geslacht, hoge leeftijd en hoge Body Mass Index. Ook blijkt dat meer dan de helft van de patiënten met incontinentie niet is gediagnosticeerd wat betreft soort incontinentie.

Hoofdstuk 3 rapporteert de resultaten van een cross-sectionele studie over soorten incontinentie bij ouderen die thuiszorg ontvangen en strategieën die door de thuiszorg worden gebruikt om deze patiënten te helpen. Dataverzameling had betrekking op de volgende aspecten: soort, frequentie en ernst van de incontinentie, tijdstip waarop men incontinent is en strategieën om incontinentie te behandelen. Daarnaast zijn data verzameld over patiëntkenmerken, de persoon die de diagnose heeft gesteld en het tijdstip waarop de incontinentie is ontstaan. Uit de resultaten komt naar voren dat van alle patiënten die last hebben van incontinentie $49.8 \%(n=615)$ een diagnose 
hebben wat betreft soort incontinentie. In meer dan de helft van de gevallen is de diagnose gesteld door de huisarts (58\%); functionele incontinentie is de meest voorkomende soort (35.4\%). Patiënten met een diagnose hebben meer last van incontinentie en ondergaan meer strategieën dan patiënten die niet zijn gediagnosticeerd wat betreft soort incontinentie. In de meeste gevallen wordt opvangmateriaal gebruikt en slechts een klein aantal patiënten ondergaan blaastraining/bekkenbodemoefeningen. Ook andere strategieën als aanpassingen in de omgeving (8\%) en speciale huidverzorging (11\%) worden weinig toegepast. Het is dan ook van groot belang dat meer aandacht wordt besteed aan het diagnosticeren van soort incontinentic en strategieën anders dan opvangmateriaal die helpen om incontinentie klachten effectief aan te pakken.

Hoofdstuk 4 geeft de resultaten weer van een studie waarin het gebruik van kwaliteitssystemen (bijvoorbeeld het inzetten van een incontinentieverpleegkundige, gebruilk maken van een protocol) ter bevordering van de kwaliteit van zorg voor patiënten met incontinentie binnen de thuiszorg centraal staat. In deze studie is onderzocht in hoeverre thuiszorginstellingen gebruik maken van kwaliteitssystemen en wat de relatie is tussen de kwaliteitssystemen en enkele aan incontinentie gerelateerde uitkomstmaten (prevalentie incontinentie, diagnose, hoeveelheid urineverlies, frequentie van het urineverlies). Negentien thuiszorginstellingen met in totaal 155 thuiszorgteams hebben deelgenomen aan de studie. De resultaten laten zien dat ongeveer een derde deel van de thuiszorginstellingen gebruik maakt van de diensten van een incontinentieverpleegkundige; documentatie in het patiëntdossier blijkt het meest voorkomende kwaliteitssysteem binnen de thuiszorgteams te zijn. Er wordt echter geen relatie gevonden tussen de kwaliteitssystemen en de uitkomstmaten. Het is dan ook de vraag of de kwaliteitssystemen goed zijn geimplementeerd en of zij voldoende tegemoet komen aan de behoeften van de thuiszorgpopulatie. Verder onderzoek is dan ook noodzakelijk naar de inhoud van de kwaliteitssystemen en de toepasbaarheid ervan binnen de thuiszorg.

Hoofdstuk, 5 beschrijft de resultaten van een systematisch overzicht van de literatuur naar de rol van een incontinentieverpleegkundige binnen de eerstelijn. Op basis van een uitgebreide zoekstrategie zijn 12 gerandomiseerde studies gevonden die qua populatie, setting, uitkomstmaten en interventies heterogeen zijn. Alle studies zijn beoordeeld op methodologische kwaliteit. Eén studie bleek van onvoldoende kwaliteit. Van de resterende 11 studies rapporteren 8 studies een significante daling in het aantal keren dat urineverlies optrad in de groep die is behandeld door de incontinentieverpleegkundige. Hiervan hebben 5 studies een follow-up die korter is dan een jaar. Het is dan ook de vraag of de gevonden positieve effecten na één jaat nog steeds aanwezig zijn, aangezien de kans op terugval na 6 maanden vrij groot is $(60 \%)$. Aanbevolen wordt om onderzoek te doen naar de lange-termijn effecten van een gespecialiseerde verpleegkundige op de zorg voor patiënten met incontinentie binnen de eerste lijn. 
Hoofdstuk, 6 geeft de resultaten weer van een RCT naar de effecten van de inzet van een incontinentieverpleegkundige op de zorg voor vrouwen die met incontinentie klachten hun huisarts bezoeken. Voor deze studie heeft de verpleegkundige gebruik gemaakt van een protocol dat was opgezet door een multidisciplinair team. Belangrijkste uitkomstmaten waren: aantal keren urineverlies, gebruikt opvangmateriaal, kwaliteit van leven en patiëntensatisfactie. In totaal zijn 101 huisartsen gerandomiseerd in de interventiegroep $(n=50)$ of de controlegroep $(n=51)$. Patiënten die huisartsen in de interventiegroep bezochten, werden doorverwezen naar de incontinentieverpleegkundige. OP basis van het protocol, alsmede haar kennis en ervaring, heeft deze verpleegkundige gedurende een jaar de patiënten geadviseerd over de meest geschikte therapie en over aspecten als huidverzorging, speciale kleding en levensstijl. In totaal zijn 3 vervolgafspraken gemaakt (na 3, 6 en 12 maanden). Tijdens deze vervolgafspraken werd de ingezette behandeling geëvalueerd; bij onvoldoende resultaat werd een doorverwijzing naar de uroloog overwogen. Patiënten die hun huisarts in de controle groep bezochten, ontvingen gebruikelijke zorg. Data-verzameling vond plaats in beide groepen (tijdens inclusie en na 3, 6 en 12 maanden) met behulp van een blaasdagboekje, de Incontinence Impact Questionnaire en de Urogenital Distress Inventory. Door tegenvallende inclusie konden gegevens van 35 vrouwen in de interventiegroep en 10 vrouwen in de controlegroep worden geanalyseerd. Uit het onderzoek komt naar voren dat na 6 maanden patiënten uit de interventiegroep minder last hadden van urineverlies dan patiënten uit de controlegroep. $\mathrm{Na} 12$ maanden bleek binnen de interventiegroep nog steeds sprake te zijn van een significante vermindering in urineverlies; er was toen echter geen sprake meer van een interventie effect tussen de beide groepen wat betreft hoeveelheid urineverlies. Ook werden na 12 maanden geen verschillen waargenomen tussen beide groepen wat betreft het aantal gebruikte opvangmateriaal. Wel bleek dat na een jaar vrouwen in de interventiegroep minder klachten rapporteerden wat betreft de 'lichamelijke' dimensie van de Incontinence Impact Questionnaire in vergelijking met vrouwen uit de controle groep. Het verdient aanbeveling de effecten van de inzet van een incontinentieverpleegkundige binnen de eerstelijn in een grotere studiepopulatie te onderzoeken.

Hoofdstuk 7 betreft een algemene discussie van de studies uit dit proefschrift. Naast een samenvatting van de belangrijkste resultaten worden een aantal methodologische reflecties weergegeven. Het hoofdstuk wordt afgesloten met implicaties voor de praktijk en aanbevelingen voor toekomstig onderzoek. 


\section{DANKWOORD}

Dank aan iedereen die heeft bijgedragen aan de totstandkoming van dit proefschrift. Een aantal van hen wil ik hier in het bijzonder noemen.

Op de eerste plaats wil ik mijn dank betuigen aan de vrouwen die hebben deelgenomen an de interventiestudie en de medewerkers van de thuiszorginstellingen die de vele data hebben geregistreerd ten behoeve van de Landelijke Prevalentiemeting Zorgproblemen. Zonder hun medewerking was dit onderzoek niet mogelijk geweest.

Mijn promotor Prof. dr. Jan Hamers wil ik danken voor zijn deskundige begeleiding en fijne samenwerking. Jan, jouw enthousiasme en betrokkenheid waren voor mij een grote steun. Dit geldt evenzeer voor $d r$. Ruud Halfens en dr. Aggie Paulus, co-promotoren, die met hun kritische blik en waardevolle adviezen een belangrijke bijdrage hebben geleverd aan dit proefschrift.

Drs. C. Berendsen, uroloog in het Atrium Medisch Centrum Parkstad, ben ik erkentelijk voor zijn betrokkenheid en deskundige adviezen tijdens de opzet en uitvoering van de interventiestudie. Monique van Gestel en Marjon Broers, incontinentieverpleegkundigen in het Atrium Medisch Centrum Parkstad, hebben met hun kennis en ervaring patiënten uit de interventiestudie op kundige wijze geadviseerd en begeleid. Ook de overige leden van de projectgroep hebben ieder vanuit hun eigen achtergrond een waardevolle bijdrage geleverd aan de interventiestudie: Hein Heynen (Zorgverzekeraar CZ Actief in Gezondheid), Peter Voorhoeve (huisarts), Ulli Haasse (incontinentieverpleegkundige) en mw. Debets (fysiotherapeute)

Dank aan Zorgverzekeraar CZ Actief in Gezondheid en CAPHRI (School for Public Health and Primary Care; programma "Innovaties in de zorg voor ouderen") die met hun financiële steun dit onderzoek hebben mogelijk gemaakt. De co-auteurs van de artikelen in dit proefschrift ben ik zeer erkentelijk voor hun opbouwende kritiek op de artikelen in dit proefschrift.

Mijn (ex-) collega's wil ik danken voor alle wijze en andere adviezen. Graag wil ik een aantal (in willekeurige volgorde) noemen: Nynke, Inge, Pascalle, Sandra, Gèr, Jolanda en Anna, dank jullie wel voor jullie betrokkenheid en de gezellige momenten op het werk.

Eind 2001 tipte Ireen Proot mij dat 'ene Jan Hamers' nog een onderzoeker zocht voor het 'Incontinentieproject'. Ireen, bedankt!

Tenslotte.... ik draag dit proefschrift op aan mijn gezin. Dank jullie wel voor de mogelijkheid die jullie me hebben gegeven om dit proefschrift te schrijven. 


\section{CURRICULUM VITAE}

Name

Date of birth

Place of birth

Education

1982-87

$1978-82$

1977-78

1971-77

Work bistory

Mar 2008 - present

Feb 2002 - Sept 2007

Jan - May 2007

May 2006 - May 2007

May 2006 - Dec 2006

June 1999 - Jan 2002

Nov 1994 - July 2002

Dec 1997 - May 1999
Monique François Marie Thérèse Du Moulin

29 August 1959

Maastricht, the Netherlands

Health Care Sciences (specialisation: Nursing Science) Maastricht University, Maastricht

radiology assistant, Maastricht St. Annadal hospital and Rotterdams Radiotherapeutisch Instituut, Rotterdam Schoevers, Nijmegen

Atheneum A pre-university secondary education

researcher: project on reporting of healthcare performance indicators, Department of Health Care and Nursing Science, Faculty of Health, Medicine and Life Sciences, Maastricht University, Maastricht PhD candidate, Department of Health Care and Nursing Science, Faculty of Health, Medicine and Life Sciences, Maastricht University, Maastricht researcher: project into the consequences of the WMO (Wet maatschappelijke ondersteuning; societal support act) for clients receiving household care (commissioned by the Provincial Council of Limburg) researcher: three projects into mental healthcare quality from the client's perspective, Stichting Kwadraad, Utrecht

researcher: project into exercise and welfare among elderly people living in Maastricht (commissioned by the City of Maastricht)

researcher: Teledermatology project, Transmuraal \& Diagnostisch Centrum, University Hospital, Maastricht

researcher: project on gender factors in training selection for a medical specialty, Department of Women's Studies, Faculty of Medicine, Maastricht University, Maastricht

researcher: International Institute for Psychosocial and Socio-Ecological Research (IPSER), Maastricht 